\title{
Trade, medicines \& human rights: protecting access to medicines in Fiji \& the Pacific
}

\author{
Sarah Meads \\ Victoria University of Wellington \\ Wellington, New Zealand \\ Submitted in partial fulfillment of the \\ Masters in Development Studies Degree
}

March, 2008 


\begin{abstract}
Restrictive provisions in international trade agreements, particularly trade related intellectual property rights (TRIPS), are impeding access to essential medicines in developing countries, making medicines unaffordable to poor people. The extent to which trade restrictions have adverse effects on health and economic development in Fiji and the Pacific region may depend critically on how Pacific Island Countries cope with the forces of regionalism and the realities of joining the global trading system, where there are pressures to make concessions in TRIPS. Yet awareness is relatively low. A central question to be asked here is what underlying factors shape how Pacific islanders view trade and access to medicines, notably in the area of trade, health, local culture, and human rights and what are the regional and national responses to mitigate potential trade impediments. By combining a public health lens with a multi-sector review of population health trends, intellectual property rights law, trade policymaking, and human rights, this research elaborates multidisciplinary findings that are usually less evident because they are conventionally researched and managed on a sector-by-sector basis. The findings suggest human rights are less significant in this debate, with challenges associated with small island developing states, local cultural preferences and pressures from regionalism, having more of a direct influence. The combined effect of these factors may be creating a unique context that is leading the Pacific region not to deal with these issues as well as some other developing countries might. This paper also discusses the emergence of two new challenges for human rights theory; to promote the collective rights of individual countries in the 'new regionalism', and the relationship with traditional knowledge.
\end{abstract}




\section{Acknowledgments}

I wish to thank the following people (in no particular order) for participating in my field research and for their generous exchange of information:

In the Pacific Islands

- Dr Wame Baravilala, Advisor on Reproductive Health, Country Technical Services Team, United Nations Population Fund (UNFPA)

- Dr Seta Vatucawaqa, Chief Pharmacist, United Nations Population Fund (UNFPA)

- Dr Robyn McIntyre, Project Officer, Expanded Programme on Immunisation, United Nations Children's Fund (UNICEF)

- Dr Temo Waqanivalu, Nutrition and Physical Activity Officer, World Health Organisation (WHO)

- Dr Stuart Watson, Pacific Regional Coordinator, United Nations Programme in HIV/AIDS (UNAIDS)

- Ms Margaret Leniston, Regional Health Program Manager, Foundation of the Peoples of the South Pacific International (FSPI)

- Mr Ferdinand Strobel, Programme Specialist HIV/AIDS, United Nations Development Programme Pacific Centre (UNDP PC)

- Professor Robert Moulds, Professor of Medicine, Fiji School of Medicine (FSM)

- Ms Gail Olsson, Trade Policy Advisor, Pacific Islands Forum Secretariat

- Ms Gina Houng Lee, Training Coordinator, Pacific Regional Rights Resource Team (RRRT)/UNDP Pacific Centre

- Ms Roshni Sami, Director and Wesley Morgan, Media Advisor, Pacific Network on Globalisation (PANG)

- Ms Tupou Vere, Director, Pacific Concerns Resource Centre (PCRC)

- Ms Judith Vusi, Director, Pacific Conference of Churches, Fiji

- Mr Semeti Qulowasa - Field Coordinator, Economic Justice, Ecumenical Council for Research Education and Advocacy (ECREA)

- Ms Elizabeth Wrench, Procurement and Logistics Officer, Pandemic Preparedness, Secretariat of the Pacific Community (SPC)

- Mr Peter Zinck, Chief Pharmacist, Fiji Pharmaceutical Services, Ministry of Health, Fiji

- Ms Muniamma Goulds, Acting Principal Pharmacist, Fiji Pharmaceutical Services, Ministry of Health, Fiji

In New Zealand:

- Mr Steffan Crausaz, Acting Manager, Supply Side, PHARMAC, New Zealand

- Mr Andrew Davies, Procurements Initiatives Manager, PHARMAC, New Zealand

- Ms Joy Liddicoat, Commissioner, New Zealand Human Rights Commission

- Dr Colin Tukuitonga, Chief Executive, Ministry of Pacific Island Affairs, NZ Government

I would also like to thank my supervisors for their assistance with this project:

- Professor John Overton, Director of the Graduate Program, Development Studies, School of Geography and Environmental Sciences

- Associate Professor Peggy Fairbairn-Dunlop, Director, Va'aomanu Pasifika. 


\section{Abbreviations}

$\begin{array}{ll}\text { ARV } & \text { Anti Retroviral Vaccine } \\ \text { CIPIH } & \text { (WHO) Commission on IPRs, Innovation and Public Health } \\ \text { CS } & \text { Commonwealth Secretariat } \\ \text { CROP } & \text { Council of Regional Organisations in the Pacific } \\ \text { EDL } & \text { Essential Drugs List } \\ \text { EC } & \text { European Commission } \\ \text { EU EPA } & \text { European Union Economic Partnership Agreement } \\ \text { FSM } & \text { Fiji School of Medicine } \\ \text { FSPI } & \text { Foundation of the Peoples of the South Pacific International } \\ \text { HAI-AP } & \text { Health Alliance International - Asia Pacific } \\ \text { HCWs } & \text { Health Care Workers } \\ \text { HIV/AIDS } & \text { Human Immunodeficiency Virus/Acquired Immunodeficiency Syndrome } \\ \text { IPR } & \text { Intellectual Property Rights } \\ \text { LDCs } & \text { Least Developed Countries } \\ \text { MDGs } & \text { Millennium Development Goals } \\ \text { MSF } & \text { Médecins Sans Frontières } \\ \text { NGOs } & \text { Non Government Organisations } \\ \text { ONZ } & \text { Oxfam New Zealand } \\ \text { PACER } & \text { Pacific Agreement for Closer Economic Relations } \\ \text { PANG } & \text { Pacific Network on Globalisation } \\ \text { PCC } & \text { Pacific Conference of Churches } \\ \text { PCRC } & \text { Pacific Concerns Resource Centre } \\ \text { PCT } & \text { Patent Cooperation Treaty } \\ \text { PICs } & \text { Pacific Island Countries } \\ \text { PICTA } & \text { Pacific Island Country Trade Agreement } \\ \text { PIFS } & \text { Pacific Island Forum Secretariat } \\ \text { PNG } & \text { Papua New Guinea } \\ \text { SPC } & \text { Secretariat of the Pacific Community } \\ \text { SOPAC } & \text { South Pacific Applied Geosciences Commission } \\ \text { TRIPS } & \text { Trade Related Intellectual Property Rights } \\ \text { TWN } & \text { Third World Network } \\ \text { UNAIDS } & \text { United Nations Programme in HIV/AIDS } \\ \text { UNDP } & \text { United Nations Development Programme } \\ \text { UNFPA } & \text { United Nations Population Fund } \\ \text { UNICEF } & \text { United Nations Children's Fund } \\ \text { WHO } & \text { World Health Organisation } \\ \text { WIPO } & \text { World Intellectual Property Organisation } \\ \text { WTO } & \text { World Trade Organisation } \\ & \end{array}$




\section{Contents}

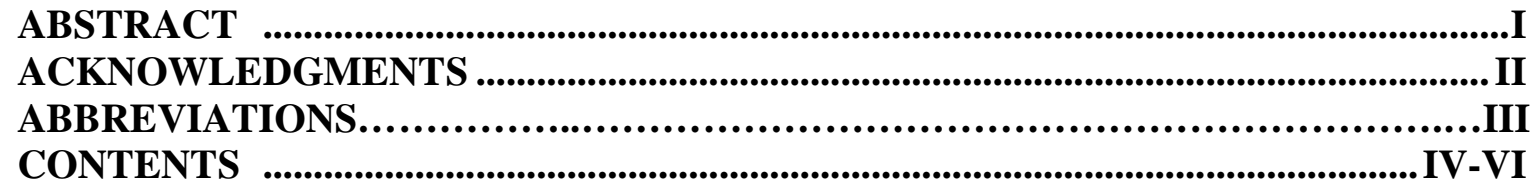

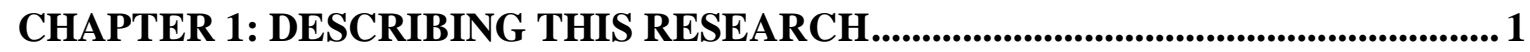

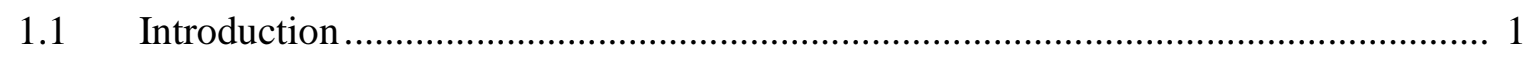

1.2 Anticipating the need for this research ......................................................... 4

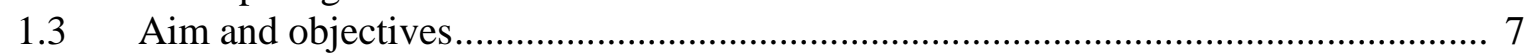

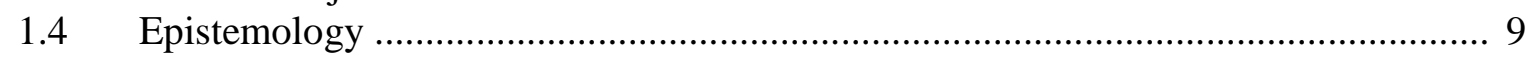

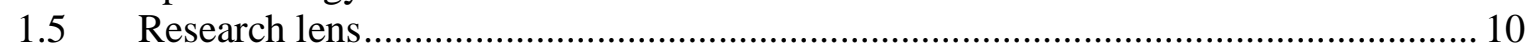

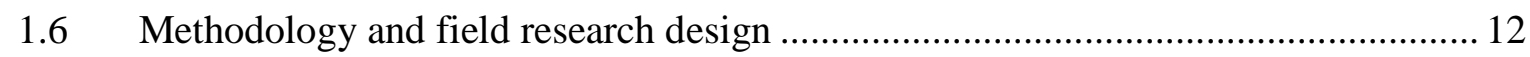

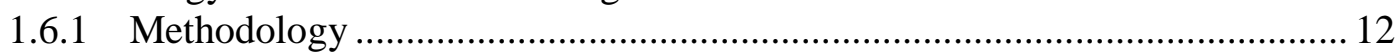

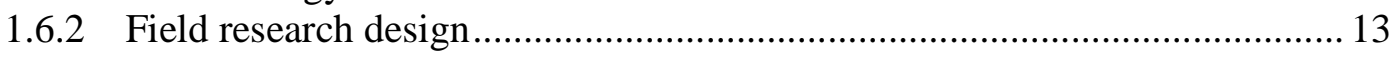

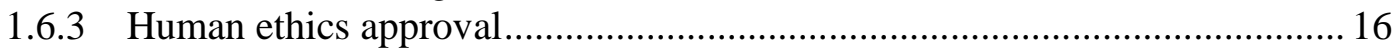

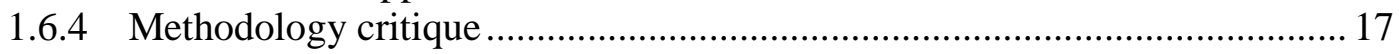

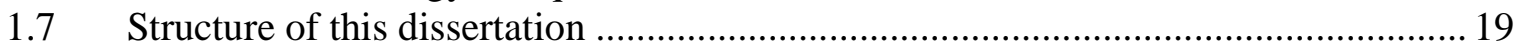

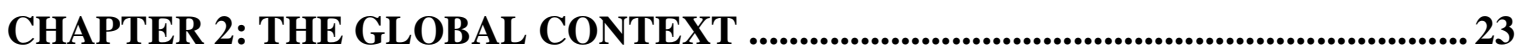

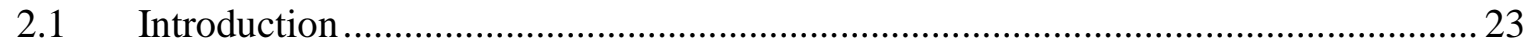

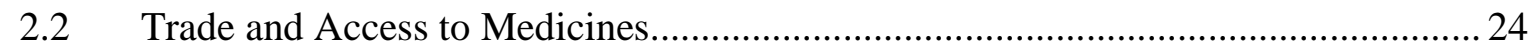

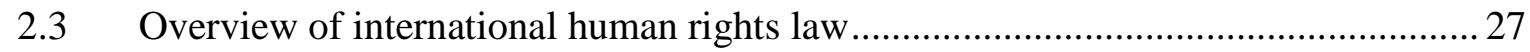

2.4 Some complex challenges surrounding the application of human rights....................2 28

2.4.1 The 'ism's': cultural relativism and euro-centrism ...................................... 29

2.4.2 Third generation rights, extending from state to other duty-holders .............30

2.4.3 The status of human rights within the world trading order ........................... 30

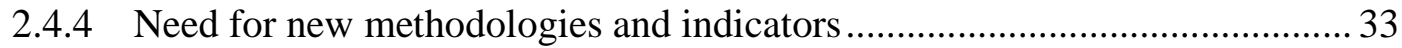

2.5 Human rights to health, the significance to access to medicines ............................. 32

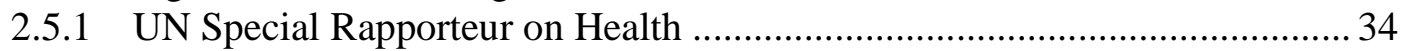

2.6 Human rights and access to medicines interface with intellectual property law ....... 35

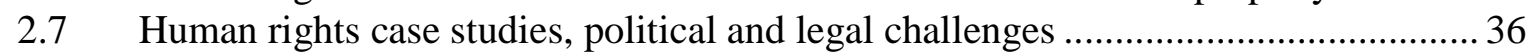

2.7.1 The Human Rights Impact Assessment of the Thai-US FTA......................... 36

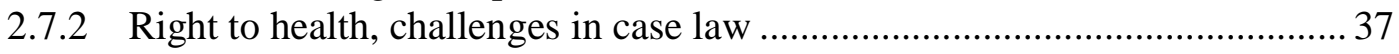

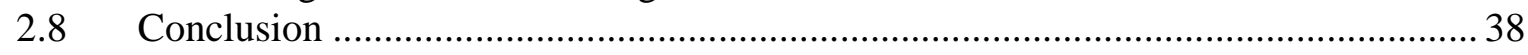

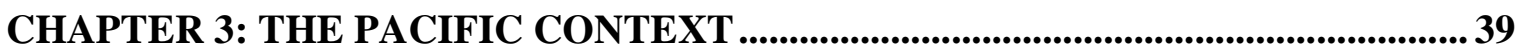

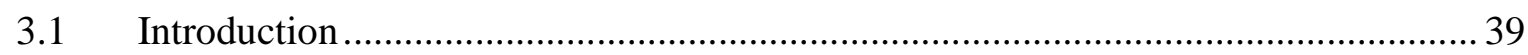

3.2 Overview of Pacific health trends and services in the Pacific ................................ 41

3.2.1 Pacific population health trends ............................................................ 41

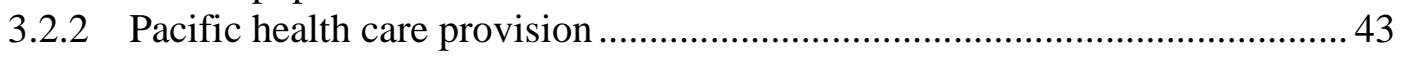

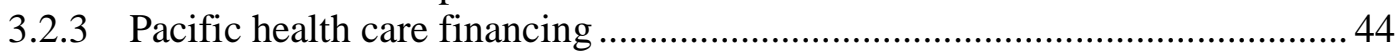

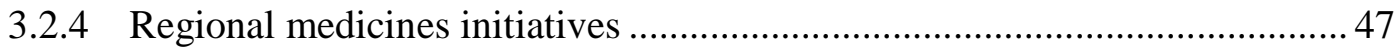

3.3 Overview of key trade agreements and trade policymaking in the Pacific................ 47 
3.3.1 Trade policymaking mechanisms in the Pacific region

3.3.2 Impact of international trade agreements on access to medicines in the PICs.....

3.4 Overview of Intellectual Property Rights in the Pacific .......................................... 50

3.4.1 Patent Cooperation Treaty.......................................................................... 52

3.5 Overview of Human Rights Mechanisms in the Pacific .......................................... 53

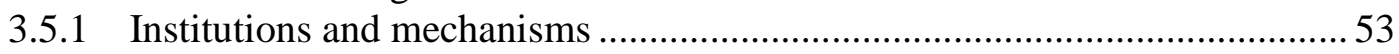

3.5.2 Concerns between custom and human rights ............................................. 54

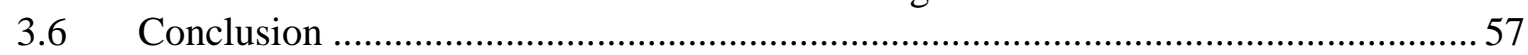

CHAPTER 4: THE NATIONAL CONTEXT ...........................................................59

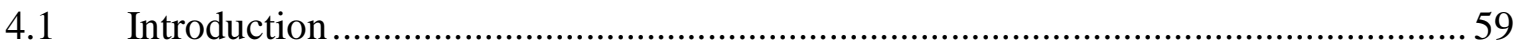

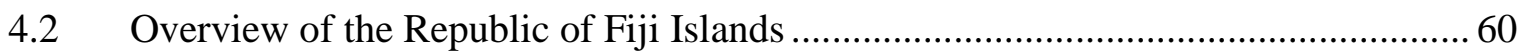

4.3 Trade policymaking, medicines procurement, IPR and human rights in Fiji ............ 64

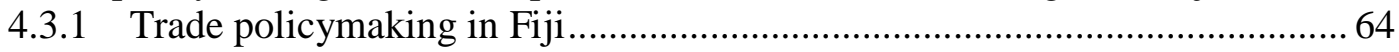

4.3.2 The capacity for trade and health advocacy in Fiji ......................................65

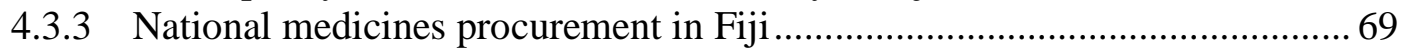

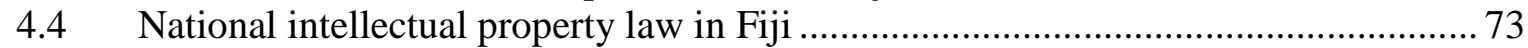

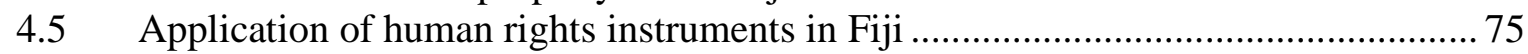

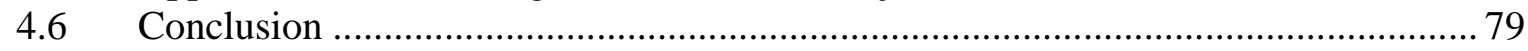

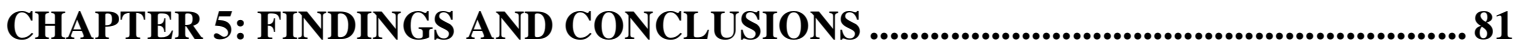

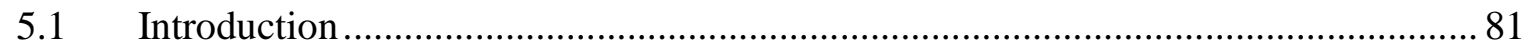

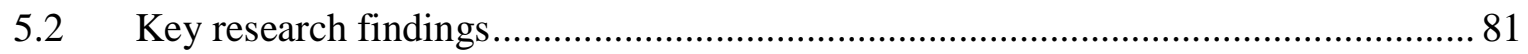

5.2.1 Do trade-related restrictions exist currently, or in future trade

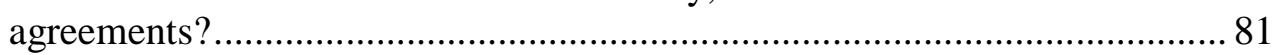

5.2.2 Is trade and access to medicines on, or off, the agenda?............................ 85

5.2.3 Which stakeholders should take responsibility for mainstreaming

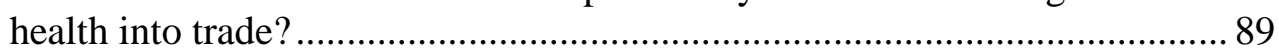

5.2.4 Is trade and access to medicines considered in regional initiatives? ............. 93

5.2.5 What is the scope for using human rights? ................................................. 96

5.3 The significance of this research for human rights theory ....................................... 97

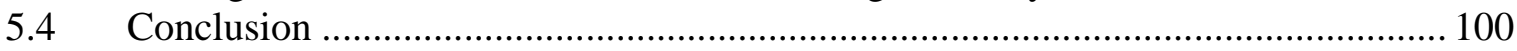

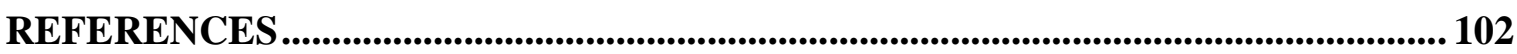

RECOMMENDED WEBSITES ...................................................................................................... 112

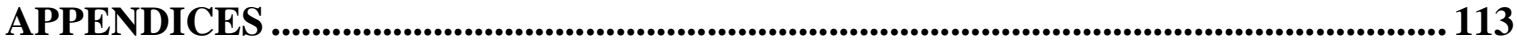

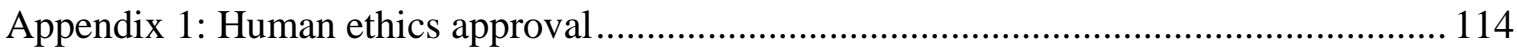

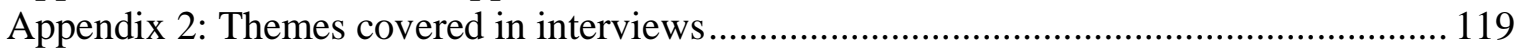

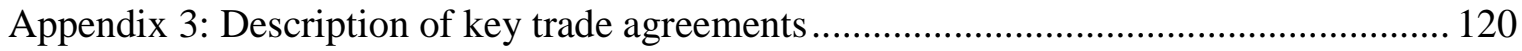

Appendix 4: Overview of intellectual property rights in the Pacific ................................... 126

Appendix 5: Protecting access to medicines: regional and national responses in

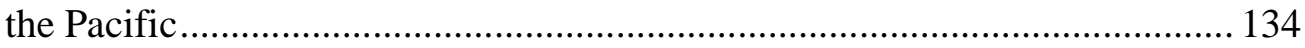


LIST OF TABLES

Table 1: Age standardised death rates per 100,000 and proportion $(\%)$ by cause, by country. 2002 43

Table 2: Indicators of health expenditure by selected Pacific Island Countries, 2003 45

Table 3: Summary of Country Development Status, WTO Membership, and IP

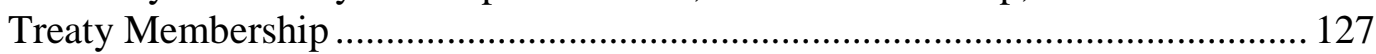

Table 4: Patent laws in the Pacific Island Countries........................................................... 129 


\section{Chapter 1: Describing this research}

\subsection{Introduction}

"The best form of leadership in this (access to medicines) debate is coalition leadership". Excerpt from, Ethics and the Pharmaceutical Industry ${ }^{1}$

The global campaign on access to medicines grew in the late 1990's in response to the major health crises in developing countries, compounded by HIV/AIDS, where those most in need of medicines were the least able to afford them (Mayne, 2002). Obligations in multilateral and free trade agreements (FTA), including trade related intellectual property rights (TRIPS), pharmaceutical patent examination and pharmaceutical pricing strategies (Danzon and Towse, 2005), are the aspects of trade that most influence access to medicines in developing countries and the structure of the global pharmaceutical industry (Abbott, 2005; Drahos, 2005).

The nub of the campaign centres on how these factors promote private rights over public commons (Drahos, 2005; Tansey, 2005; Ulrich, 2005) and restrict development policy space in developing countries (Wade, 2005; Chang, 2005). Opponents contend these block generic competition, raise drug prices, and divert $R \& D$ investment away from neglected diseases ${ }^{2}$ (Mayne, 2002; Balasubramanian, 2002). Yet proponents claim the enforcement of strong intellectual property rights (IPR) encourages technology and knowledge transfer and incentivises research; a globalised IPR system will produce economic growth for all who participate (Stiglitz, 2005).

Paradoxically, these supply-side constraints are at odds with the triple burden ${ }^{3}$ of diseases afflicting developing countries, which is driving up demand for $R \& D$ and affordable medicines (UNESCAP, 2007), and a growing recognition that health is fundamental to accomplishing economic and social development (WHO, 2007a).

\footnotetext{
${ }^{1}$ See reference Santoro and Gorrie, 2005, pp. 258

${ }^{2}$ See www.WHO.int, for diseases categories: Category I,II (neglected diseases), III (very neglected diseases)

${ }^{3}$ These include: communicable disease, that disproportionately affect developing countries, non communicable diseases and pandemics
} 
In this chaos, a variety of independent initiatives are underway that have the potential to gradually transform the un-level playing field, so that more medicines reach the poor in developing countries. Thailand's defiant application of compulsory licences (CL); new global solutions to improve R\&D and drug supply discussed at the World Health Assembly; a human rights committee (ICESCR) urging Costa Rica to review CAFTA under the right to health; prizes to replace patents to encourage R\&D (Love, 2007); political pressure for he US to back out TRIPS-plus from the Peru-US FTA; a call for adoption of human rights norms by drug companies (Hunt, 2006; Oxfam, 2007a); inclusion of health in foreign policy with the emergence of a new global health diplomacy (WHO, 2007b); and elevation of intellectual property rights to the highest level in the World Health Organisation (WHO) structure, are some examples.

\section{The neoliberal context of the access to medicines debate}

Tensions arise between access to medicines and the global trading system because the latter is an axiom of the neoliberal consensus (Hestermeyer, 2007). Human rights instruments are the most comprehensive socioeconomic rights framework outside this system; providing a counter balance by placing public goods, such as health, above purely economic growth (Robinson, 2006). However this arrangement pits 'soft law' against 'hard law', which often means neoliberalism dominates (Uvin, 2004).

Furthermore, proponents of intellectual property rights enforcement, for example, the US, EU, Japan and transnational companies, continue to formulate stronger protections which are spread globally through FTAs. This trend is reinforced by the trilateral agreement between the three major trading blocs (US, EU and Japan) to harmonise their patent offices and by political coercion to join the Patent Cooperation Treaty (PCT) ${ }^{4}$, that then acts as a 'patent pipeline' by streamlining patent registration in developing countries (Drahos, 2007).

This research acknowledges that structural and financial limitations place significant impediments on access to medicines at a country level, particularly in small island developing

\footnotetext{
${ }^{4}$ For a description of PCT see Section 3.4.1
} 
states where the logistics and costs of providing a full range of health services to remote islands are high. However, this research is concerned about the gross asymmetry between developed and developing countries and how the current systems are not providing stronger incentives to make sure medicines reach people in need (Balasubramaniam, 2002). The technology for treating tuberculosis is an example of this. Tuberculosis is a significant infectious disease in developing countries, including the Pacific region. However, the technology for treating tuberculosis is over 30 years old and growing resistance is diminishing its effects. Despite this, there were only six drugs for treating tuberculosis in clinical development in 2006 compared with around four hundred for treating cancer (WHO, 2007a).

\section{What determinants influence access to essential medicines?}

The WHO defines essential medicines as those medicines that are necessary to satisfy the healthcare needs of the majority of the world's population and therefore ought to be available to all individuals, in adequate dosage, and at affordable prices. It estimates that approximately one third of the world's population lacks access to essential medicines, with the proportion being as high as two thirds in some of the poorest countries in Africa and Asia.

The WHO Essential Medicines List (EML) is a list of medicines to satisfy the majority of healthcare needs in developing countries, making it easier for developing countries to procure affordable, safe medicines. Of the 312 medicines on the list in 2006, only sixteen are newer patented drugs, including fourteen for the treatment of HIV/AIDS. No patented drugs for non communicable diseases, for example, cancer, diabetes, or for ischemic heart disease, are included. This is despite the fact that non communicable diseases are the leading cause of mortality in low-income countries, including in the Pacific region, and that many new drugs offer substantial improvements in their treatment.

Some groups argue the EML contains enough varieties of drug, with a few exceptions, to satisfy the majority of health needs in developing countries (Mould, 2004) while others are pushing for modifications. Still others argue that developing countries don't take full advantage of the WHO EML at present and therefore shouldn't need to criticise 
pharmaceutical companies or to raise compulsory licences that override pharmaceutical patents (Lofgren, 2007).

There are multiple determinants influencing access to medicines, globally and in the Pacific. Many originate from outside the health sector, highlighting the complex linkages between health, poverty, development and trade. They include: domestic factors, for example, lack of adequate finance, limited, or no, domestic manufacturing capacity; market factors, for example, undisclosed, differential pricing strategies, and trade factors, for example Bilateral Investment Treaties (BITS) ${ }^{5}$. Some of the adverse effects of the internal domestic factors are compounded in the Pacific region because of the cost and logistics of delivering a full range of services to isolated, remote islands with limited infrastructure and resources. The particular focus of this research is on the implications of external trade factors and on private property rights that are legally enforced through TRIPS agreements.

\subsection{Anticipating the need for this research}

Most advocacy for access to medicines is centred on HIV/AIDS (Maynes, 2002). However, with the exception of Papua New Guinea (PNG), where HIV/AIDS is an epidemic (Tukuitonga, 2006) ${ }^{6}$, the incidence is relatively low in most other Pacific Island Countries (PICs). HIV/AIDS therefore does not provide the same catalyst for advocacy for access to medicines as in other countries. Alternatively, the region is experiencing the double burden of disease with non communicable diseases (NCDs) now accounting for most deaths, and poor health indicators contributing to the poverty trap and to political and human insecurity (Tukuitonga, 2006).

Unlike some neighbouring emerging economies, such as Thailand, where access to medicines

\footnotetext{
${ }^{5}$ BITS have been signed with a number of PICs. BITS may mean use of public health safeguards eg. those in TRIPS flexibilities could be expropriation and so require compensation from the host government to the investor from the other country in an international tribunal. They are not enforceable through trade sanctions. Some are listed on http://www.unctadxl.org/templates/DocSearch779.aspx and www.paclii.org referred to in a conference presentation by Ms Sanya Reid Smith, Third World Network, Regional High Level Consultation on HIV and the Law April 2007, Auckland NZ on file with the author.

${ }^{6}$ Though there is an increasing trend in Fiji.
} 
has a high public profile (because of HIV/AIDS) and health and human rights advocacy is well organised, in the PICs, and in Fiji, the profile appears to be comparatively low, and the topic has not generally featured on the trade or health agenda. ${ }^{7}$

Research to gain insights into how Pacific islanders view trade and access to medicines, which is the topic of this research, and the reasons for the lack of priority it is accorded, is vital; especially as the regional trade landscape is about to change with the EU EPA. This research uses a public health sector perspective, as distinct from a trade sector perspective, to evaluate the factors influencing people's views and the impact of trade and TRIPS on access to medicines.

Furthermore, to my knowledge a comprehensive overview, and the relationship between, the four systems (population health trends and services, intellectual property rights law, the process of trade policymaking, and human rights) has not been documented in one paper before. These four separate, but interrelated, systems have a profound impact on access to medicines in developing countries and the structure of the global pharmaceutical industry. This multi-system approach I will apply, may provide a new tool for policymakers and development practitioners working in the trade and health sector, where conventionally these issues are managed in isolation, using a sector by sector approach.

The main focus of this research will be on Fiji, which is set within the broader Pacific context. As small island economies, Fiji and other PICs face economic and geographic barriers that make them dependent on foreign trade and investment that is secured through trade agreements with developed countries. Fiji's trade policymaking is dominated by issues relating to regionalism (Crocombe, 2005), neoliberalism (Slatter, 2006), the re-negotiation of major trade agreements, such as EU- EPA and PACER (which may be triggered under Cotonou), the Sugar Protocol with the EU and expansion of multilateral agreements under WTO into services, intellectual property rights and investment.

\footnotetext{
${ }^{7}$ An exception appears to be the substantial knowledge of the Chief Pharmacist, and senior staff of Fiji Pharmaceutical Services and a staff member of the PIFS. The Chief Pharmacist has provided a point of reference for some other PICs that have sought assistance to understand the trade issues relating to medicines in their own countries
} 
Another factor of importance in this thesis is that in December 2007, Fiji and Papua New Guinea, under external pressures from the EU, had agreed to sign individual agreements with the EU instead of continuing to negotiate a regional economic partnership with all 14 PICs. Earlier versions of the EU draft agreement offered to African and Caribbean regions included TRIPS-plus provisions (CIEL, 2007), which were opposed by the international development community (Correa, 2007). In September 2007 the EU had signaled that IPR issues would be negotiated with the PICs in 2008 if a regional economic partnership agreement was signed by the 14 PICs by the December 2007 deadline. It is not yet clear, when the EU intends to negotiate IPR issues with Fiji and PNG.

Fiji's existing national IPR law, inherited from its colonial past, does not contain all of the WTO TRIPS safeguards. A more development-friendly version, that removes these inflexibilities, was recommended to the Fijian Government in 2003 by an expert commissioned by the WHO. Although the benefits of doing this were acknowledged at the time, the law has not yet been re-drafted by the Attorney Generals Office. The reason for this delay is unclear. Progress has been further halted following the 2006 coup. Furthermore, Fiji is not a member of Patent Cooperation Treaty (PCT), yet in 2007 the Fijian Patent Office already had over one hundred and twenty pharmaceutical patents registered. Information about what drugs and companies these were for is not readily available.

While the empirical evidence isn't any where as stark as for HIV/AIDS (that galvanised the access to medicines debate in other developing countries) there is nevertheless one example in Fiji of a drug (the antipsychotic, Olanzapine), patented in 1998, that is in high demand because of its low side effects. Fiji is required to patent Olanzapine to comply with WTO obligations. However if, for example, Fiji was to sign a trade agreement with the EU that contained TRIPS-plus, this 20 year monopoly could be extended by another five, or even 20 , years. This extension would mean these drugs would continue to cost the Fijian Government more than if it had declared its public good priorities (Shaffer, 2005) and refused to sign away WTO TRIPS safeguards.

Furthermore, although not directly caused by trade impediments, drug stock-outs in hospitals 
and clinics are not infrequent (Bailey, 2004). Whereas a specified range of generic medicines are publicly funded and freely available to the Fijian public through hospitals and clinics, when this happens the public are expected to pay full price at a private pharmacy. Anecdotal evidence suggests many people often miss out on these essential medicines because they cannot afford them. The price sensitivity reinforces a two-tier health system and social inequality (Marmot and Wilkinson, 1999). Empirical studies on the affordability of drugs in Fiji and the PICs are very limited, but again would be valuable.

This combination of these and other factors suggests there is a growing urgency to commence developing national and regional strategic and policy responses to assess and mitigate any future trade restrictions and the effects of these on access to medicines. In a worst case scenario, TRIPS inflexibilities may be signed away by trade negotiators, with little attention to their health costs. Once integrated into national legislation, these obligations might sit, like a 'trojan horse', to be triggered at a later stage when the Ministry of Health or private pharmacies may wish to import a particular drug and are restricted from using safeguards, such as parallel importation.

There is an immediate need to begin raising the general levels of awareness and to commence the internalisation of policies in the trade and health sector, in order to limit any potential impact on health development in the future.

\subsection{Aim and objectives}

\section{Aim}

The primary aim of this research is:

To evaluate whether current trade obligations, such as Trade Related Aspects of Intellectual Property (TRIPS), impede access to essential, affordable medicines in Fiji and to suggest national and regional responses, including human rights instruments, which might address this by putting a public health perspective into trade and property rights. 


\section{Objectives}

The primary objectives are:

1. To assess any reported trade-related restrictions on access to essential medicines in Fiji, including any potential impacts of future regional trade agreements.

2. To assess whether trade related impacts on access to medicines is on the agenda in the public or civil society sector in Fiji and, if not, to determine why, and what, factors would trigger PICs adopting this focus.

3. To identify which stakeholders have a role in putting a public health perspective into trade and intellectual property law and whether the impact of trade obligations on access to medicines is factored into trade negotiations.

4. To evaluate whether trade-related impacts on access to medicines are taken into consideration in regional integration initiatives identified under the Pacific Plan; in particular, the review of collective medicines procurement and regulation, and regional integration of intellectual property rights.

5. To assess the general scope, for using human rights instruments to protect access to medicines in Fiji.

6. Based on the analyses, suggest national and regional responses that are culturally and politically appropriate, to mitigate trade-related factors from impacting on access to essential medicines. Such responses might include human rights instruments (along with a range of other strategic, policy and advocacy initiatives) designed to mainstream a public health perspective into all aspects of international trade that impact on access to medicines. This will include: (i) the analysis of international trade agreements (in particular TRIPS and Bilateral Investment Treaties (BITS), (ii) drafting of national intellectual property law, and (iii) the 
examination of pharmaceutical patents.

These primary objectives are underpinned by a secondary objective, which is:

7. To describe how four seemingly, separate systems work, and interrelate, in Fiji and the Pacific region, so that a cross sector analysis may be undertaken under the primary objectives. These are:

(i) Pacific population health trends and public health services, including national medicines policy and procurement and how global schemes for treating communicable diseases eg. Global Fund, UNICEF, function alongside national procurement;

(ii) intellectual property law, including pharmaceutical patent law and examination;

(iii) the process of trade policymaking, the capacity for trade and health advocacy and the key multilateral and free trade agreements, including the potential impact of proposed agreements currently under negotiation, such as EU EPA;

(iv) the application of human rights instruments, in particular the right to health (and to access to medicines).

\subsection{Epistemology}

Epistemology, or the theory of knowledge, is the branch of philosophy which is concerned with the nature and scope of knowledge. A description of the various epistemologies associated with different worldviews and of the considerable academic debate about each of these is not included in this research. Instead, I identify the epistemology that best describes my research position and how this has influenced the methodology.

The epistemology used in this research can broadly be classified as Critical Realism; a blend of Realism and Critical Theory. My approach is Realist in that I accept that a real world exists outside, and independently, of our senses and perceptions. It also seeks to find out how something happens (causal mechanisms) and how extensive a phenomenon it is (empirical 
regulatory) in order to influence its root causes (Kitchin and Tate, 2000). Realism considers these root causes stem from people's knowledge rather than simply experiences (the latter is associated with Pragmatism, another epistemology).

The Critical Theory that accompanies this Realism is associated with reformulations of Marxism (Johnston et.al., 2000) which considers the purpose of social research is to enable people to act on their findings to improve society, a process referred to as emancipation. Unlike classical Marxism however, Critical Theorists have a broader view of interactions between individuals and society than as just a means of capital production (exchange of labour for a wage); taking into account other dynamic, social factors into its research (Johnston et.al., 2000).

Building on the different types of science is the recognition of different types of research. For example, it is possible to select a position along the continuum between descriptive and explanatory, or value-free and action- based. It is important to identify positionality because individuals do not conduct research in a vacuum (Murray and Overton, 2003).

My positionality is best described as 'action-based' research instead of 'value-free' research, and as 'problem solving' as opposed to 'exploratory', and as 'market-oriented' and 'applied' rather than as 'pure' and 'academic'. This is illustrated by the research methodology, which seeks to comprehensively describe four systems that impact on access to medicines, the potential impact this may have on the health and wellbeing of individuals, and how this may inform local responses to mitigate any impediments. This approach is also consistent with the purpose of Critical Theory which seeks to describe processes and relations and to communicate these so that people may act upon them to improve society (Murray and Overton, 2003).

\subsection{Research lens}

This research uses a public health sector perspective, as distinct from a trade sector perspective, to evaluate the impact of trade and TRIPS on access to medicines. This approach 
is underpinned by two fundamental principles. First, the concept of using trade (and of using TRIPS) as a means to promote sustainable social, economic and environmental development, rather than to prioritise economic and financial growth regardless of the social costs (Winters, 2005), and secondly, the principle that trade policy is not central, but is complementary, to alternative domestic, heterodox, institutional innovations (Rodrik, 2001).

Furthermore, it is important to clarify that I am not using human rights theory as a 'lens' to evaluate IPR and access to medicines, but as a perspective. As stated above, my aim is to elaborate whether aspects of trade and IPR currently impede access to essential medicines in Fiji and to suggest national and regional responses to help mitigate these. A human rights perspective is considered here as one response, along with a range of other strategic, policy and advocacy responses, which might address this by putting a public health perspective into trade and property rights. My research therefore includes a detailed description of human rights theory to set the context for discussing the existing institutions and challenges facing human rights in Fiji and the Pacific region.

I could have selected other development discourse, besides human rights, as a perspective to research and promote equitable access to essential medicines. Some alternative discourses include: gender equality, pro-poor development, and studies in social inequality. For example, a gender equality approach would challenge schemes which provide contraception to young boys but deny access to young girls, with the stated rationale that access might prompt girls to be sexually active (Youth Research, 1997). These are however not covered in this thesis.

A human rights perspective was preferred for this research because it is the only discourse with a comprehensive, globalised, legal, political and philosophical framework (Gruskin et al, 2005). At the international level, it is also the 'closest thing the international community has to a common resource of values that might be used to guide issues of access to property and knowledge' (Drahos, 2005, pp.16). Such a 'common source' may not be an appropriate descriptor in the Pacific region, where reports have noted tension exists between human rights and customary rights (PIFS/NZHRC, 2006). As a result of these tensions, the potential to use human rights to advocate for access to medicines is explored after discussing how Pacific 
communities view human rights.

\subsection{Methodology and field research design}

\subsubsection{Methodology}

This methodology primarily uses qualitative research, combined with some quantitative research. This choice of methodology reflects my chosen epistemology, Critical Realism, discussed in Section 2.1

Several research theorists advocate that, rather than exclusively using one method, quantitative and qualitative may be effectively mixed to complement each other; leading to a richer research result (Murray and Overton, 2003; Brockington and Sullivan, 2003). My emphasis on qualitative data and anecdotal evidence is also partly due to a lack of quantifiable data relating to this topic. The statistical data would have been useful to better understand the impact on the health of people, for example, the affordability of medicines for poor people when there are stock-outs of government procured drugs, the estimated cost of patented medicines versus generic versions if patent extensions were approved, the social and economic costs caused by ill health when people cannot afford drugs, or the efficacy of free medicines and whether diseases persists despite being medicated. Further research is recommended in instances where I considered quantifiable data would have been useful.

The methodology consisted of a two main steps. First, an extensive literature review of the trade, access to medicines and human rights issues at a global, regional and national level. This step set the context and guided the second step which was to conduct field research. The field research involved a series of semi-structured interviews with twenty two participants from a range of trade and health-related government ministries, non government organisations (NGOs) and UN agencies in Fiji and New Zealand. This second step explored the questions set out in the literature review. Both steps are elaborated below.

The literature review commenced by compiling information on the global evolution of Trade 
Related Intellectual Property Rights (TRIPS) in multinational, regional and bilateral trade agreements. This included empirical evidence and the arguments raised by opponents and proponents about the impact of intellectual property rights on access to medicines in developing countries. The literature relating to international human rights theory, in particular 'human rights and access to medicines' was then reviewed. This included the complex challenges associated with the application of human rights instruments, the interface with other world systems, for example the World Trade Order, and case studies that exemplify the application of human rights to successfully improve access to medicines. The review then focused on the Pacific region and examined the literature relating to the regional population health status and description of health services and the mechanism for trade policymaking. The potential for trade-related provisions, such as TRIPS, in proposed regional trade agreements (for example, EU EPA) and a description of human rights mechanisms and challenges was also included.

Finally, the literature review was narrowed down to a national level in Fiji. Here the review scoped out the capacity for trade policymaking and advocacy, the content and status of Fiji's national patent law and a description of the national human rights mechanisms. The literature describing the national pharmaceutical policy, medicines procurement and medicines regulation in Fiji was also researched, taking note of any regional integration initiatives that may impact on medicines.

\subsubsection{Field research design}

In-country interviews were conducted in Suva, Fiji, over a two week period from $8-21$ October 2007. Suva was selected because of the concentration of Fiji Government Ministries, UN agencies and domestic and regional NGOs. It is also the head quarters for the Fiji Pharmaceutical Services, the bulk procurement and regulatory agency for medicines in Fiji. Findings were that the Chief Pharmacist responsible for this agency has been proactive in raising awareness about safeguarding access to medicines, particularly in regard to national IPR law, and is acknowledged amongst other PICs as having acquired substantial knowledge on this subject. 
The majority of interviews were conducted on a face-to-face, individual basis, using a set of thematic questions to prompt discussion (refer to Appendix 1 for an example of interview themes). ${ }^{8}$ The four interviews conducted in New Zealand were completed in early November 2007.

A representative sample of organisations were selected from a cross section of the Fijian Government, Council of Regional Organisations in the Pacific (CROP), UN agencies, and domestic and regional NGOs using four criteria. Organisations selected to be included in this research qualified if they were directly involved in any of the following:

(i) the procurement or prescribing of medicines in the public health sector - and therefore are directly involved in measuring the impact of the safety, affordability and access of Fijian citizens to medicines;

(ii) critiquing or drafting of national IPR law and pharmaceutical patent examination;

(iii) policy or advocacy for health development, trade or human rights and health;

(iv) trade negotiations or providing technical assistance to the Pacific Island Forum Secretariat on trade, intellectual property rights and/or health issues.

Around half of the interviewees were contacted using telephone and email and meetings were scheduled in advance of my trip to Suva. Generally I did not experience difficulty arranging further interviews once I was in the country as the topic was of great interest to most people. The remaining interviews were arranged as referrals from existing interviewees, or by making further telephone calls.

Twenty two participants were interviewed from pre-selected organisations, including the following organisations in Fiji:

(i) Fiji Pharmaceutical Services, under the Fijian Ministry of Health, responsible for Fiji's public medicines procurement (2);

(ii) Fijian Government Patent Office located within the Company's Registration Office $(1)$;

\footnotetext{
${ }^{8}$ One international participant was interviewed by telephone and one meeting included two participants at the same time.
} 
(iii) Pacific Island Forum Secretariat, trade section. The Secretariat is responsible for providing technical support on trade and economics to the Pacific Island Forum Leaders (1);

(iv) health-related UN agencies: WHO (West Pacific Regional Office), UNAIDS, UNICEF, UNDP (Pacific Centre), UNFPA (6);

(v) regional and national NGO's involved in trade and health advocacy to varying degrees: PANG, PCRC, ECREA, FSPI and PCC (5);

(vi) Pacific Regional Rights Resource Team; a project of the UNDP Pacific Centre (1)

(vii) CROP agency: Fiji School of Medicine (1);

(viii) senior pharmacist from a Pacific Island agency involved in health development (1).

In New Zealand, prior to, and following on from my trip to Fiji:

(ix) PHARMAC NZ, the NZ agency responsible for procurement of all government funded pharmaceuticals (2);

(x) New Zealand Ministry of Pacific Islands Affairs, the Ministry responsible for researching, designing and advising the New Zealand Government on policies that enhance the economic and social wellbeing of the Pacific Island community living in New Zealand (1);

(xi) NZ Human Rights Commission, involved in supporting PICs to establish appropriate human rights instruments aligned with local custom (1).

When I commenced designing this field research methodology I had intended to travel from Suva to Noumea, New Caledonia, to interview key people within the Secretariat of the Pacific Community (SPC). SPC is one of the Council of Regional Organisations in the Pacific (CROP). The Secretariat is responsible for implementing many of the Pacific Plan health objectives and undertakes other health-related work, such as public health surveillance, laboratory, communicable disease control, healthy pacific lifestyle, HIV/AIDS projects, and Global Fund to fight AIDS, Tuberculosis and Malaria under its Public Health Program.

However, when I approached a senior manager within the organisation they commented it wouldn't be worth my while and declined to be telephone interviewed, stating the Public 
Health Program 'was not involved in trade issues'. 9 I did however conduct a telephone interview with an SPC staff member who agreed to provide personal comments and not to answer on behalf of SPC. These comments are discussed under the findings in Chapter 5 alongside my views on what I perceive as an opportunity for regional level agencies, PIFS and SPC, together with WHO, to play a significant role in promoting a public health perspective in trade policymaking and to raise awareness of the potential impediments of trade on access to medicines in Fiji and other PICs.

A critique of this research methodology, including the absence of interview participants from SPC, and any limitations this may have on gathering and interpreting information, is covered in Section 1.6.4. This critique is taken into account in my key findings and recommended responses in Chapter 5.

\subsubsection{Human ethics approval}

Human Ethics Committee (HEC) approval was gained from Victoria University of Wellington prior to any interviews taking place and every attempt was made to maintain confidentiality where this was requested.

Prior to each interview all participants were made aware of the 'Information Sheet', explaining the reason for my research, and 'HEC Participant Form' (see Appendix 2 for both forms). Participants were given an opportunity to complete this form either prior to the interview, or after, at completion of the interview. Some participants elected to retain the form and to determine how they would fill it out once they had read a draft copy of the thesis which I gave a verbal undertaking I would send to them, prior to the final version being submitted. Others did not consider there was any need to sign HEC forms as the information they were providing was general in nature. The same procedure was followed with the single interview conducted by telephone. In this case, the forms were exchanged by email prior to the interview. By undertaking these steps I have fulfilled the University's ethics policies.

\footnotetext{
${ }^{9}$ Personal email correspondence
} 
Scheyvens and Storey note that ethical considerations in field work should extend beyond obtaining ethics consent to also take the potential effects of the research, and researcher, on the participants into consideration (Scheyvens and Storey, 2003). Since my interview participants didn't appear to be particularly marginalised or vulnerable people, and appeared to be familiar with participating in an interview, this consideration was relatively less complex. However, trade and health issues are particularly political in nature and the Fijian community is relatively small and closely networked. Because of this I was aware of the need for diplomacy in articulating some of the research findings and for respecting the integrity of those interviewed.

To that end I undertook to send a draft version of the thesis to interviewees which enabled them to see the information and quotations they provided in the context of the thesis and to modify these if required. In addition, I asked if the participants had any ethics approval criterion particular to their organisation or association that I needed to complete prior to the interview. No participants indicated that prior ethics approval by their organisation was necessary.

\subsubsection{Methodology critique}

Limitations of this methodology primarily related to assuming a representative sample of stakeholder organisations when not all organisations were available to be interviewed, portraying the views of an individual as if they represent the views of their organisation, overreliance on qualitative data versus quantitative data, limited comparison with other PICs to assess how recommended responses may be translated to a regional level, and my own ability to interpret correctly participant's views and realities without misrepresenting their response.

The number of stakeholder organisations that I managed to interview is perhaps the major limiting factor. Several key interviews were not possible for a variety of reasons. These included: meeting arrangements disrupted because my trip coincided with the $38^{\text {th }}$ Forum Leaders Conference in Tonga and the Civil Society Conference which preceded it; key individuals working overseas; the Fijian coup which placed additional responsibilities on 
several Fijian Government Ministries, extending their resources and limiting their time to meet.

Some of the key people that I would have liked to interview included: officials from the Ministry of Foreign Affairs and External Trade and the Ministry of Health involved in trade and health policy; the Solicitor Generals Office involved in drafting national IPR law; hospital clinicians and managers who administer medicines paid for by the government; the Pharmacists Association commenting on drug efficacy and frequency of stock-outs; the Human Rights Commission; other NGOs, for example the World Council of Churches.

As a result there is a danger of an over-reliance on information supplied by the organisations interviewed which may have been overly critical or supportive of other stakeholders without my being aware. This presented less of a problem where information was factual in nature (for example, a description of how medicines are procured, or the status of the draft IPR Bill) than when it related to say, a description of the mechanisms, both formal and informal, used to put a public health perspective into trade negotiations.

Another limitation arose from interviewing a single individual from each organisation which may not represent that organisation's views. This is less critical because my objective was to elaborate processes, mechanisms and mandates around trade and medicines rather than to document the views of one organisation about another.

A lack of quantitative data is noted, however this would have helped to underpin the research rather than to substantively change the findings. For example, it would have been useful to establish which pharmaceutical firms and what products were registered in the existing pharmaceutical patents. However, this was not feasible because the documents are not yet stored electronically at the Fijian Patent Office making it necessary to make a prior request and to manually check each registration. Furthermore, these are complex documents which would require employing someone with specialist expertise to interpret. For example, the records often describe the active chemical agents and process of manufacture, which a pharmacist would recognise, rather than a brand name. 
The limitations described in this section are acknowledged and wherever possible they are taken into consideration in the findings and recommendations. Despite its flaws, the methodology did however provide three valuable insights.

First, when I established contact with the Ministry of Health and asked to speak with someone involved in trade issues, or I contacted the Ministry of Foreign Affairs and External Trade and asked to talk to someone who dealt with health-related issues in trade, I was advised that person did not exist. I did not dismiss these responses because they did not result in an interview. Potentially this might have reflected my approach, not explaining well enough my research. Alternatively, such responses may be an indication that trade and health issues are not currently factored into decision making processes, or that they did not see the need to do so; warranting further research. I have factored these responses into my findings in Chapter 5. Second, some of the research questions cannot readily be answered at present because of a lack of capacity and information on the topic. Third, individuals had incomplete knowledge of the whole system making it critical to cross-reference information from several different sources. This wasn't always possible within the scope of this project, and so sometimes raised more questions than answers. The qualitative nature of this research methodology means that this cross-section of organisations and cross-referencing of information is very important.

Finally, where divergent responses were given to my interview questions I attempted to use analytical rigour to clarify the issues that were raised. In the very few cases, when different answers were made, I highlighted both sides of the issue and identified the need for subsequent research. This occurred in particular in discussions about the appropriateness of using human rights to advocate for trade and access to medicines, exemplifying the tension with customary rights in the Pacific region.

\subsection{Structure of this dissertation}

This thesis researches four seemingly separate, but interrelated, systems that have a profound impact on access to medicines in developing countries and the structure of the global 
pharmaceutical industry. These are:

1. regional population health trends and public health services, including national medicines policy and procurement;

2. intellectual property rights, including pharmaceutical patent law and examination;

3. trade policymaking, including trade and health advocacy, and key multilateral and free trade agreements, and;

4. human rights instruments, in particular the right to health (and access to medicines).

These four systems are mutually reinforcing, however, they are generally researched and managed in isolation, on a sector by sector basis. This situation continues to exist despite an increasing awareness of the benefits of a multi-sector approach to public sector management, particularly as the effects of trade liberalisation cut across different sectors (WHO, 2007b). To my knowledge, an overview of these four systems in the Pacific region, and an attempt to critique across the four systems, has not been undertaken before. This multi-sector research may therefore be useful to policymakers and development practitioners working in any of these, or related fields, as it has the benefit of elaborating a wide range of multidisciplinary findings that are usually less evident because they are conventionally researched and managed in isolation.

This research sequentially describes each of the four systems at a global, regional and national level. After broadly describing the global level, the thesis then explains how these four systems work (in principle) in the Pacific region and, more specifically, in Fiji. This reinforces the understanding of how local issues are being shaped by global forces. This overview, combined with a brief description of the local cultural, political and economic context in Fiji, then provides an insight into the way Pacific communities generally might view access to medicines and the political status that access to medicines is accorded compared with neighbouring emerging economies, such as Thailand.

A discussion of how these four systems work at a regional level is included because several of their components, for example, collective medicines procurement and regionalised patent 
administration, are identified as areas for regional cooperation under the Pacific Plan. This research therefore sees the Pacific Island Forum Secretariat (PIFS) as a regional stakeholder, as it is the agency that provides technical assistance on economic and trade development to the Forum Leaders.

This thesis is divided into five chapters as follows:

Chapter 1: Describing this research. An introduction and outline of the research aim, methodology and epistemology are provided in this chapter. It also discusses how my epistemological approach has shaped the methodology and provides a critique of the methodologies limitations and how these might influence my findings.

Chapter 2: The global context. This chapter is designed to place the debates surrounding trade and access to medicines and a description of international human rights mechanisms within a theoretical and global context before the research is narrowed down further to describe how these mechanisms function in the Pacific region and then in Fiji. Human rights theory is extensively described, in particular the human right to health, and to access to medicines, including challenges and opportunities facing human rights and the interface with the WTO global trading order where private property rights are dominant over access to public goods.

Chapter 3: The Pacific context. Following an introduction to the Pacific context this chapter provides an overview of the four interrelated systems that impact on trade and access to medicines. They include a description of population health trends and public health services, intellectual property rights and pharmaceutical patent examination, trade policymaking mechanisms and key multilateral and free trade agreements, and the application of human rights instruments. The chapter includes a discussion of the potential impact of the proposed regional trade agreements with Europe (EU EPA), and with New Zealand and Australia (PACER), on access to medicines and how human rights are generally perceived by Pacific islanders.

Chapter 4: The national context. Here, the research focus is narrowed down to Fiji. It begins with a general introduction to Fiji that sets the socio economic and political context before it 
focuses on how the same four systems function at a national level. The information in this chapter is mainly drawn from my field research interviews. Also in this section I pay close attention to examining local cultural preferences towards western medicines culture and views about human rights. These attitudes and understanding contribute to how trade and access to medicines is perceived in Fiji and at the regional level of the Forum Secretariat.

Chapter 5: Findings and conclusions. This chapter provides an extensive summary of the main research findings under each of the five primary research objectives. These findings, together with suggestions from interview participants and personal observations are then used to design multi disciplinary responses to help mitigate trade-related factors from restricting access to medicines in the future. The need for regional cooperation on health, IPR and trade has been acknowledged by the Pacific Forum Leaders under the Pacific Plan. ${ }^{10}$ The responses are summarized in Appendix 5. Finally, this chapter discusses the significance of this research for human rights theory and for the wider academic audience, in particular the emergence of human rights mechanisms needing to adapt to promote 'collective' national sovereignty within economic trading blocs and the relationship at the interface with traditional knowledge.

\footnotetext{
${ }^{10}$ See Strategic Goal 11 in reference PIFS. (2007). Pacific Plan. Available at www.pacificplan.org last accessed $5 / 12 / 07$
} 


\section{Chapter 2: The global context}

\subsection{Introduction}

This chapter grounds this research in the global context firstly by briefly describing development theory and international trading systems that influence access to medicines, and secondly, by providing a more detailed description of international human rights theory, and of human rights and access to medicines in particular. ${ }^{11}$

Debates on universal human rights needs to distinguish between legal, political and philosophical human rights perspectives. The practice of shifting seamlessly between these perspectives has been criticised as an unfortunate trait within literature and public discourse (Evans, 2002). Evans points out this practice serves to undermine the status of human rights to global politics because it opens the possibility of gaining the moral status that ratifying international human rights law brings, while simultaneously denying socioeconomic rights philosophically and politically. This research aims to clearly distinguish between these three perspectives in the discussion of human rights in the Pacific region (and in Fiji) in order to reduce the possibility of misrepresenting the entire human rights framework by selectively describing parts of it.

The section on human rights commences with an overview of the international human rights framework and summarises some of the complex challenges confronting its application in developing countries. This is particularly relevant to the Pacific region where reports have noted human rights are generally regarded with suspicion because of the tension with customary rights (PIFS/NZHRC, 2006; NZ Law Commission, 2006). The focus is then narrowed down to one particular aspect of the comprehensive international human rights framework; human rights and access to medicines, which is a sub-category of human rights

\footnotetext{
${ }^{11}$ As explained in Section 1.5, human rights theory is not used as a lens in this research. I do not intend therefore to describe human rights theory comprehensively. Extensive references and appendices are provided however for readers who require in-depth information on a particular aspect of human rights.
} 
and health ${ }^{12}$. Here I also describe the theoretic and legal interface of human rights and access to medicines with two other World Orders. Namely, the global economic (WTO) order, and intellectual property rights (WIPO). Considerable tension exists between human rights and these Orders because they represent the dominant neoliberal consensus that is axiomatic of the global trading system (Hestermeyer, 2007) which is often given priority over environmental, social and cultural rights (Gruskin et al, 2005).

Two case studies are included that illustrate the successful application of a human rights instrument to protect the right to essential medicines in developing countries. For example, the national level critique of the Thai-US FTA by the Thai Human Rights Commission contributed to its rejection on the basis that it limited the Government's ability to fulfill the Constitutional Right to Health (UNDP, 2006). Finally I reflect on the main themes in the global context that will influence how trade and access to medicines are viewed and to what extent health may be mainstreamed into trade policymaking in the Pacific region.

\subsection{Trade, TRIPS and access to medicines}

"Intellectual property rights are about balancing public goods and private rights. The (Pacific Island) Forum Secretariat has an obligation under its mandate to be the eyes and ears for the public (interests) as opposed to the private rights. Because Pacific Island Countries don't have a huge private sector, and they are not abundant creators of technology, or net producers of intellectual property, they are overwhelmingly dependent on accessing public goods. So, intellectual property rights needs to reflect this development reality. We need to ensure Pacific Island Countries have access to these goods and that they are affordable. Any indication otherwise, the Forum Secretariat would need to flag (to Forum Leaders)."

Ms Gail Olsson, Trade Consultant, Pacific Island Forum Secretariat, interviewed October 2007

TRIPS are established at the international level by a number of treaties including those

\footnotetext{
${ }^{12}$ For a comprehensive discussion of different aspects of human rights and health see reference Gruskin, S. et. al. (eds) (2005)
} 
administered by the World Intellectual Property Organisation (WIPO), which is a specialized UN agency, and the WTO. TRIPS especially had an impact after 2000, when the WTO TRIPS Agreement came into force. Under the Agreement, all WTO members are obliged to implement a set of minimum principles and rules, including patents and their enforcement. These rights include the control of production, sale, use and sometimes importation of medicines. TRIPS therefore give pharmaceutical companies near-global monopolies, allowing them to block competition from generic manufacturing companies and to raise the price of patented pharmaceuticals (Lofgren, 2007; WHO 2007a). ${ }^{13}$

More restrictive TRIPS, called 'TRIPS-plus', and trade related provisions are contained in bilateral and free trade agreements (FTAs), especially US FTAs. These include patent extension, data exclusivity, linkage evergreening and restrictions on compulsory licensing and parallel importation ${ }^{14}$.

In the past developed countries have set IPR standards to suit their own stage of economic and social development and used them to successfully distance themselves from rival economies by preventing developing countries from employing these same policies (Drahos and Mayne, 2002; Wade 2005); a tactic Chang has described as 'kicking away the ladder' (Chang, 2005). However, the globalisation of IPR means states no longer have discretion in setting their own preferred levels. This globalisation fails to recognise the importance of allowing countries to retain national sovereignty to manage the rules that regulate development goals such as health (Oxfam, 2007b; WHO, 2007a; UNESCAP, 2007).

The intended outcomes of globalised IPR regime is to improve markets for trading information internationally by encouraging invention and technology transfer. However, it is also recognised that the system creates roadblocks in the path of generic medicines, competition and the attainment of public goods (Maskus and Reichman, 2005). In response to significant and mounting international concern that property rights are impeding access to medicines, various multinational working groups have been established under the WTO,

\footnotetext{
${ }^{13}$ See reference WHO (2007a) for a comprehensive description of all of the issues

${ }^{14}$ For a description of these terms see reference WHO (2006a) and visit the health section of the Third World Network website at http://www.twnside.org.sg/heal.htm
} 
WHO and UN agencies to monitor the impact of TRIPS on public health ${ }^{15}$ and to explore new models to stimulate investment in R\&D and medicines supply for developing countries. For example, offering prize money to encourage more research and development into neglected diseases instead of awarding patents once a medicine has been discovered.

The WTO TRIPS Agreement includes a number of transition periods for developing countries and LDCs ${ }^{16}$. Under the original TRIPS agreement these members had until 1 January 2005 and 1 January 2006, respectively, to implement patent protection for pharmaceutical products. Prior to this, many developing countries only protected patented processes, and not products. This enabled countries like India to develop generic drug manufacturing capacity.

Under the Doha Declaration, Least Developed Countries (LDCs) can now delay legislation to protect pharmaceutical products until 1 January 2016. However, if LDCs graduate to being developed countries, the extended timeframes no longer apply. These dates are not beyond challenge, for example, under the proposed WTO accession package of 2007, Samoa is under considerable pressure to implement TRIPS far earlier than the dates specified under the Doha Declaration $^{17}$.

TRIPS implementation has been debated by two sides ${ }^{18}$. One favours swift compliance and limited use of flexibilities using coercive pressures such as trade deals and threats, WTO disputes and diplomatic demands, to foster a pro-IP climate. The other advocate for a more flexible approach tailored to specific national development priorities by harnessing ideational power, such as running access to medicines campaigns (Abbott, 2005). To win over developing country decision-makers, the two groups have been engaging in a research war and compete in the area of capacity building (Deere, 2007).

\footnotetext{
${ }^{15}$ Examples include: WTO and Public Health; WHO Commission on Intellectual Property, Innovation and Public Health (CIPIH); International Centre on Trade and Sustainable Development (ICTSD) a UN accredited NGO eg. UNCTAD-ICTSD joint working group

${ }^{16}$ Least Developed Countries in the Pacific region include: Solomon Islands, Samoa and Vanuatu. PNG and Fiji already have to comply, Solomon Islands is delayed until 2016, while Tonga's deadline is 1 June 2008

${ }^{17}$ Personal correspondence with Oxfam New Zealand re. evaluation of the proposed WTO accession package for Samoa, July 2007.

${ }^{18}$ For an excellent overview of trade and access to medicines see reference Abbott, F.M.(2005).
} 


\title{
2.3 Overview of international human rights law
}

\author{
"Human rights are what reason requires and conscience demands. They are us and we \\ are them. Human rights are rights that any person has as a human being. We are all \\ human beings; we are all deserving of human rights. One cannot be true without the \\ other."
}

Kofi Annan, Former Secretary General, United Nations

Human rights are legally guaranteed by human rights law. These laws protect individuals and groups against actions that interfere with fundamental freedoms and human dignity (WHO, 2002). A moral imperative created the impetus for their development during the post-World War II settlement. The Universal Declaration of Human Rights was originally envisaged as a single instrument. However, a disagreement ${ }^{19}$ resulted in the drafting of two major Covenants; exemplifying the cultural relativist debate (Uvin, 2005) discussed in more detail below.

The legal instruments which form the foundation of modern international human rights law ${ }^{20}$ include:

(i) the International Bill of Human Rights which is the name given to the Universal

Declaration and the two Covenants, the International Covenant on Economic, Social and Cultural Rights (ICESCR) ${ }^{21}$ and the International Covenant on Civil and Political Rights (ICCPR), adopted by the UN General Assembly on 10 Dec 1948. This Bill is the most important international human rights legal instrument, (ii) other UN instruments with supervisory bodies, of which there are currently six Conventions, and (iii) other major human rights treaties and standard setting by the $\mathrm{UN}^{22}$

\footnotetext{
${ }^{19}$ By the time States were prepared to turn the Declaration into binding law, the Cold War had polarised human rights into two separate categories. The West argued that civil and political rights had priority and that economic and social rights were aspirations while the Eastern bloc argued to the contrary.

${ }^{20}$ For a detailed description of the 7 main international HR law instruments see reference RRRT/UNDP, (2005).

${ }^{21}$ For a description of the Committee for ICESCR and others refer to NZ MFAT, (2003). pp. 57.

${ }^{22} \mathrm{HR}$ instruments normally consist of formal treaties and declarations drafted by HR bodies, such as the UNCHR, as well as authorized interpretations of these instruments, such as General Comments by Treaty Bodies. These are the normal reference documents of HR lawyers. When these do not exist, or do not adequately cover the concerns of the international community, documents by professional organisations and major international
} 
These instruments form the bedrock of contemporary international human rights law, not only because of their potential worldwide application, but also because of the breadth of the human rights contained in each. ICCPR places an immediate and absolute obligation on states, whereas the implementation of rights under ICESCR is both progressive and dependent upon the availability of resources.

\subsection{Some complex challenges surrounding the application of human rights}

There are many complex challenges preventing broad political support for the human rights mechanism. Passing more human rights legislation will not overcome these challenges as they represent fundamental differences in values, or blatant disregard by those in charge (Farmer and Gastineau, 2005). Some of the main challenges identified from the literature research include: cultural relativism and euro-centrism; emergence of third generation rights, for example, the responsibility of pharmaceutical companies in the right to health; the status of human rights within the neoliberal global economic order, and the need for new methodologies and indicators to operationalise the human rights framework. Each of these challenges is discussed below.

\subsubsection{The 'ism's': cultural relativism and euro-centrism}

The separation of the two major Covenants (the ICESCR and ICCPR), combined with the West's almost exclusive focus on the latter, has created a sense that there are two levels of human rights, called first and second generation ${ }^{23}$. Although they can be categorised in this

conferences and summits are developed. These do not carry the same legal authority, but are invaluable to understanding the normative issues involved in the relationship between health and HR and to elaborating policies and programs in this field.

${ }^{23}$ First generation rights are for civil and political rights which prevent the State from interfering in the day-today lives of citizens. Second generation rights are economic, social and cultural rights that require the State to ensure provision of goods and services which contribute to these rights to people at all levels of society. They are not interpreted as being of 'lesser' priority. 
way, the UN has consistently stressed the universality and indivisibility of human rights. ${ }^{24}$

There has, nevertheless, been ongoing debate as to whether the human rights enunciated in the UDHR and core human rights treaties are in fact universal or should instead be culturally relative. The cultural relativists hold that not all states can be, or should be, expected to protect human rights to the same degree, due to varying levels of economic, political and legal development and differing cultural views on the necessity of freedom (NZ MFAT, 2003).

Related to the cultural relativism debate is the argument over so-called (eastern) Asian versus western values, or euro-centrism. The former focus on duties and discipline rather than on rights and entitlements; on community and the common good as opposed to individualism; on respect for authority, as opposed to freedom and on hard work and savings, as opposed to consumption, and contend that these values are superior to those in the West (Uvin, 2004).

Proponents also argue that the UDHR is essentially a product of western countries and values, given the limited UN membership (56 States) at the time of its adoption in 1948 (Uvin, 2004). Furthermore, given all state members of the UN are also members of WTO, they see developed states as having a duty of international cooperation and assistance in the ICESCR to work towards equitable multilateral trading investment and financial systems. This means that states should respond to these rights in all jurisdictions to ensure trade agreements or policy will not adversely affect these rights (Hunt, 2005).

The relativism debate is further compounded by the misunderstanding by some groups that human rights is a hegemonic, package that can simply be adopted (Uvin, 2004; Farmer and Gastineau, 2005). Increasingly however, it is acknowledged that local customs need to be taken into consideration and a human rights 'blend' developed, that is owned by local people and suited to the cultural setting of each country (PIFS/NZHRC, 2006)

\footnotetext{
${ }^{24}$ The debate on universality and indivisibility continues in international fora, especially when more controversial issues are discussed such as gender preferences and reproductive rights. The term means that everyone has rights and freedoms set forth in the Declaration, without distinction of any kind, such as race, etc. Despite general acceptance that HR are universal and indivisible, there may be occasions, for example, when it is necessary to restrict certain rights for the welfare of society as whole.
} 
Eurocentrism and the juxtaposition of custom and human rights are significant to how human rights is perceived and applied in the Pacific region. "In the Asia/Pacific region, there is some resentment about the concept of human rights. Some of our leaders are fond of decrying them as a western or alien concept at odds with our values." (NZ Law Commission, 2006, pp.15). This is discussed further under Section 3.5.

\subsubsection{Third generation rights, extending from state to other duty-holders}

In traditional international law only states are subjects of the law. The duty to promote and protect health as a human right is therefore assumed to lie with the state, although the liberal expectation is that this duty can only be fulfilled progressively (Gruskin et al, 2005).

However, given the conditions of globalisation, the changing contexts of the social determinants of health are becoming increasingly supra-national, in turn challenging the notion of national duty-holders. Recent additions to human rights legislation have sought to bind non state actors as duty-holders, especially transnational corporations. ${ }^{25}$

Third generation rights, or rights of fraternity or solidarity, represent a more controversial category since these require states to cooperate to improve the lives of their entire populations for example, the Right to Emergency Assistance and the Right to Development. The status of these rights in international law is not yet clear and poses significant challenge to much traditional human rights thinking (Hunt, 2005).

\subsubsection{The status of human rights within the world trade order}

Human rights interface with other World Orders that determine the behaviour of states and third parties, such as transnational corporations. These include the World Bank and WTO, through multilateral and free trade agreements, and WIPO, through private property rights. These institutions are dominated by the neoliberal consensus which emphasise the freedom of

\footnotetext{
${ }^{25}$ One important step in clarifying these responsibilities was taken in the form of Norms adopted in 2003 by the UN Sub-Commission on the Promotion and Protection of HR which include reference to economic, social and cultural rights. Another example, is the "Ethical Globalisation Initiative' which explores with pharmaceutical companies what the right to health and corporate responsibility implies, particularly in relation to patents, pricing and R\&D (Robinson, 2004; Hunt 2005).
} 
individual action, non interference in the private sphere of economics, and the right to own and dispose of property; a set of principles axiomatic to the ideology of the free market (Drahos 2001; Cullet, 2005; Hoen, 2005; Hestermeyer, 2007).

Furthermore, human rights law is also fundamentally different from world trade law. For neoliberals, socioeconomic claims are legitimate claims, or aspirations, but these can never be legal rights. Such soft law, associated with human rights, versus hard law of the WTO Order, and its dominance in determining the behaviour of states, is commented on by Hestermeyer:

"Enforcement of human rights law is further hampered by the fact that, unlike economic law, the most common case of a states's violation of HR law - namely a violation of the rights of its own citizens - does not harm other states directly which therefore lack an incentive to complain about the violation... It is a recipe for perplexity; while the claim of normative superiority of human rights has strong emotional (but far less legal) appeal, state behaviour will be largely dominated by the tenets of WTO law. The question to be tackled ....is whether there is a way to make human rights law count within the WTO system, as it is that system that will determine the behaviour of states"

Hestermeyer, H. (2007). pp.207

Proponents of human rights contend that the dominance of the neoliberal consensus remains the single most important factor hindering the establishment of socioeconomic rights as legitimate claims. They argue that the process of globalisation itself, and of structural adjustment programmes (Gruskin et al, 2005) that themselves are guided by neoliberal principles, cause the conditions that increasingly threaten health security in all regions of the world (Robertson, 2004; Evans, 2003). For example, the WHO estimates that nearly a quarter of disease and injury is connected to environmental degradation and decline attributable to globalisation and notes that $90 \%$ of malaria deaths are caused by the settlement of people in and around rainforests and the construction of large open-water irrigation schemes which increase human exposure to disease carrying mosquitoes (WHO, 2006b).

These tensions are perhaps illustrated in the (uncomfortable) role of the UN agencies involved 
in evaluating and monitoring human rights (Uvin, 2004) when they are also told not to get involved in multilateral trade agreements. For example, some UN agencies are expected to highlight obstacles that impact on specific human rights treaties, such as violence against women, or on progress towards the Millennium Development Goals (MDGs); yet the WTO system is often implicated as the major source of restrictions on health development.

\subsubsection{Need for new methodologies and indicators}

The human rights framework is broad and may be expressed through a wide range of mechanisms from a state's constitution to national case law. However, a fundamental difference between human rights and trade and development theories is expressed in Article 2 of the Universal Declaration of Human Rights. The Declaration emphasizes 'universality' and 'indivisibility', and the delivery of rights to 'all', rather than accepting that on some occasions, some people may be disadvantaged in order to provide a net benefit to society. For example, having to decide between investing in a school facility or water sanitation may advantage some people, while disadvantaging others, in realising their right to health and the right to education.

Human rights practitioners acknowledge there is a need to develop new skills and techniques to make this operational; especially if it is to extend beyond the classic methodologies of political naming and shaming and taking test cases in case law, into engaging with policy making. Appropriate human rights indicators and benchmarks are also needed, especially in relation to socioeconomic and cultural rights to assist with 'getting a handle on the slippery concept of progressive realisation' (Hunt, 2005, pp. 58). Integrating human rights into development entails empowering poor people, ensuring their participation in decision-making processes which concern them, and incorporating accountability mechanisms that improve transparency. These strategies take time to develop and introduce, particularly as developing human rights capacity and culture amongst organisations, and society as a whole, is a long process (Uvin, 2004). 


\subsection{Human rights to health, the significance to access to medicines}

"It is my aspiration that health will finally be seen not as a blessing to be wished for, but as a human right to be fought for."

Former United Nations Secretary General, Kofi Annan

The right to the highest attainable standard of health (the right to health) was first reflected in WHO's Constitution and has been firmly endorsed in a wide range of international and regional human rights instruments. ${ }^{26}$ The most authoritative interpretation of the right to health is outlined in Article 12 of the ICESCR, which has been ratified by approximately 150 countries (NZ MFAT, 2003).

Since its inception the UN has focused on classic civil and political rights, such as the right to a fair trial. However, in 2000, the UN began to address cases of historical neglect when the UN Committee on Economic, Social and Cultural Rights, which monitors the Covenant, adopted a General Comment (14) on the right to health that further clarified the nature, scope and content of the right to health.

The General Comment 14 of ICESCR sets out four criteria by which to evaluate the right to health: availability, accessibility (affordability), acceptability (medical ethics) and quality. This Comment acknowledged that health promotion goes beyond the health sector and that coordinated, multi-sector action is necessary to foster greater equity in health, income and social policies.

\footnotetext{
${ }^{26}$ Most HR and health issues are thoroughly covered at the website of the United Nations Commission on HR available at www.unchr.ch. Health-related information, including explicit references to HR, is available at the website of the WHO (www.who.org). The Francois-Xavier Bagnoud Center available at http://www.hsph.harvard.edu/fxbcenter/international_hhr.htm and Global Lawyers and Physicians for HR have collaborated in the preparation of a 'Perspectives in Health and Human Rights' Gruskin (eds) (2005) which is accompanied by a special website containing links to documents, organisations and other references on health and human rights (http://www.glphr.org/resources/appendix.). The University of Minnesota Human Rights Collection also provides a valuable list of documents on bioethics (see http://www1.umn.edu/humanrts/links/bioethics.html)
} 
The Ottawa Charter ${ }^{27}$ provides a common understanding of health promotion internationally which reflect the human rights ideology. It was developed at the first International Conference on Health Promotion meeting in 1986 as a charter for action to achieve Health for All by the year 2000 and beyond. The Ottawa Charter built on the progress made through the Declaration of Primary Health Care at Alma Ata, the World Health Organisation's Targets for Health for All document, and debate at the World Health Assembly on moral action for health.

\subsubsection{UN Special Rapporteur on Health}

The UN Special Rapporteur on Health has a mandate to focus on the right of everyone to the enjoyment of the highest attainable standard of physical and mental health ${ }^{28}$, as reflected in article 25 (1) of the Universal Declaration of Human Rights (UDHR), article 12 of the International Covenant on Economic, Social and Cultural Rights (ICESCR), article 24 of the Convention on the Rights of the Child (CRC) and article 12 of the Convention on the Elimination of All Forms of Discrimination against Women (CEDAW), as well as on the right to non-discrimination as reflected in article 5 (e) (iv) of the International Convention on the Elimination of All Forms of Racial Discrimination (ICERD).

The Special Rapporteur is further mandated to apply a gender perspective and to pay special attention to the needs of children in the realization of the right to health. The role also serves as a useful political tool to apply pressure to developed countries to remove TRIPS-plus from FTAs. For example, in 2005 a collective of international NGOs wrote to the Special Rapporteur citing the impact on the right to health, as interpreted by Article 12 of the ICESCR, for an urgent appeal to stop European-FTA member states (Switzerland, Norway, Iceland and Liechtenstein) from imposing TRIPS-plus rules in an FTA with Thailand. ${ }^{29}$

\footnotetext{
${ }^{27}$ For a description of the Ottawa Charter see WHO/HPR/HEP/95.1 at www.WHO.int

${ }^{28}$ The current holder is Professor Paul Hunt.

${ }^{29}$ Personal correspondence with field research interviewee, "Letter to UN Special Rapporteur on the right to health regarding the forthcoming EFTA-Thailand negotiations”, 20/6/05. On file with the researcher
} 


\subsection{Human rights and access to medicines interface with IPR}

"We thus find ourselves at a crossroads: health care can be considered a commodity to be sold, or it can be considered a basic social right. It cannot comfortably be considered both of these at the same time."

Mr Paul Farmer, Director, People's Health Movement, 2005

During the negotiations of the TRIPS Agreement, developing countries especially voiced public health concerns to argue for weaker, or more flexible, patent protection in the pharmaceutical sector. What had been essentially policy-based objections against minimum patent standards for pharmaceuticals during the negotiations started to be coined in human rights terminology by the UN and NGOs after the TRIPS Agreement came into force in 2000 .

Analytically this claim by proponents of human rights is three pronged. Firstly, it alleges the existence of a legal right to access to medicine. Secondly, it asserts that the adoption of patent legislation, now mandatory under the TRIPS Agreement, leads to inventors charging higher prices because of their ability to patent new drugs, rendering those drugs unaffordable for parts of the population. Thirdly, it maintains that this price effect can infringe the right to access to medicines, and that this infringement is not justified by other considerations, such as the necessity of patents to enable research and development.

Many proponents of TRIPS have replied to this challenge that patents are necessary to stimulate research for new medicine (Love, 2007; Oxfam 2007a). ${ }^{30}$ Others have added that intellectual property too, is protected as a human right (Hestermeyer, 2007; Werhane and Gorman, 2005).

In the early 2000's, the UN human rights system began addressing trade laws and practices in relation to human rights law. For example, the Commission on Human Rights in 2001

\footnotetext{
${ }^{30}$ One might tolerate the linkage of prices with R\&D incentives if the system was more efficient, but globally, only 8.5 percent of sales were reinvested in R\&D in 2005. Furthermore, only 14 percent of new drug approvals are both new and better than older products, and clinical trials for me-too products are about twice as large as for innovative drugs. See reference Love (2007)
} 
adopted a resolution on access to medication in the context of pandemics such as HIV/AIDS ${ }^{31}$ which reaffirms that, in this context, access is a fundamental element for the progressive realization of the right to health. States are called upon to promote the right to health indicators: availability, accessibility and affordability for all, without discrimination for treatments, and to adopt legislation, or measures, to safeguard access to pharmaceutical and medical technologies, from any limitations by third parties eg. US FTAs.

\subsection{Human rights case studies, political and legal challenges}

Two case studies (included below) illustrate how human rights may be applied to promote the right to health and access to medicines. ${ }^{32}$ The first is for a human rights impact assessment of an FTA in Thailand, the second is an example of human rights case law in South Africa.

\subsubsection{The human rights impact assessment of the Thai-US FTA}

Thailand is an example of well organised and multi-sectoral mobilisation of human rights. In 1997 Thailand developed an advanced constitution where human rights, in particular, the right to health and community rights, figures prominently. In 2004, the US and Thailand began negotiating on a comprehensive bilateral FTA. The FTA negotiations attracted great concerns and opposition, yet the human rights dimensions had not been thoroughly examined. In 2006, the Thailand National Human Rights Commission (NHRC), studied the potential impacts of the Thai-US FTA using a sub-committee of eminent experts. This was the first, and only, example at national level.

The aim of the NHRC assessment was to inform the Thai people about the implications of the Thai-US FTA on their rights, and to generate a public debate for transparency and accountability. The Thai NHRC also provided a clear analysis and policy recommendations to the Thai government to ensure that what was being negotiated was consistent with, and

\footnotetext{
${ }^{31}$ United Nations Commission on HR resolution 2001/33: access to medication in the context of pandemics such as HIV/AIDS (E/CN.4.RES.2001.33), available www.unchr.ch

${ }^{32}$ For a description of a wide range of case studies and mechanisms used to protect HR, health and access to medicines see references: Robinson (2004), Gruskin (2005), Rothman (2006)
} 
respected, human rights obligations enshrined in the Thai Constitution and international conventions to which Thailand is a party. The health stakes were high because Thailand prides itself on its universal health care coverage program and, for example, the inclusion of HIV treatment in the 30 baht scheme. The effect of TRIPS-plus provisions would raise drug prices, limiting treatment for the high $(800,000)$ HIV/AIDS population (Oxfam, 2006a). This would also mean there was no going back as HIV-positive people inevitably develop resistance to first-generation drugs, the public health services will be morally and legally obliged to find new ways to ensure access to second- and third- generation treatments to keep these people alive and healthy.

To launch the report ${ }^{33}$ and raise public knowledge, the NHRC organised a two day seminar, in cooperation with international and national partners, including the UNDP ${ }^{34}$, followed by a half day expert group discussion with key participants from ASEAN countries to formulate regional perspectives. The work of the group contributed to the rejection of the Thai-USFTA on the basis that it was contrary to the enjoyment of several fundamental human rights, including the right to health and access to medicines, and that it also challenged Thai sovereignty. The Thai government was supported in this work by UN agencies, becoming a global model of best practice. ${ }^{35}$

\subsection{2 'Right to health', challenges in case law}

Human rights case law is a good illustration of how the right to health can be formally introduced into the national justice system so that it ultimately leads to concrete changes in government policy and to people's wellbeing.

\footnotetext{
${ }^{33}$ Draft translation 'report on results of examination of HR violations by ad hoc sub-committee to review and examine the establishment of Thailand-United States Free Trade Agreement, complainer, issues raised by the national HR commission, against the government and agencies of Thailand responsible for Thailand-US FTA negotiations, 2006'. Personal source from field research interviewee. On file with the researcher

${ }^{34}$ UNDP supported the Thai government to organise reviews of FTAs implications on A2M. In Dec 2005 for example, the Thailand National Technical consultation on FTAs and IPR: implications for A2M was coorganised by $\mathrm{MOH}$ departments, Universities, the joint UN program on HIV/AIDS, UNDP and WHO, sponsored by UNDP.

${ }^{35}$ Sourced from 'Personal notes on the Thai national HR commission seminar on the HR implications of the Thai-US FTA' (Bangkok 18 - 19 Jan 2007) provided by field research interview participant on file with the researcher. Several of the eminent persons included the worlds leading thinkers on TRIPS and A2M (and HR).
} 
A majority of the right to health case law relates to access to anti-retroviral treatment. The most commonly described case is the Treatment Action Campaign (TAC) v. Minister of Health case in South Africa in 2002; also known as the Nevirapine case (Robinson 2004) In this case, the Constitutional Court of South Africa held that the Constitution, which protects the right to access healthcare services, required the government to devise and implement a comprehensive and coordinated program to progressively realize the right of pregnant women and their newborn children to have access to treatment in order to prevent mother-to-child transmission of HIV.

\subsection{Conclusion}

Some of the main challenges to human rights identified from the literature research include: cultural relativism and euro-centrism, the emergence of third generation rights, for example, the responsibility of pharmaceutical companies in the right to health, the status of human rights within the neoliberal global economic order, and the need for new methodologies and indicators to operationalise the human rights framework.

Human rights advocates need to be aware of these challenges when they draw on international human rights instruments to initiate change in governance, policy, legislation, and traditional and cultural practices in different countries. I have taken these into consideration in evaluating Primary Research Objective 5 which is to assess the general scope for using human rights instruments to protect access to medicines in Fiji and in the wider Pacific context. 


\section{Chapter 3: The Pacific Context}

\subsection{Introduction}

The Pacific region is comprised of 20,000 to 30,000 islands that are grouped into three main areas: Micronesia, Melanesia and Polynesia ${ }^{36}$. Approximately $90 \%$ of the 8.5 million people who live in the region reside in the Melanesian countries: Papua New Guinea (PNG), the Solomon Islands and Fiji.

The region's remoteness from major trading blocs, such as the United States, and the relatively small and highly dispersed population, presents major obstacles to achieving economic growth either through south-south trade between Pacific countries, or trade with the north. These factors contribute to the region's dependence on preferential foreign trade agreements, remittances and international development aid.

Pacific island countries are under pressure from the north to move towards formal regional integration, dubbed 'new regionalism', in order to engage with the global free trading system and adapt to the global security environment. Recent negotiations with the EU to replace existing preferential trade agreements with a reciprocal, regional trade agreement that includes conditional aid administered at a regional level, rather than directly to individual countries (as it is currently), is a poignant example of this. Here the EU has dictated the nature, terms and configuration of regional integration in ways that cut across organic developments that are underway based on south-south cooperation (Kelsey, 2006).

The application of 'new regionalism' is problematic in the context of the Pacific. Not only is this due to the lack of competitive or comparative advantage in most sectors, and of the prioritisation of economic growth over the development agenda, but because Pacific people do

\footnotetext{
36 'Melanesian' countries and territories consist of: Bismarck Archipelago, Fiji, New Caledonia, New Guinea (Papua New Guinea mainland and the Indonesian province of Papua), Maluku Islands, Solomon Islands, Torres

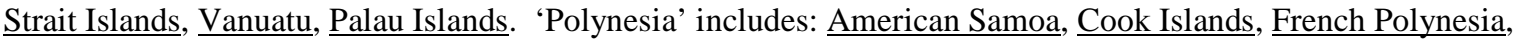
New Zealand, Niue, Pitcairn, Samoa, Tokelau, Tonga, Tuvalu, Wallis and Futuna. 'Micronesia' includes the

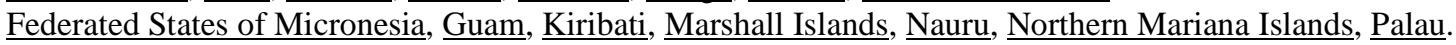


not view themselves as a 'region' in the same sense that is cultivated by Western neoliberalism (Thomas, 2004). For example, Hau' ofa notes that the identity of Pacific islanders is associated with a seamless oceanic world where communities based themselves on kinship and chieftainship and traversed the oceans for trade, marriage or war (Hau'ofa, 1998). Furthermore, the notion of independent countries, rather than of regionalism, was imposed on this Pacific identity by the colonial occupation of many Pacific island countries and early European cultural mapping (Thomas, 2004).

Concern for the region's marginalisation in 2004 led the Pacific Eminent Person's Group to develop the Pacific Plan, a framework that represents the first articulation of a new Pacific vision of the region and which has been signed off by all Forum Island Leaders. The Plan's concept of regionalism is not as far reaching as the western concept and provides scope for Pacific countries to pursue self determination and to explore their own common identity, the 'Pacific Way', which is different from the neoliberal way; an identity that continues to evolve in response to western hegemonic discourse.

An in depth analysis of the implications of regionalism in the Pacific is beyond the scope of this thesis. However, this research describes some of the key features of regionalism that are shaping how Pacific people view, and respond to, trade impediments to access to medicines; which is the topic of this research.

This chapter describes the three separate systems that influence access to medicines in the Pacific region (outlined in Section 1.3) and what are some of the factors which influence Pacific peoples' access to medicines. The Chapter commences with the demand-side; a description of population health trends and public health services. The focus then moves to the supply side and elaborates on the regional and national trade policymaking mechanisms in the Pacific. Here, the potential impact of proposed international trade agreements (EU EPA and PACER) on access to medicines is discussed, along with the diverse forms of national intellectual property rights law that currently exist. The chapter concludes with a description of the architecture of human rights mechanisms in the Pacific region and how human rights are perceived by Pacific people. 
The countries comprising the Pacific region are: the Cook Islands, Federated States of Micronesia, French Polynesia, the Fiji Islands, Kiribati, Nauru, New Caledonia, Niue, Palau, Papua New Guinea, the Republic of Marshall Islands, Samoa, Solomon Islands, Tonga, Tuvalu and Vanuatu.

\subsection{Overview of health trends and services in the Pacific}

\subsubsection{Pacific population health trends}

Despite good progress being made in selected health statistics in some PICs, there is increasing concern over the variation in health statistics between, and within, countries with progress slowing down or reversing in some areas. Furthermore, the MDGs progress report showed that some PICs are unlikely to achieve the health-related goals by 2015 without significant additional investment in health and related sectors (Tukuitonga, 2006).

The economies of several PICs are static or in decline, and despite substantial external development assistance over several decades, indicators are that living standards have either deteriorated or only slowly improved. Health indicators suggest that much more needs to be done to improve health in the region and to offset some of the adverse effects of poor economic performance, political instability, urbanization and globalisation, and fragile health systems.

The region is undergoing a demographic transition in which birth and mortality rates continue to decline, although several PICs continue to have high fertility rates. Morbidity and mortality patterns are also changing in the region, and notably age-standardised all-cause death rates are two to three times higher than in neighbouring developed countries. Although each country exhibits its own health trends, there are some common trends.

As seen in Table 1, non communicable diseases (NCDs) and their common risk factors, including unhealthy diet, inactivity and tobacco use, are the leading causes of death, disease 
and disability in all PICs. For example, NCDs accounted for $70-75 \%$ of all deaths in all PICs except for PNG where they accounted for 58\%. Pacific overweight and obesity rates are among the highest in the world, with seven PICs ranked in the top ten most obese countries in 2007 (WHO, 2007c). Obesity can slice 2-3\% off the gross domestic product (GDP) in indirect costs to the economy as a result of poor health and an inability to work.

After NCDs, communicable diseases, maternal, perinatal conditions and nutritional disorders are the second largest group of conditions causing death. Generally, this group accounted for about $20 \%$ of all deaths in most PICs except in Kiribati (27\%) and PNG (34\%). Diarrhoeal diseases and tuberculosis are the leading infectious diseases causing death. WHO estimates that over $4 \%$ of the global burden of disease is accounted for by diarrhoeal diseases, mainly concentrated in children, and that $88 \%$ of this burden is caused by unsafe water supply, sanitation and hygiene. Deaths caused by HIV/AIDs were infrequent in all PICs except in PNG which is experiencing annual increases in HIV/AIDS of 15-30\% (similar in scale to subSaharan Africa in 1992). Left unchecked it could affect 30\% of all women by 2010. HIV/AIDS is also a rising problem in Fiji.

The proportions of the three major causes of death in each country are depicted in Table1 below. 
Table 1: Age standardised death rates per 100,000 and proportion $(\%)$ by cause, by country. 2002.

\begin{tabular}{|l|l|l|l|l|}
\hline Country & $\begin{array}{l}\text { All } \\
\text { Causes } \\
\text { (Age Std } \\
\text { Rate) }\end{array}$ & $\begin{array}{l}\text { NCDs } \\
\text { (Age Std Rate } \\
\text { and \% of all } \\
\text { deaths) }\end{array}$ & $\begin{array}{l}\text { Communicable, } \\
\text { Maternal, Perinatal, } \\
\text { Nutrition } \\
\text { (Age Std Rate and } \\
\text { \% of all deaths) }\end{array}$ & $\begin{array}{l}\text { Injuries } \\
\text { (Age Std Rate } \\
\text { and \% of all } \\
\text { deaths) }\end{array}$ \\
\hline American Samoa & $\mathrm{Na}$ & $\mathrm{Na}$ & $\mathrm{Na}$ & $\mathrm{Na}$ \\
\hline Cook Islands & 817 & $616(75)$ & $163(20)$ & $38(5)$ \\
\hline Fiji & 1,065 & $825(77)$ & $200(19)$ & $40(4)$ \\
\hline Kiribati & 1,099 & $773(70)$ & $303(28)$ & $22(2)$ \\
\hline Marshall Islands & 1,333 & $998(75)$ & $274(21)$ & $62(5)$ \\
\hline Micronesia & 1,062 & $782(74)$ & $242(23)$ & $39(4)$ \\
\hline Nauru & 1,446 & $1,136(79)$ & $178(12)$ & $132(9)$ \\
\hline New Caledonia & $\mathrm{Na}$ & $\mathrm{Na}$ & $\mathrm{Na}$ & $\mathrm{Na}$ \\
\hline Niue & 856 & $637(74)$ & $181(21)$ & $39(5)$ \\
\hline Palau & 968 & $744(77)$ & $186(19)$ & $39(4)$ \\
\hline PNG & 1,413 & $815(58)$ & $494(35)$ & $104(7)$ \\
\hline Samoa & 1,026 & $782(76)$ & $204(20)$ & $40(4)$ \\
\hline Solomon Islands & 1,092 & $786(72)$ & $269(25)$ & $37(3)$ \\
\hline Tonga & 888 & $684(77)$ & $174(20)$ & $29(3)$ \\
\hline Tuvalu & 1,428 & $1,046(73)$ & $314(22)$ & $69(5)$ \\
\hline Vanuatu & 1,033 & $772(75)$ & $223(22)$ & $38(4)$ \\
\hline
\end{tabular}

Source: http://www.who.int/healthinfo/bodestimates/en/index.html

\subsubsection{Pacific health care provision}

In the region, health care systems are organised into three levels: community-based health/nursing stations (primary care), district or provincial health centres, and central hospitals (secondary care). These systems provide services for the whole country, including remote areas and outer islands. Due to a lack of in-country capacity and facilities most small PICs provide a referral system for specialised medical care (tertiary care) to overseas health facilities. These referrals consume up to $20 \%$ of total health care expenditure in some countries which further depletes budgets allocated to drugs (Tukuitonga, 2006).

As documented, health care systems are generally orientated towards primary health care with the bulk of services provided by nurse practitioners and non-physician providers from village and district-based facilities. Reform of health care systems has been undertaken in several PICs including Fiji, Samoa,Vanuatu and PNG. These have focussed on improving policy, 
planning and management of health services and health care financing arrangements. Reforms are ongoing and the impact on health systems and outcomes remains uncertain. Several PICs have decentralised their health systems, which may have inadvertently contributed to the problems of providing a basic level of secondary health care.

\subsubsection{Pacific health care financing}

Governments are the major funders and providers of health services in the Pacific with limited private provision in Samoa and Fiji. Under WTO GATS, countries may elect to include 'health' in their set of services nominated for trade liberalization. This is how foreign health insurance can enter local markets. However, countries may also apply 'certain conditions' to the liberalization to gradually introduce the transition. Table 2 shows selected health care expenditure indicators in some PICs. The proportion of GDP spent on health care and the per capita expenditure varies considerably within the region with high rates of per capita expenditure in Pacific Island Territories affiliated with France, USA and NZ (except the Cook Islands).

As seen, the three most densely populated PICs (Fiji, PNG and the Solomon Islands) spend proportionately lower amounts of GDP on health (3.4\%. 3.7\% and 4.8\% respectively) while countries in Micronesia and Polynesia generally spend a higher proportion of GDP on health compared with Melanesian countries.

There is no recommended level of national health spending although 5\% of GDP is generally used as a benchmark level, in particular for primary health care and health system support. Table 2 shows at least five PICs are below this level. The recommended per capita health spending per year is \$35USD (WHO, 2006b) and PNG and the Solomon Islands are below this benchmark (refer to Table 2 below). 
Table 2: Indicators of health expenditure by selected Pacific Island Countries, 2003

\begin{tabular}{|c|c|c|c|c|c|c|}
\hline $\begin{array}{l}\text { Country/ } \\
\text { Population }\end{array}$ & $\begin{array}{l}\text { Per capita } \\
\text { health } \\
\text { expenditure } \\
\text { US\$ (2003) } \\
\#\end{array}$ & $\begin{array}{l}\text { Total } \\
\text { expenditure } \\
\text { on health } \\
\text { as \% of } \\
\text { GDP }\end{array}$ & $\begin{array}{l}\text { General } \\
\text { Government } \\
\text { expenditure } \\
\text { on health as } \\
\% \text { of total } \\
\text { expenditure } \\
\text { on health }\end{array}$ & $\begin{array}{l}\text { Private } \\
\text { expenditure } \\
\text { on health as } \\
\% \text { of total } \\
\text { expenditure } \\
\text { on health }\end{array}$ & $\begin{array}{l}\text { General } \\
\text { government } \\
\text { expenditure } \\
\text { on health as } \\
\% \text { of total } \\
\text { govt. } \\
\text { expenditure }\end{array}$ & $\begin{array}{l}\text { External } \\
\text { resources } \\
\text { for health } \\
\text { as \% of } \\
\text { total } \\
\text { expenditu } \\
\text { re on } \\
\text { health }\end{array}$ \\
\hline $\begin{array}{l}\text { American } \\
\text { Samoa }\end{array}$ & 500 & na & 98.0 & 2.0 & 14.0 & 70.0 \\
\hline $\begin{array}{l}\text { Cook } \\
\text { Islands }\end{array}$ & 294 & 3.8 & 87.9 & 12.1 & 9.6 & 12.2 \\
\hline $\begin{array}{l}\text { Fiji } \\
846,090\end{array}$ & 104 & 3.7 & 61.3 & 38.7 & 7.8 & 13.4 \\
\hline $\begin{array}{l}\text { Kiribati } \\
99,000\end{array}$ & 96 & 13.1 & 92.4 & 7.6 & 7.8 & 0.8 \\
\hline $\begin{array}{l}\text { Marshall } \\
\text { Islands }\end{array}$ & 255 & 13.1 & 96.7 & 3.3 & 14.4 & 16.4 \\
\hline Micronesia & 147 & 6.4 & 88.0 & 12.0 & 8.8 & na* \\
\hline Nauru & 798 & 12.3 & 88.5 & 11.2 & 8.8 & $\mathrm{Na}$ \\
\hline $\begin{array}{l}\text { New } \\
\text { Caledonia }\end{array}$ & $1558 €$ & 9.2 & $\mathrm{Na}$ & na & na & $\mathrm{Na}$ \\
\hline $\begin{array}{l}\text { Niue } \\
1,200\end{array}$ & 655 & 9.7 & 98.4 & 1.6 & 9.3 & 9.2 \\
\hline Palau & 607 & 9.7 & 86.7 & 13.3 & 15.2 & 15.8 \\
\hline $\begin{array}{l}\text { PNG } \\
5.8 \text { mill }\end{array}$ & 23 & 3.4 & 88.9 & 11.1 & 10.9 & 28.3 \\
\hline Samoa & 94 & 5.4 & 79.0 & 21.0 & 20.1 & 18.9 \\
\hline $\begin{array}{l}\text { Solomon } \\
\text { Islands } \\
478,000\end{array}$ & $83 * *$ & 4.8 & 93.4 & 6.6 & 9.4 & 68.5 \\
\hline Tonga & 102 & 6.5 & 85.1 & 14.9 & 21.2 & 30.9 \\
\hline Tuvalu & 142 & 6.1 & 83.3 & 16.7 & 6.0 & 70.5 \\
\hline $\begin{array}{l}\text { Vanuatu } \\
211,000\end{array}$ & 54 & 3.9 & 73.8 & 26.2 & 12.9 & 25.4 \\
\hline $\begin{array}{l}\text { New } \\
\text { Zealand }\end{array}$ & 1618 & 8.1 & 78.3 & 21.7 & 17.2 & 0 \\
\hline Australia & 2519 & 9.5 & 67.5 & 32.5 & 17.7 & 0 \\
\hline
\end{tabular}

\#WHO Western Pacific Region internet statistical tables. Refer to data for year of collection

* previous average of $11.8 \%$ for the last 4 years

** \$US83 was submitted by the country and referred to the General Government Health Expenditure at internal dollar rate. The per capita health expenditure for 2003 was \$US28.

Source: World Health Report 2006 except CHIPS for American Samoa and New Caledonia 
While the share of GDP spent on health and government expenditure on health as a percentage of total health expenditure is comparatively high in some PICs, these indicators do not reveal an accurate picture of health spending. This is because unit costs are high in the region due to the high cost of transportation and communication which exists in small island developing states. The government is expected to provide the full range of services even though throughputs can be extremely low for some specialist services. As noted also Pacific governments are reliant on developed countries for some off-shore treatment, which the Pacific government pays for at great cost.

Therefore, even though the share of GDP spent on health is higher in some PICs, this level of expenditure may be insufficient to meet the cost of providing basic health care services. For example, Kiribati and the Marshall Islands spend in excess of 13\% of GDP on health. However the isolation and remoteness of the islands are a factor as they have higher infant mortality rates and maternal mortality rates, and lower immunisation coverage in the region. Conversely, Fiji and the Cook Islands have better results for the same indicators yet they spend less than $4 \%$ of GDP on health (WHO, 2006b).

Private expenditure on health is highest in Fiji, Samoa and Vanuatu where the government share are also the lowest in the region. For example, government expenditure as a percentage of total health expenditure is lowest in Fiji (61\%) and Samoa (79\%) which corresponds with higher private contributions. In the case of Fiji, $100 \%$ of private funds are derived from patients paying for their own medicines, a term called 'out-of-pocket payment'. In contrast, $78 \%$ of private contributions in Samoa are derived from people making their own payments out-of-pocket. However, health outcomes and health system performance indicators are comparable in both countries.

Private expenditure on health is usually made from out-of-pocket expenses as prepaid, and insurance, schemes are rare in the region. Out-of-pocket expenses have increased considerably in recent years in the region but detailed information is not available. User fees are reported to be widely used in several PICs mainly for primary care, pharmaceuticals and 
related services but most hospital services are free.

\subsubsection{Regional medicines initiatives}

A 'Regional Strategy for Improving Access to Medicines in the Western Pacific Region 20052010' has been developed by the PIFS and Pacific Health Ministers, in conjunction with the WHO (WHO, 2005), and partly funded and resourced by the European Community. The strategy has eight technical areas of work including: collective procurement, access to medicines, trade globalisation and the TRIPS Agreement. The WHO WPRO office in Suva is the lead coordinating agency.

The information gathered from literature research and participant interviews did not indicate that the TRIPS agreement and trade issues feature very strongly in this WHO regional strategy, which will be discussed further in the findings in Section 5.2. The SPC is also investigating the benefits of collective pharmaceutical procurement for communicable diseases under various regional public health programmes. Larger PICs, such as PNG and Solomon Islands, have indicated they are unlikely to benefit from a regional procurement approach.

\subsection{Overview of key trade agreements and trade policymaking in the Pacific}

\subsubsection{Trade policymaking mechanisms in the Pacific}

Trade policymaking in Fiji is institutionally linked to the Forum Secretariat at a regional level, where Fiji is represented by its Prime Minister as a Forum Leader, and at the Forum Secretariat by its Minister of Foreign Affairs and External Trade. Prior to the 2006 coup, Fiji used to share an alternating leadership role with Samoa for the Pacific ACP Regional Negotiating Team which meets with European Commissioners to resolve political and policy matters. The Forum Trade Ministers are advised by the Trade Experts Advisory Group (TEAG) who prepares regional strategic documents. When TEAG was created, discussions 
with regional NGOs resulted in the Pacific Concerns Resource Centre (PCRC) providing a member from civil society to join in discussions with this advisory group, but information and representation at meetings was reported to have been obstructed and there were few resources to support this work (Kelsey, 2005).

It is likely that trade agreements that are specific to Fiji, such as the Bilateral Trade Agreement being negotiated with New Zealand and China, are formulated at a national level, without reference to the Forum Secretariat. However, it can be assumed that many of the resources and key trade personnel involved in these are common to both. This situation raises issues of accountability and sovereignty.

Regional representation, such as the PIFS, in trade negotiations is not uncommon amongst small developing economies, for example the Caribbean small island developing states has a similar mechanism. However this mechanism introduces issues that would not exist if trade policymaking remained exclusively within the national domain. These national and regional issues need to be thought through and proactively managed. They include: legal and sovereignty rights; access to research undertaken by other members of the regional negotiating team, which are officially limited (Kelsey, 2005); accountability and the increasing risk that agreements will only be approached from a trade perspective (Kelsey, 2004).

The role of the PIFS is to provide technical assistance on trade and economic issues requested by Forum Leaders. This assistance includes alerting national leaders to trade obligations of significance to their economies. This regional structure draws on the technical expertise and support of ten independent agencies, referred to as the Council of Regional Organisations in the Pacific (CROP). These provide technical advice to the PIFS, and to individual PICs that lack the capacity, across a range of scientific, social, and cultural areas. The CROPS collaborate with UN agencies and foreign aid agencies on numerous regional programmes such as the Pandemic Preparedness Programme coordinated by the Secretariat of the Pacific Community (SPC) in conjunction with WHO. 


\subsubsection{Impact of international trade agreements on access to medicines in the Pacific}

Most PICs are signatory to several, often overlapping, multilateral, regional and bilateral agreements. ${ }^{37}$ These are listed in Appendix 3. The number and complexity of the various trade agreements and official deadlines set for negotiations places significant pressure on the governments whose ability to effectively respond is limited by factors such as a lack of financial and technical resources, human resources, expertise and analysis.

The proposed regional trade agreement between the EU and 14 PICs (EU EPA) is the most current, and relevant to access to medicines, not only because of the potential TRIPS-plus, and PCT membership, but because it can trigger PACER. If PACER is triggered, the PICs could be obliged to commence negotiating this trade agreement with Australia and New Zealand and to offer similar concessions made in an EU EPA.

The EU's primary interest is to liberalise trade and to introduce regulatory reform and TRIPS (Oxfam, 2006b). The proposed texts and responses from the EU suggest that the treatment of IPR under the EPAs is more likely to converge with the practice of the US, which has TRIPSplus provisions in FTAs. These include obligations with standards of protection beyond those required by the WTO TRIPS Agreement and compromise the use of TRIPS flexibilities in the Doha Declaration (CIEL, 2007) which are opposed by the international development community (Correa, 2007). If an agreement had been signed with all 14 PICs in 2007, the EU had earlier signaled IPR issues would be negotiated in $2008 .^{38}$

These terms of the EU would apply to all PICs signed up to the EPA, regardless of their existing WTO member status. Patent activity could be expected to increase significantly as a result, including pharmaceutical patents, which could impeded access to medicines through raising the price of patented drugs and block the importation of cheaper generic versions of that drug, even several years after the patent expired.

\footnotetext{
${ }^{37}$ For updates on the trade negotiation processes see www.bilaterals.org.

${ }^{38}$ For a description of the EU EPA trade negotiations with the PICs and other updates see, for example, the website of Oxfam New Zealand (2007)
} 
Under special circumstances, such as a national health emergency (where patents are restricting access to cheaper medicines) governments in developing countries have the ability to use Compulsory Licences (CL). A CL permits the government to import, or to manufacture, medicines that are patented in their country, without the patent owners consent. These medicines must be used to respond to public health crises and not sold for commercial gain. TRIPS-plus provisions can either limit the use of compulsory licences, or block generic manufacturing using data exclusivity and linkage evergreening provisions.

As this thesis was being written in early December 2007, Fiji and PNG, under pressure from the EU, had negotiated individual agreements rather than continuing to negotiate as a regional bloc. A full evaluation of the content of these individual agreements and the economic and political significance to the individual countries, and to the region as a whole, was not yet published in the public domain when this thesis was being written.

\subsection{Overview of intellectual property rights in the Pacific}

"It is the responsibility of all of us to raise TRIPS and access to medicines issues, not just leave it to one or two specialised health-related agencies"

Dr Stuart Watson, Pacific Regional Coordinator, UNAIDS, interviewed October 2007

A comprehensive explanation of the key treaties dealing with substantive patent law (which includes the Paris Convention and Patent Cooperation Treaty (PCT), and of WTO membership status, the main features of national intellectual property law, application in the Pacific of the Doha Declaration and the Paragraph 6 Decision and of traditional knowledge model law) is included in Appendix 4. Several of the key features of intellectual property rights and of these treaties are discussed here because they contribute to how Pacific islanders view trade and access to medicines.

Firstly, the PICs are net 'users', rather than 'generators', of intellectual property rights. Secondly, although there is a low membership of international IP treaties, most PICs have national patent laws which vary widely and are influenced by factors such as WTO 
membership activity, donor assistance and colonial-era regimes. Thirdly, PNG, Tonga, Fiji and the Solomon Islands have international obligations regarding substantive patent law under WIPO and WTO. By 1 January 2005, Fiji and PNG had to provide patent protection for pharmaceutical products. Being an LDC, the Solomon Islands do not have to comply until 2016 (and until 2013 to implement other elements), while Tonga, under its WTO accession package, has until 1 June 2008. Fourthly, in some countries, the Patent Office function is limited to re-registration of patents already granted in another nominated country, for example the United Kingdom, while in others, all patents are registered without scrutiny and their validity tested in court if they are ever appealed. Search and examination capacity is limited and the IP offices of Tonga, Fiji and PNG has an arrangement with IP Australia to provide patent searches and examination (Farquhar, 2005). Fifthly, the economic and cultural preferences for allocating limited resources to further developing the framework for traditional knowledge instead of to developing regional policies and strategies for IPR also appear to be relevant to this discussion.

PICs continue to face unauthorized use of their traditional knowledge (Mead, 2007) which, in the main, conventional IP law fails to protect. A model law on 'Traditional Biological Knowledge, Innovation and Practices' was drafted in 2000 by the South Pacific Regional Environment Programme (SPREP). This involved considerable national and regional discussion. It will be developed further in 2008 by the PIFS. However, resource constraints mean that any further IPR initiatives are suspended over that same period, in preference for resources being allocated to the development of a traditional knowledge framework. The Pacific Plan refers to a regional institution, such as the SPC, developing a regional framework for the Pacific cultural identity and for this framework to (ambitiously) force both IPR and traditional knowledge to concede to wider development objectives.

Finally, the patent activity is relatively low and the majority of applications are made by foreign applicants, many of these patents are in the pharmaceutical categories (Ey, 2005). This activity can be expected to rapidly increase if TRIPS obligations, or PCT membership, are introduced to more countries in the region. The literature research and field research interviews suggest this could happen as a result of four independent mechanisms: through 
regional trade agreements that require all countries, not just WTO members, to implement TRIPS and/or to join the PCT; when more countries accede to the WTO; if IPR functions were integrated and centralized through a regional patent office, making it easier for foreign applications to be registered in several countries at once; in the long term if a review of collective medicines regulation were to result in joining the Australian TGA (or proposed ANZTPA) that already incorporates TRIPS-plus patent obligations inherited under the AustUS FTA.

\subsubsection{Patent cooperation treaty}

The draft EU EPA being negotiated in 2007 signaled a requirement for all PICs to join the Patent Cooperation Treaty (PCT). At present only PNG is a member of PCT. After it joined in 2003, one information source indicated that PNG had received 940 designations and that it appeared to be routinely designated under the PCT by applicants (Drahos, 2007). If other PICs join the Treaty, the current low rate of patent registration in the region is expected to escalate dramatically (Ey, 2005).

There are currently only a few PCT offices worldwide capable of examining PCTs, prior to filing in individual countries. The financial investment required to establish these offices and the specialised knowledge required to examine the patents are prohibitive for developing, and some smaller developed, countries to consider establishing. For example, New Zealand uses IP Australia to file PCTs in this region. PICs are likely to have no option but to do the same, which would be a reasonable solution if they conceded to join PCT.

PCTs are usually examined using a more flexible set of criterion than in individual countries. When the patent holder decides to file in individual countries it is up to the national patent office in that country to re-examine the patent against its own (usually stricter) patent law to determine if it will be accepted. However, PICs would not have the capacity to examine each PCT case, and therefore may end up accepting products that other countries may reject, such as pharmaceuticals dumped on them with commercial rights to raise their price. 


\subsection{Overview of human rights mechanisms and challenges in the Pacific}

"You cannot look at human rights in the Pacific without looking at custom. There is a perceived conflict between human rights and custom - a cultural relativist approach. Advocacy around custom and advocacy around human rights has caused conflict and a better quality of advocacy around both is required. There is a need to walk through the issues on a case by case basis rather than parking human rights, or custom, to one side and trying to advance one without the other."

Ms Joy Liddicoat, Commissioner, NZ Human Rights Commission, interviewed November 2007

This section builds on the background information provided in Chapter 2 and discusses existing human rights mechanisms and obstacles to its application in the Pacific region.

\subsubsection{Institutions and mechanisms}

Regional networks between national human rights mechanisms are encouraged by the UN General Assembly and exist throughout the world, with the exception of the Asia-Pacific region. The possibility of including the Pacific in an Asia-Pacific regional human rights mechanism has been suggested, but it is recognised that the two areas are so diverse, presenting a major obstacle to achieving this. Other regional networks, such as Africa, America and Europe, share a greater degree of cultural and philosophical homogeneity (New Zealand Law Commission, 2006).

If there were a regional mechanism it may be preferable to limit it to the Pacific which constitutes a distinct region, or possibly start with sub-regional mechanisms covering countries that share particular cultural and historical affinities. This could take the form of including a human rights desk at the PIFS for example.

There has been progress in regional human rights dialogue and cooperation in recent years through: (i) annual workshops in the Asia Pacific Forum of National Institutions under the mandate of the UN Commission, and (ii) a process founded on national institutions and the 
benchmarks of the Paris Principles.

The Pacific region has the lowest ratification rates worldwide of the core international human rights treaties. There is however, a broad infrastructure for the promotion and protection of human rights in the Pacific amongst the existing institutions (PIFS/NZHRC, 2006), albeit some of these are in their early infancy. Human rights mechanisms vary widely amongst the PICs. ${ }^{39}$ They include national constitutions, parliamentary systems, governance structures and systems, legal systems (including the judiciary), an active civil society and regional mechanisms. The efficacy and efficiency of these systems are highly contested and Pacific leaders have acknowledged, in the Pacific Plan ${ }^{40}$, that more work is needed to fine these up. Initiatives for the first three years include steps to support regional consolidation of key institutions such as audit and ombudsman offices, custom, leadership codes and departments of attorney-generals that underpin good governance.

The Law Commission currently notes that Pacific people raise three broad concerns about human rights: limitations on progressing them as a result of competing and significant demands on limited resources, onerous international treaty body reporting obligations, and tensions at the interface between custom and human rights (New Zealand Law Commission, 2006).

\subsubsection{Concerns between custom and human rights}

"In the Pacific region there is some resentment about the concept of rights. Some of our leaders are fond of decrying them as western or alien concept at odds with our values. Human rights is universal in nature... Interestingly, it is not the downtrodden, the oppressed or the marginalized who make the criticism. It is those of us who are part of established power structures that query the applicability of these rights"

\footnotetext{
${ }^{39}$ For a thorough discussion of existing infrastructure and attitudes to HR refer to NZ Law Commission, 2006 and visit the UN website www.unchr.ch

${ }^{40}$ In 2004, the PIFS leaders adopted a vision for a 'region of peace, harmony, security and economic prosperity....respected for quality of governance, the sustainable management of resources, the full observance of democratic values, and for its defence and promotion of human rights".. The leaders agreed to give effect to the vision through the Pacific Plan, which was endorsed in 2005.
} 
Strong philosophical differences exist in the Pacific, particularly relating to the interface of custom and human rights (PIFS/NZHRC, 2006). For example, Pacific people view the good of the family as paramount rather than individuals; a fundamental difference that reinforces the concept of cultural relativism discussed earlier in Section 2.4.1. Furthermore, in contrast to human rights instruments, customary rights are not codified so they cannot be separated from the people enacting them. As a consequence, customary rights, and the many forms of traditional courts and accompanying traditional law, are changing as community opinions evolve in response to human rights and globalisation.

These differences are highlighted in a recent village banishment case in Samoa where, despite a High Court ruling, there remained a wide range of views about a proposed commission of inquiry to examine inconsistencies between the application of the Village Fono Act and the Constitution of Samoa (PIFS/NZHRC, 2006). This situation is acknowledged in the Pacific Plan where the PIFS has identified the need to consider how best to reconcile traditional systems with formal legal systems, including human rights law.

However, the quote by Ratu Joni Madraiwiwi (above) suggests human rights upsets a political economy associated with, and advantaged by, custom. The group of people who are 'part of the established power structures' are also the potential beneficiaries. Resistance to human rights can therefore originate from a range of sources, including the church, local police and provincial council workers, who feel their authority may be threatened.

Conflicts also exist, for example in relation to children's rights, where there is a general misconception that giving women and children rights might undermine patriarchal authority and the parent's respectively. Human rights education is needed to shift this perception to enable people to understand how human rights can be used to improve social, economic and cultural rights. A New Zealand Human Rights Commissioner observed, 'The thesis of the NZ Law Commission Report on custom and human rights in the PICs is that the values that

\footnotetext{
${ }^{41}$ Custom and HR workshop, Nadi, 1May 2006 in, NZ Law Commission (2006). Converging Currents. pp. 15
} 
underlie custom, and the values that underlie human rights, are shared. Human rights provide a vehicle for custom to be valued and vice versa.' ${ }^{42}$

The NZ Law Commission Report discusses the current approach and role of several state and non state actors and makes suggestions for the way forward. These range from noting that UN agencies active in the Pacific ${ }^{43}$ have the potential to support PICs to build on customary rights and human rights, while long term aid donors such as NZAID, AusAID and ADB, having a role in capacity building ${ }^{44}$. Furthermore, civil society organisations, for example NGOs, trade unions and churches, that provide welfare and other services and engage in advocacy on social, economic and political rights are acknowledged as having a significant role in making human rights culturally meaningful and in helping to enhance customary governance by harmonising it with human rights principles (Fairbairn-Dunlop, 2002) ${ }^{45}$.

Above all, it is acknowledged that Pacific people need to be in control of change in their societies and of shaping harmonisation of human rights and custom. The NZ Law Commission Report identified a common accord on fundamental Pacific values and an agreed approach to resolving the tension between custom and human rights would be a necessary step for achieving such consensus.

The information from this literature research on human rights, together with field research interviews provide an understanding of some of the challenges and opportunities for using human rights (and any future human rights and customs blend) more extensively than it is perhaps currently, to help protect access to medicines in Fiji and the Pacific region. Key findings and responses relating to human rights instruments are discussed in Section 5.2.5 and Appendix 5, respectively.

\footnotetext{
${ }^{42}$ Field research interview participant

${ }^{43}$ See United Nations Development Programme (2007) and UNCHR Pacific Regional Centre http://www.regionalcentrepacific.undp.org.fj, accessed 7/11/07

${ }^{44}$ For example, NZAID is to work with traditional leaders in Vanuatu in reforming the corrections system. Oxfam recently suggested the strengthening of customary dispute resolution systems in the Solomon Islands: Oxfam Australia and Oxfam NZ 'Bridging the gap between State and Society: New directions for the Solomon Islands (2006) 26. The reference UK DFID (2004) relates to a briefing paper that considers strategies for engagement with non-state justice systems (including customary systems)

45 Useful documents on civil society in the Pacific are available in the South Pacific Civil Society Library at http://www.vanuatu.usp.ac.fj, last accessed 5/11/07
} 


\subsection{Conclusion}

Pacific people are reliant on their national governments to provide health care services and medicines. A significant difference in the level of awareness of trade and access to medicines in the Pacific region compared with some other developing countries might be explained by relative differences in population size, level of industrialisation, range of primary healthcare services and content of international trade agreements and TRIPS provisions. However, other contextual issues that are specific to the Pacific region also appear to be shaping the findings in this research.

The Pacific region is comprised of several independent small island developing states, which face their own set of development obstacles as a result of diverse ethnicity, geographic remoteness, isolation, and poor competitive or comparative advantage. Furthermore, the region is under pressure to enter the global trading system as a regional trading bloc and to deepen trade liberalisation while making concessions in areas such as TRIPS provisions that subsequently affect the government's ability to deliver public goods, including access to medicines.

The concept of regionalism appears to have a significant influence on how Pacific people view trade and access to medicines. Firstly, this is because Pacific people have not historically identified with regionalism, which is by and large an externally imposed concept, raising major issues of national sovereignty and prompting the exploration of regional identity in the 'Pacific Way'.

Secondly, regional integration initiatives under the Pacific Plan and regional trade negotiations with the north are introducing a new layer of mechanisms that have an influential effect. Some examples of these include the strength of institutional linkages and policy coherence between regional agencies, for example PIFS and SPC, and between regional and national stakeholders, for example information sharing and domestic trade representation in regional negotiations. The capacity of the CROPS to deliver strategic policy advice as well as 
technical assistance to the PIFS and to individual PICs is a further factor while, interestingly, the juxtaposition of traditional knowledge and IPR, and how these two systems are perceived by Pacific people as instruments to protect access to public goods and to contribute to economic development are also significant. 


\section{Chapter 4: The National Context}

\subsection{Introduction}

Fiji is one of the larger and more developed PICs. Fiji's geographic location and comparatively better developed infrastructure provide a hub for local islands to develop their industry and exports. The main sources of foreign exchange, which include sugar, agriculture, mining, garments and tourism, are currently in general decline. The cessation of preferential trade agreements and the failure to capitalise on the export sector's temporary market strength (Robertson, 2006), ethnic tensions and political instability are some of the reasons for their collapse.

With sugar and garment production in decline, Fiji is now more reliant on tourism, an industry which is most vulnerable to political instability. This sector has been pushed into further decline by the 2006 coup, the latest in a series of four coups since colonial independence in 1970, with two coups taking place in 1987 and one in 2000.

With the gradual loss of preferential trade agreements, Fiji (and other PICs) is being pressured to sign reciprocal trade agreements with major trading partners in the north. Such agreements are modeled on the free market liberalisation of goods and services with far reaching provisions that restrict development policy space (Stiglitz, 2005). Changes to a country's intellectual property rights law that restrict the parallel importation of cheaper pharmaceuticals is an example of this. Thus, Fiji is facing the collapse of previous export earning industries, such as sugar and textiles, at the same time as being expected to deepen, and expand, its current liberalisation process. Further, these trade agreements are likely to contain provisions that impact on national sovereignty and the ability to achieve culturally appropriate, sustainable development.

Fiji's failure to sustain economic growth has been criticised by proponents of free trade who attribute this to aid dependence, public sector cronyism and corruption (Chand and Bowna, 2007; Hughes, 2003). In contrast, opponents of the hegemonic free trade model point out that 
trade agreements must be development-friendly (Oxfam, 2005; Oxfam, 2006b) and require 'good governance' to bring about the synchronised actions of deepening and diversification of economic activity and the construction of social and economic infrastructure to achieve sustainable development (Robertson, 2006).

This chapter provides a brief introduction to Fiji and examines the national process for trade policymaking and the capacity of public and civil society organisations to deliver trade and health advocacy. This is followed by a description of national medicines procurement process and of the main features of the national intellectual property law. Here I also describe how pharmaceutical patents are examined. The final section elaborates on the challenges and application of human rights instruments by government, UN agencies and NGOs. I conclude by reflecting on the key factors that shape Fijian people's views of trade and access to medicines and compare these with factors in the broader context of the Pacific region. Information in this chapter is drawn substantially from my field research interviews. It is noted that many of the processes described do not appear to be as concisely documented in primary literature sources.

\subsection{Overview of the Republic of Fiji Islands}

The Republic of Fiji Islands is located in the South Pacific and comprises 332 islands, approximately one third of which are inhabited. The two largest islands, Viti Levu and Vanua Levu, contain most of the population of 850,000 (2005) with around $20 \%$ residing in the capital, Suva (ADB, 2006). 


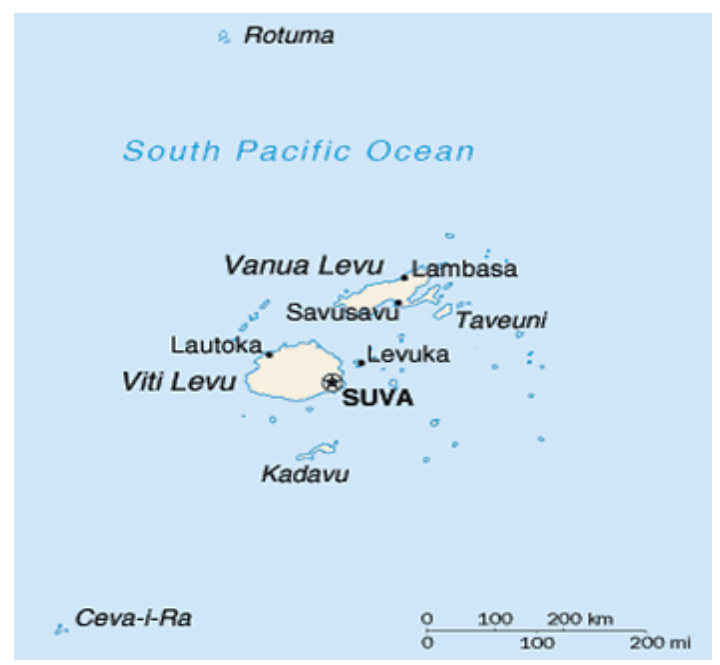

Figure 1: Map of Republic of Fiji Islands (source: NZ MFAT, 2006)

Fiji's population is composed of indigenous Fijians (54\%), Indo-Fijians (39\%) and other ethnicities (7\%). The estimated annual population growth rate per annum is $0.99 \%$ (19902005), the fertility rate is 3.3 children per woman, infant mortality is 18 per 1000 (2002) (UNDP, 2005) and more than 90\% of adults can read and write. In 2003 life expectancy at birth was 67.8 years. The World Bank classifies Fiji as a lower middle-income country and the estimated Gross Domestic Product per capita in 2004 was FJD3384 (\$1,952.40USD) (ADB, 2006). Estimates are around 25\% (1:4) of households live below the poverty line due to uneven distribution of income. An additional one third of all households are highly vulnerable to poverty as a result of the flatness of the income distribution. The incidence of poverty is equally as high amongst the Indo-Fijian population, although this tends to get overlooked. In the Human Development Index Fiji was ranked 92 out of 177 in 2003 (UNDP, 2005).

\section{Economy and international trade}

As noted, Fiji's economy is primarily based on sugar, agriculture, mining, garments and tourism. Tourism is Fiji's largest source of foreign exchange which, together with distribution, transport and communications, contributes to approximately 20 percent of GDP (NZ MFAT, 2006). Political instability has contributed to a decline in tourism in recent years. It is important also to emphasise that the garment industry and sugar exports have also 
declined after the gradual phasing out of preferential trade agreements. For example, the sugar industry thrived because of preferential trade with Europe under the Sugar Protocol (that guaranteed up to three times the then world prices for at most 70 per cent of its production), while the export-oriented textile industry grew under preferential export conditions in Australasia after 1980 and later in the United States and Europe (Robertson, 2006).

Fiji acceded to the GATT in 1993, becoming a member of the WTO in 1996. It accords at least Most Favoured Nation (MFN) tariff status to all its trading partners. In common with most PICs, Fiji is also signatory to several overlapping regional and bilateral agreements. These agreements, and the regional mechanisms for trade policymaking, are discussed in Section 3.3.

The proposed EU EPA currently has the most relevance to protecting access to essential medicines because it is likely to contain reciprocal trade arrangements, TRIPS provisions and obligations that restrict health development policy space. In early December 2007, under considerable pressure from the EU, Fiji and PNG, whose economies are most reliant on trade with the EU, broke away from the regional group of 14 PICs to sign individual agreements. An anaylsis of the content and of the economic and political implications of this tactic by the two countries had not yet been prepared as this thesis was being written.

\section{Political environment}

Since gaining independence from Britain in 1970, Fiji has experienced four coups as a result of many factors, some of which relate to the underlying ethnic tension, policy that favours indigenous Fijians and government corruption. Amongst other factors, the political and civil instability have contributed to the decline of the Fijian economy, placed limitations and conditions on the flow of development aid and constrained long term, cohesive planning and management in the public and private sector.

Following the first seventeen years of independence, in 1987, a coalition of the Fiji Labour Party and the National Federation Party came to power under Dr Timoci Bavandra. A month 
later, it was overthrown by the first of two military coups led by Lt. Col. Rabuka. Fiji was declared a republic following a second coup in October 1987. A new constitution was adopted in 1990 which favoured indigenous Fijian control of Fiji. Heavy Indian emigration, particularly of the middle to high income bracket, followed the coup. The 1997 Constitution contained a range of new provisions to encourage multi-ethnic government.

In May 2000, George Speight overthrew the Labour Party-led elected government of Prime Minister Mahendra Chaudhry, taking the Cabinet hostage and surrendering after a 56-day standoff. He was sentenced to death for treason (later commuted to a life sentence) in 2002. The military installed Laisenia Qarase to lead an interim government. Qarase was elected Prime Minister in 2001. The constitution requires any party receiving more than $10 \%$ of seats be offered Cabinet posts, but Qarase refused to do this. During his term, Qarase ruled in coalition with the Conservative Alliance. Their actions appeared to support the attempted coup in 2000. The two parties merged just before the 2006 elections.

In September 2005, Qarase appointed Ratu Naiqama Lalabalavu, his former Lands Minister convicted for involvement in the May 2000 coup, to head the transport and shipping portfolio. A central plank of Qarase's Party campaign was the Reconciliation, Tolerance and Unity Bill which would pardon supporters of the 2000 coup, including Speight, and erase the criminal records of those convicted. This was strongly rejected by opposition parties, including human rights groups and the military. The strong public reaction pushed Qarase to amend the amnesty provision of the Bill and delayed parliamentary debate until 2006.

The ruling SDL Party won the election in May 2006, enabling the incumbent Prime Minister, Qarase, to remain. Chaudry, who heads the Labour Party, decided to remain outside government. Citing corruption in the government, Commodore Josaia Voreqe (Frank) Bainimarama, Commander of the Republic of Fiji Military Forces, staged a military take over on December 5, 2006, placing senior military officials in Government agencies and systematically taking in people for interrogation who spoke out against his take over.

Following the 2006 coup, the Commonwealth of Nations suspended Fiji's membership and 
several major foreign countries withdrew aid; this included the postponement of EU development aid for restructuring the declining sugar industry. Political instability remains a major contributing factor in the decline of the economy, and in turn to a decline in government revenue used for expenditure on public goods, such as healthcare.

\subsection{Trade policymaking, medicines procurement, IPR and human rights in Fiji}

\subsubsection{Trade policymaking in Fiji}

"There is no point in discussing health related trade issues unless the importance of this is conveyed to the trade sector and to Forum Leaders. Any safeguards in national strategies and policies may be undermined by trade negotiators signing an agreement under political pressure."

Comment by a senior health official in Fiji, interviewed October 2007

Trade policymaking in Fiji, and the PICs in general, needs to be understood within the context of the introduction of the neoliberal agenda by external advisors in the late 1980's. In the absence of an alternative economic paradigm, it set the direction and pace of trade policy and economic reform and its core values (based on open access and global integration) introduced the concept of economic regionalism which is intrinsic to all of the major trade agreements Fiji is engaged with today (Slatter, 2006).

Slatter considered this neoliberal thinking was conveyed to Pacific Island Leaders through the South Pacific Forum (Slatter, 2006), which subsequently became the Pacific Island Forum Secretariat (PIFS). Established in 1991 to investigate free trade among the Forum Island Countries, since 1997 it has become pivotal in coordinating negotiations under PICTA, PACER, and Cotonou, and recently set up an EU funded WTO Office in Geneva (Kelsey, 2005). The Forum Economic Minister's meetings encourage input from World Bank, IMF and ADB representatives. Traditionally the PIFS has had an exclusive economic focus. This has changed recently to include a human development mandate with the support of a number 
of UN agencies and CROPS, including SPC. This change is relevant to this research because government policy on social spending, access to medicines and the right to health are essentially socioeconomic and cultural issues that would be expected to be promoted within this neoliberal agenda. There is a tension between human rights and health within the dominant neoliberal, global economic order. This is covered in Section 2.4.3.

The Ministry of Foreign Affairs and External Trade is the key agency involved in trade policymaking. Fiji's national trade policymaking mechanism is institutionally and legally linked with trade policymaking at the regional level at the Forum Secretariat. A description of trade policymaking at a regional level is included in Section 3.3.1. This situation introduces sovereignty and inter-agency management issues that impact on the Fijian Government's capacity for trade policymaking.

At a domestic level, the process of trade policymaking faces internal challenges. These relate to issues of connectivity. Views are that trade policy needs to be better linked with industrial policy to ensure investment is more broadly articulated throughout the economy (Robertson, 2006), improved public sector governance, better coordination of expenditure on social services, and pressure by CSOs to implement formal mechanisms for trade dialogue and deeper analysis of various trade options (Oxfam, 2006a).

\subsubsection{The capacity for trade and health advocacy in Fiji}

“We espouse the Pacific way as being 'consultative' but we do not acknowledge our Pacific values include revenge. It is up to leaders of the various organisations to create a culture of 'collaboration', and for NGOs to fulfill the role of advocating for improving the interface between different sectors and structures (to improve our trade policymaking)."

Ms Tupoe Vere, Director, Pacific Concerns Research Centre (PCRC), interviewed October 2007 


\section{Background}

In response to the global trade agenda and development of transnational coalitions, civil society organisations (CSOs) are challenging governments to have more active involvement in trade policymaking and dialogue. These challenges are placing significant demands on governments, particularly with its uneasy mix of traditional economic and social issues (Ostry, 2002). This trend is accompanied by the emergence of new, and stronger, civil society actors, supported by international NGOs, to play significant roles, especially in consultation mechanisms for trade negotiations and in building capacity amongst domestic CSOs to pressure governments for increased consultation and transparency (Stairs, 2000). For example, Oxfam New Zealand provides trade advocacy assistance to the Pacific Network on Globalisation (PANG), a regional NGO based in Suva.

This trend is seen in Fiji where CSOs are demanding greater involvement in the EU EPA trade dialogue, where the asymmetry in bargaining power is illustrated by the PICs combined GDP being 1,400 times smaller than the 25 EU countries (Oxfam, 2006b).

The most descriptive documented account of the trade negotiations and civil society consultation under PICTA and EPA has been written by Kelsey (see Kelsey, 2004; Kelsey, 2005). Kelsey's description of 'obstruction' to involvement by civil society was reinforced by a Trade Workshop facilitated by Oxfam New Zealand in June 2006 which attracted representatives from around 60 CSOs. The Press Release for this meeting stated, "The lack of meaningful consultation and transparency on the EPA is a concern. It seems that it is only government trade officials and their counterparts in the Pacific Island Forum Secretariat who have knowledge on the EPA and what it offers. The regional CSO group is fearful that the EPA trade negotiations are being carried out purely on the basis of theoretical economic analysis" (Oxfam 2006c).

In Fiji the various groups representing civil society are mostly based in Suva, with outreach programmes to the rural regions. Many of the CSOs requesting to be involved in trade dialogue are already involved in social and environmental policy issues and some are 
receiving assistance by external agencies, such as the Asia Development Bank (ADB, 2006) to develop capacity to engage in development. This phenomenon illustrates how civil society has traditionally been associated with activism around development issues rather then trade. Furthermore, as these CSOs develop capacity for engaging in social and environmental issues there is the likelihood that these skills can be transferred to trade related issues, the primary constraint being limited resources and finance.

In 2005, the PIFS introduced two formal mechanisms to engage with CSOs. This was a highly significant step. The first is through a collective communiqué prepared by regional CSOs at a meeting held prior to the annual meeting of the Pacific Forum Leaders. The second is an official PIFS accreditation system that enables accredited CSOs to attend Working Party and CROP meetings as observers. PCRC is the only accredited CSO at this stage, with four others due to apply in 2008. Although the process has been slow, the mechanism offers considerable potential to elevate CSO input into trade policymaking in the future.

\section{Current situation}

With the exception of the World Council of Churches and PANG, it was found that few CSOs provide advocacy on trade in Fiji. This low number is not a reflection of how they rank trade compared with other issues. Often it is because trade is considered too complex (and IPR even more so) by CSOs who are challenged by resource constraints and more immediate local advocacy issues; an observation reinforced by the Director of PCRC:

"I attended a national workshop on trade and IPR. One reason why I think there has been a lack of focus on IPR by NGOs is it's overly complicated. That is also the reason why few NGOs tackle trade advocacy. I can remember thinking 'how do I surface through this beast?' I think that is the reason why there were no further discussions on it amongst NGOs. As a consequence, the focus has shifted to developing traditional knowledge (frameworks) amongst NGOs and not on IPR....also traditional knowledge comes onto the community's agenda more directly and NGO's need to respond to that." 
In contrast, there are several NGO's and UN agencies providing health advocacy, for example FSPI, ECREA, UNAIDS and UNFPA. However, apart from some specialised areas of health, for example tobacco and alcohol, the type of advocacy excludes trade-related factors that impact on medicines; which might be a missed opportunity. A description of national and regional NGOs involved in human rights advocacy is included under Section 4.5.

While it is the role of health-related UN agencies, in particular, WHO, UNICEF, UNDP, UNDP Pacific Regional Office and UNAIDS, to provide leadership and assistance on WTO and public health issues, these agencies face considerable political pressure, that arise from advocating for universal health rights, without being seen to interfere with national sovereignty in multilateral and regional trade agreements.

A sector based approach to formulating health and trade advocacy and policymaking presents a further challenge to the work of these advocacy agents. The need for bridging different sectors is acknowledged by the Director of PCRC:

"Most of the agencies are very sectoral. There is a need for bridging across sectors on some of these issues. For example, the Forum Secretariat plays a lead technical advisory role on trade negotiations, SPC and WHO provide technical advice on health; they need greater 'bridging' between them. This isn't only limited to government and intergovernmental agencies it is also reflected in our own regional NGO structures and roles. The structures and mechanisms the government have put in place for NGOs to engage with them, including the way the Pacific Plan is structured, often reflects this sectoral approach and so the NGOs structure themselves around this too."

Ms Tupoe Vere, Director, Pacific Concerns Research Centre (PCRC), interviewed October 2007

These factors of: political tensions for UN agencies, low capacity of CSOs and sector based approaches to trade policymaking are a disadvantage to raising awareness on access to medicines. 


\subsubsection{National medicines procurement in Fiji}

"A critical issue in the Pacific is the absence of a (Western) culture of healthcare. People go to their pastor or traditional healer and leave it until their health has significantly declined before seeking hospital or medicinal care. By then, the immune system has already been severely compromised."

Dr Stuart Watson, Pacific Regional Coordinator, UNAIDS, interviewed October 2007

Fiji's Essential Medicines List, was adapted from the WHO EML and currently lists around 430 drugs. These are available free from government health centres and hospitals but do not include medicines (or infrastructure) for most non communicable diseases, such as statins, chemotherapy and dialysis. Drug stock-outs in hospitals and medical centres are not uncommon (Bailey, 2004). When this occurs people are expected to pay full price for drugs at a private pharmacy.

There are no foreign multinational or local manufacturing companies in the Pacific region. This situation creates a dependency on foreign countries for all medicines which are imported directly from wholesalers or manufacturers by the public and private sectors. The Fiji Pharmaceutical Services (FPS) funds, procures, stores, registers, and distributes all government drugs; relying on re-registration from the source to regulate drug quality. Occasionally drugs are sent to the Australian Therapeutic Goods Agency (Aust TGA) for quality testing and regulation, but this is expensive.

Fiji's middle income development status and efficient pharmaceutical procurement agency means that Fiji does not qualify for as much financial aid for health as some other PICs. Global schemes such as UNICEF, UNFPA, GAVI and the Global Fund, provide financial loans or full to partial financing of medicines for treating most communicable diseases, and provide varying levels of assistance for their procurement and distribution.

Fiji Pharmaceutical Services operates within a fixed budget which has increased marginally over the last four years to partially accommodate formal requests for additional medicines. 
Requests for budget increases to allow for increased patient numbers or additional medicines are submitted to the Ministry of Health by the National Drug and Therapy Committee, which is comprised of clinicians, pharmacists, and community representatives. These requests are often declined, or meet with mixed success because of the Governments' limited public health budget.

Here I use the metaphor of a 'generics bubble' to describe the current public medicines procurement scheme. In this case, trade related impediments acting on newer medicines technology would exist outside the bubble, with the focus of the generics only procurement policy being within the bubble. As a consequence Fiji's limited health resources appear to be directed to internal determinants and improving things they believe they can control, such as efficient forecasting and distribution, rather than on protecting WTO safeguards and IPR law. For example, the Fijian government does not currently have to use parallel importation because of the generics only policy.

Interview participants were asked, from a public health perspective, what would puncture the 'generics bubble'? Their responses included: (i) local clinicians and civil society lobbying the Government for a 'wishlist' of medicines not currently procured, for example, patented medicines such as statins which are designed to lower the risk of vascular events, new diabetic treatments, chemotherapy and dialysis, (ii) the Fiji Pharmaceutical Services goal is to achieve the health-related MDGs by 2011. Reaching this point, or the international deadline in 2015, could trigger pressure for greater access to patented medicines if the health goals haven't been met, (iii) increased resistance to first generation medicines so that second generation patented versions are needed, (iv) increased demand for second generation antiretroviral drugs for the treatment of HIV/AIDS in the Pacific region, (v) an external factor, such as a pandemic, and (vi) withdrawal of global aid funding for medicines, placing greater financial burden on local governments.

\section{Availability, affordability and efficacy of medicines}

Despite being better off economically than some PICs, availability of medicines in Fiji is a 
problem because of drug 'stock-outs':

"Frequently, there are media reports about lack of medicines in the public sector (in Fiji)... Although an Essential Drug List (EDL) is in place, no absolute commitment has been given by the Ministry of Health on guaranteed availability of those medicines to the public. Anecdotal reports from health service staff indicate that the medicines supply situation in hospitals and in health centres is worsening. The problem has reached such a low point (in 2004), that a committee of enquiry into medicine supply has been established by the government."

Dr M Bailey, Assoc. Prof. Pharmacy, Fiji School of Medicines, Sept 2004. ${ }^{46}$

One local clinician commented, 'A local saying in hospitals is the 'O.O.S- Syndrome', which means 'Out-Of-Stock Syndrome'. This can cause rapid deterioration of a patients health if, for example, a staphylococcus infection is left untreated for 24 hours'. Rather than a trade-related or affordability issue, the problem was considered to be the responsibility of Fiji Pharmaceutical Services to fix factors such as consumption, prescribing, quantification, and ordering and wastage. To address the stock out problem, the National Drugs and Therapy Committee devised the 'Vital Medicines List', a subset of the Fiji EML. This lists drugs that should never, ever have stock outs.

In turn, stock-outs create an access issue because of a lack of affordability:

"You see lines of settlement people queuing at outpatients for medications and they will be told the hospital has run out, go to the pharmacy. But these cost money at the pharmacy, so people go without. Who is accountable for the fact the drugs are not there for people? Whose role is it to audit and to advocate?"

Mr Semeti Qulowasa, Field Coordinator, Economic Justice, ECREA, interviewed October 2007

An analysis of the price of drugs in the Pacific region is beyond the scope of this thesis. However, further research to determine the extent that price and affordability prevent access,

\footnotetext{
${ }^{46}$ See reference Bailey (2004).
} 
and for which drug groups, would be valuable. Although the results may not be extrapolated to other PICs, a study undertaken in 2004 by the Fiji School of Medicine (Bailey, 2004) suggests that both the public and private sector procurement of drugs in Fiji compared very favourably with international comparator prices and that this was affordable to the waged population. However the results stopped short of predicting what this would be for the unwaged.

Given that around 25\% of Fijian households living below the poverty line due to uneven distribution of income, and an additional one third of all households being highly vulnerable to poverty as a result of the flatness of the income distribution (ADB, 2006); clearly for a large percentage of the population even essential drugs would be unaffordable during medicine stock-outs. This situation, where medicines are sometimes only available to those who can afford them begins to establish a two-tier health system which in turn reinforces social inequality (Marmot and Wilkinson, 1999).

Price regulation of pharmaceutical products is a tool that has been used by many developed countries to control the price of essential medicines and is a tool used in Fiji. Out of 135 countries covered in the World Drug Survey in 1999, over $40 \%$ had no measures in place to regulate medicine prices, whereas almost $80 \%$ of high-income countries and $50 \%$ of middleincome countries practiced some kind of price regulation (WHO, 2004). The Fijian Government controls drug prices through the Fiji Prices and Income Board which sets, and effectively limits, percentage mark-ups at wholesale and retail level.

As a result Fijian citizens are probably better off for the range of free drugs they have access to compared with some other PICs. At the same time, there was early evidence of individuals and CSOs starting to question the efficacy of some drugs to produce intended results. This is illustrated by the Field Coordinator of ECREA working with Fijian settlement people:

"The quality of the drugs people access are sometimes under-par, but people who can afford them, get better drugs through the private sector; reinforcing social inequality. For example, I was helping a man in the settlements, he was inhaling on the asthmatic drugs given to him by the hospital and he was still wheezing. I went to the pharmacy 
and bought a $\$ 7$ inhaler. He puffed on it and immediately improved. I took the hospital one back and they told me that's what they issue. It cost $\$ 1.90$. It makes me start to think the qualities of the drugs that are free are inferior to those in the private system. So although you can say we have access, the quality may not help people's health improve. This man could not afford to pay for the pharmacy version."

Mr Semeti Qulowasa, Field Coordinator, Economic Justice, ECREA, interviewed October 2007

The quality and efficacy of the medicines that are provided could raise a further access issue for many Fijian people if they are unable to afford more efficacious medicines. The efficacy of publicly procured medicines would warrant further research and must be on the agenda of the WHO and the National Drugs and Therapy Committee, or a regional organisation such as SPC. Linking the efficacy of medicines into the access to medicines and trade discussions at some point would be valuable, especially if new patented technology offered significant improvements in treating some diseases than current generic versions on the Fijian EML.

The private provision of health services and medicines for those who can afford them, or have health insurance, is known to reinforce social inequality in health (Marmot and Wilkinson, 1999). A two-tier health system may be further reinforced by physicians who advise their clients who can afford it, to go to private suppliers to purchase better versions of the medicines supplied free by the Government, for example broader spectrum penicillin. A review of the impact of privatisation of health services on access to medicines and on health development in developing countries warrants further research.

\subsection{National intellectual property law in Fiji}

Fiji is working towards WTO TRIPS compliance. Fiji's current national IPR law contains some inconsistencies between the Act and the TRIPS Agreement with regard to substantive requirements. At the same time, the Act does not provide for the flexibilities and safeguards allowed by the WTO TRIPS Agreement, notably the exception to exclusive rights (such as parallel importation and the 'Bolar' exception) and compulsory licenses (Correa, 2003). This was discovered when the WHO funded a review of the national IPR law in 2003. The 
researcher, Dr Carlos Correa, recommended these were removed as soon as possible (Correa, 2003). A draft IPR Bill is pending completion in the Attorney Generals' Office where its slow progress appears to have come to a halt since the 2006 coup.

A full description of the process of pharmaceutical patent examination and registration and whether there is any current evidence of trade related impediments impacting on Fiji's public medicines procurement scheme is covered in detail under Section 5.2.1. Of particular interest here is that some PICs use IP Australia to examine some pharmaceutical patents which could mean they use examination criterion that is appropriate for Australia, and this is unlikely to reflect the development needs of poorer countries, such as the PICs.

The sequence of events describing the lead up to the IPR law review, and ongoing initiatives to establish formal and informal stakeholder meetings after this event, is relevant to this research because this core group of individuals and organisations are showing interest in access to medicines and have realized the significance of trade and IPR law on future access; although no ongoing agreement to continue meeting is yet in place.

In1999 the Chief Pharmacist of the Ministry of Health first noticed a pharmaceutical patent for Olanzapine had been registered, and this stimulated his own research into WHO policies, WTO and TRIPS. This coincided with a paradigm shift at the WHO when the international pharmaceutical company, Cipla, publicly shared drug pricing information for HIV/AIDS for the first time. At that point the WHO shifted its policy on access to essential medicines from the 'majority', to 'priority', diseases to receive essential medicines. In 1999/2000 Fiji started to develop an HIV/AIDS policy which, amongst others tasks, included a review of the national IPR law. In 2003, WHO brought in the legal consultant, Dr Correa, through its South to South collaboration who suggested re-drafting current patent law. The IPR review process brought together pharmacists, lawyers and different Ministries, for example, agriculture, finance, foreign affairs and external trade, for discussions.

In June 2006, Third World Network (based in Asia) in collaboration with WHO WPRO organised a workshop in the Pacific on TRIPS and public health. This was attended by over 
40 legal and health officials from seven countries and representatives from the UNDP, Commonwealth Secretariat, MSF, and the PIFS.

Shortly afterwards, FPS proposed a national follow-on workshop, with funding (hosting) from WHO, to which officials from the Ministry of Justice, Commerce, Prime Minster's Office, Ministry of Health, PIFS, civil society, patent office, and regional directors of the clinicians were all invited. The meetings were not attended by the private sector for example, the association representing private pharmacists, which was later acknowledged as an oversight.

A third meeting, organised and facilitated by the Forum Secretariat, invited stakeholders to an informal discussion to get their views about IPR (amongst other issues) and to identify common issues of concern. Not all stakeholders were invited to this general session however. Currently there are no formal mechanisms in place to continue meeting over these issues on a regular basis. However, the FPS Chief Pharmacist is keen to ensure an IPR meeting of all stakeholders is held every two years; the next being 2008.

\subsection{Application of human rights instruments in Fiji}

Fiji's national constitution includes the Fijian Bill of Rights whose overall emphasis is on civil and political rights, rather than socioeconomic and cultural rights. Like most Asia Pacific countries, Fiji has not yet ratified ICESCR, but has signed up to CEDAW and CRC. ${ }^{47}$ The Fiji Human Rights Commission, established in 1997, temporarily had its accreditation revoked by the UN Human Rights Commission in early 2007 following political disputes over the coup.

The application of human rights instruments vary widely among the Fijian state and non state agencies and generally emphasise civil rights, for example non discrimination of community testing and education of people with a disease, rather than socioeconomic and cultural rights. Such an emphasis on civil rights is likely to reflect local cultural and political values and historical colonial ties (This is discussed in more detail under Sections 2.4 and 3.5).

\footnotetext{
47 'CEDAW' is the Convention on Elimination of Discrimination Against Women; 'CRC' is the Convention on the Rights of the Child
} 
At the present time, there was no evidence in my research that any agencies are applying human rights to specifically advocate for access to medicines. Where human rights are linked to health, for example with UNDP, UNAIDS and RRRT programmes and policies, the emphasis is predominantly on civil rights. Two examples of this include the regional strategies and policy documents prepared by the UN agencies UNAIDS and WHO. The Regional HIV/AIDS Strategy, which has been signed off by all 14 PICs, and the Regional policy document relating to the preventative management of non communicable diseases developed by WHO, in conjunction with other stakeholders, not yet fully signed off, are prominent regional frameworks for coordinating public health programmes however both strategies do not include the right to access medicines. Several of the UN agency participants that I interviewed raised these two strategies as examples of a missed opportunity to include access to medicines, mainly because they had been unaware of the need.

There also appears to be a lack of awareness of the need for trade and access to medicines advocacy amongst CSOs. The Training Coordinator from the Pacific Regional Rights Resource Team (RRRT) specifically commented on this:

"Our use of human rights and rights-based approach do not currently specifically address access to medicines however this is something that the community paralegals could address at the community level. Our health advocacy mainly relates to civil rights and non-discrimination. For example, a senior official in the Ministry of Health once described the victim of a sexual assault who contacted HIV. This creates problems in a small community as it enabled people in her community to identify who she was. This breech of confidentiality and privacy could lead to social stigmatisation. Our partner organisations in Fiji highlighted this concern. We could extend into this area however if the need was identified. RRRT could also work at the meso and macro level with the Ministers of Trade on building capacity on how they could use international human rights law to decline TRIPS-plus in trade agreements by falling back on the fact they have signed these international Human Rights Conventions." 
The Pacific Regional Rights Resource Team (RRRT) is a project of the UNDP Pacific Centre and specialises in providing training, advocacy, technical support and policy advice on human rights to the Pacific Island states and non government organisation partners. ${ }^{48}$ RRRT receives primary funding from the New Zealand Aid and International Development Agency. It works simultaneously at the community level, where they educate and support rights-holders to claim their rights, and at the government level, where they strengthen the accountability of dutybearers towards their human rights obligations. They also target the meso-level (senior civil servants, access to justice agencies, legal profession and law graduates) through training and technical advice. They also publish a Pacific Human Rights Law case digest. ${ }^{49}$ RRRT Training Coordinator emphasised this approach was a deliberate strategy on their part in order to get the human rights message across:

"Sometimes the human rights language is perceived as confrontational or in conflict with the way things are being done. So we try to promote awareness through the macrolevel, and filter it downwards, and through the grass roots and meso-level, and push it upwards".

Ms Gina Houng Lee, Training Coordinator, RRRT, interviewed October 2007

In contrast to RRRT, the human rights approaches and strategies of the national NGO, ECREA, focuses on empowering people who live in the settlements to advance social change. In this instance human rights are not fully integrated into their work processes but they are applied to increase the political status of a message once a community's needs have been evaluated. Using a human rights platform to successfully facilitate dialogue between government and squatter settlements is an illustration of this. This also reflects how NGOs have adapted human rights tools to deal with resistance by communities they work with, as expressed by the Field Coordinator at ECREA:

"We have a culture of silence in this country - people don't question leaders or leadership but just accept their word. They look to the chief system and faith system for

\footnotetext{
${ }^{48}$ RRRT website available at http://www.rrt.org accessed 5/10/07

${ }^{49}$ RRRT website available at http://www.rrrt.org accessed 5/10/07
} 
answers. We need to empower people to question how good that leadership is for improving the people and how involved that leader gets in trying to bring this about. Although they are suspicious of them, human rights is one, useful tool to help bring this about".

Mr Semeti Qulowasa, Field Coordinator, Economic Justice, ECREA, interviewed October 2007

The significance of the role of NGOs is further reinforced by the views of the New Zealand Law Commission:

"We believe that CSOs have a significant role to play in making human rights culturally meaningful for Pacific communities and in helping to enhance customary governance by harmonizing it with human rights principles."

NZ Law Commission, 2006. pp.234

In response to the question, "Could human rights, which have successfully been used to galvanize the HIV/AIDS campaign, be extended to protect other drugs such as diabetes treatments?" An expert in public health development in the Pacific, who is also a Pacific Islander, responded:

"No, I explored the possibility some years ago. It's been associated with HIV and the nature of HIV is the pandemic. Chronic non communicable diseases are associated with other forms of prevention such as trade in food stuffs, tobacco, alcohol, drugs and fatty foods. Besides which, Pacific Islanders are suspicious of human rights. They see it as a means for the West to promote things like, an end to violence against women, and do not associate it with helping them to access better health" 50

In contrast, another Pacific person who is a senior academic specialising in social and economic development in PICs observed:

\footnotetext{
${ }^{50}$ Field research interview participant
} 
"As a rights language, the right to health (through the right to medicine) would have more acceptance, than, say civil rights, because it is less confrontational to customary rights and to traditional forms of decision making. Traditional decision making is normally the domain of men in the Pacific. The new generation of human rights strategies, such as the right to education, the right to health, and the right to housing, is therefore less likely to upset a power balance, and consequently has significant potential to bring about improvements in health". 51

These two responses illustrate the diverse perspectives about human rights and health held by different stakeholders. In this case, the responses further reinforce how contentious and challenging the application of human rights can be, even if it is blended with local custom in the Pacific region. These views are possibly commonly held by other people in the global context and are not just unique to Pacific people, particularly as the human right to access medicines and to health is an emerging right.

\subsection{Conclusion}

Several interrelated factors associated with trade, health and the local culture, and to much less of an extent, human rights, appear to shape how Fijian people view trade and access to medicines. Most factors are not entirely unique to Fiji and are generally applicable to other PICs to varying levels depending on, amongst other factors, their WTO status. The views of some domestic and foreign workers employed in international development organisations, such as the UN agencies, also appear to be shaped by some of the same factors even when they have strong international affiliations and an established profile in access to medicines campaigning in other developing countries, for example the WHO and UNDP assisting the Thai Government to undertake a human rights impact assessment of the proposed Thai-US FTA.

In the trade sector these factors are directly related to the expansion and deepening of trade liberalisation and regionalism. For example, the national trade policymaking mechanism in

\footnotetext{
${ }^{51}$ Comment made in general discussion with the researcher in November 2007
} 
Fiji is institutionally connected with the regional trade policymaking mechanism at the Forum Secretariat. The strength and alignment of these linkages and who they receive assistance from has a bearing on domestic perspectives on trade and access to medicines. This is compounded by a sector by sector approach towards trade and health policymaking, instead of a multi sector approach, that compromises coherency.

In the health sector, the concept I have referred to as the 'generics bubble' appears to direct key stakeholders to focus exclusively on internal determinants of access to medicines, rather than including the external environment to protect WTO safeguards and to push for stronger institutional linkages between the health and trade sector.

The conflict between human rights and local custom presents a major challenge to how useful local people might view human rights as a tool to help protect the right to access to medicines. These challenges also appear to contribute to the low capacity for human rights advocacy amongst national and regional CSOs. The current emphasis on political and civil rights is likely to be less relevant to the aim of protecting the right to access to medicines than socioeconomic and cultural rights. In the Pacific setting therefore, a shift in philosophical thinking from civil rights to socioeconomic and cultural rights might be required before existing, or new, human rights mechanisms can accommodate the right to access medicines in their strategies and programmes. Moreover, a cultural preference for traditional herbal medicines rather than a health culture based on western medicines appears to reduce awareness of medicines availability and affordability at both the grass roots and amongst some government officials.

Finally, some of these factors may not be unique to Fiji and the Pacific region. Hypothetically, other regions comprised of SIDS, such as the Caribbean, may share some of the same factors, for example issues associated with regionalism, cultural preferences, and health trends, and therefore share similar views on trade and access to medicines. This would be interesting further research, particularly if the findings suggested that different regions comprised of SIDS would benefit from information sharing on trade and access to medicines and the development of creative solutions, such as collective compulsory licensing. 


\section{Chapter 5: Findings and Conclusion}

\subsection{Introduction}

Key findings are presented in this chapter under each of the five primary research objectives (the objectives were earlier listed in Section 1.3). I conclude this chapter by reflecting on how this research informs human rights theory and contributes knowledge to the wider academic audience. As noted, limitations to the research methodology include: assuming a representative sample of stakeholder organisations, accurate recording of participant's views and realities, and the potential over-reliance on qualitative data. I have attempted to minimise these factors by cross referencing interviewees, structuring interviews to allow for information exchange at the end of interview questions and acknowledging that quantitative data would have helped to underpin my findings rather than changing them substantively.

Finally, the findings from this chapter, together with suggestions made by interview participants and personal observations, were used to compile a range of multidisciplinary responses to help mitigate trade restrictions on access to medicines at the national and regional level. These suggested responses are summarised in Appendix 5. The need for regional cooperation on health, IPR and trade has been acknowledged by the PIFS and is implicit in the Pacific Plan. The suggested responses also assist with the mainstreaming of health into trade policy to enable any adverse effects on the health sector to be considered in trade negotiations and regional institutional design.

\subsection{Key research findings}

\subsubsection{Do trade-related restrictions exist currently, or in future, proposed trade agreements?}

The findings in this section relate to research objective one which is "to assess any reported restrictions on access to essential medicines in Fiji introduced by trade-related factors and the 
potential impact of future, proposed trade agreements".

Four main findings that relate to Fiji emerged from this research objective. Firstly, with the exception of one patented product, an antipsychotic drug called 'Olanzapine', there was no evidence of TRIPS provisions, or of pharmaceutical patent rights, posing a major obstacle to the public procurement of medicines by the Fijian government. The Ministry of Health's policy of only purchasing generic drugs is the primary reason for this finding. These drugs are from the Fijian Essential Medicines List, which generally lists older, generic medicines adapted from the WHO EML. This generics only policy might be a major factor contributing to the comparatively low profile of trade and access to medicines in Fiji and the Pacific region compared with some other developing countries; which is the main finding under objective two.

Olanzapine is one of over one hundred and twenty pharmaceutical patents that are currently registered with the Fijian Patent Office, double the number recorded in 2003. Which drugs and companies these are for is not a simple exercise to determine because patents are not electronically available and require specialized skills to interpret, that are not readily available in the PICs. Identifying these would warrant further investigation as it would enable the Fijian government to consider alternative options to ensure affordability or to anticipate increases in the pharmaceutical budget.

The second main finding relates to the current practice of out-sourcing the examination of some pharmaceutical patents to a developed country, such as Australia, because of the limited search and examination capacity. Currently Fiji either re-registers pharmaceutical patents from the United Kingdom or has them examined by IP Australia, at the patent holder's expense.

As discussed in Chapter 2, IPR standards used to be set by developing countries to meet their development needs (Wade, 2005; Chang, 2005). With globalisation, IPR systems are becoming more homogenous and countries are no longer able to set their own levels. This could mean that IP Australia examines a medicine patent using criterion that is appropriate for their own country, but is unlikely to reflect the development needs of poorer PICs (Correa, 
2007; Drahos, 2007), such as Fiji and other PICs. The granting of pharmaceutical patents by patent offices for essentially what appear to be trivial steps in the innovation process is a real concern and one that may be valid in this situation. This means Fiji has no discretion over whether these criterion are set at a level to suit their own development needs unless it establishes a monitoring mechanism and raises a pre-grant challenge. This may result in a higher acceptance rate of applications, setting a legal precedent that may be inappropriate for the country's development agenda.

Furthermore, the Australian examination is likely to have incorporated stronger, TRIPS-plus, provisions, such as the interpretation of the requirement of an 'inventive step'. These provisions were introduced to Australia in the free trade agreement with the United States; which is a further reason to monitor new registrations in Fiji.

A three month pre-approval period enables patents to be challenged in Fiji, however there is no formal, external monitoring of patent examinations at present, so none are being challenged. Here, the Brazilian model of patent monitoring is a good example of a preventative measure. The model uses a panel of experts to review patent registrations, applying a framework that links patentability criteria for drugs to the goal of welfareenhancing innovation in the health sector. The process also avoids the high costs of attempting to remove patents after they are granted. Another mechanism, the 'transparency register', requires pharmaceutical companies to disclose information requested by the developing country which is set depending on the level of risk pharmaceutical patents pose. These may include ownership, licensing, and full disclosure of patents surrounding the targeted technology (Drahos, 2007).

The Chief Pharmacist is keen to establish pharmaceutical patent monitoring which would enable public health experts in the Ministry of Health to scrutinise registered patents, and allow time to oppose the registration during the three month pre-grant period, on such grounds as affordability.

Unlike many developed countries that use a range of institutional and bureaucratic procedures 
to deter patent holders from registering a patent, for example translation into a local dialect and high filing fees, these barriers are very low in Fiji. For example, the cost of filing one patent is $\$ 50 F J D .^{52}$ This is relevant to the PICs because the region is not a net producer of intellectual property. Consequently, it is not in the national interest to encourage patent registration which will result in higher prices as well as weakening the transfer of technology. Here, Fiji could consider appropriate mechanisms to provide additional barriers to patent registration.

The third finding relates to the existing national IPR law which needs to be modified to introduce WTO safeguards, but there appears to be a lack of impetus for this, particularly following the 2006 coup. A review in 2003, sponsored by WHO under a HIV/AIDS policy review, found the Fijian national IPR law did not contain all WTO TRIPS safeguards. The reviewer, Dr Carlos Correa, recommended re-drafting the law. In the short term, forming a loose coalition of health-related stakeholders may help to re-stimulate its progress.

The likelihood that future proposed trade agreements will contain TRIPS-plus provisions is the fourth finding. It is important to clarify at this stage that the patent for Olanzapine meets, and does not exceed, the WTO TRIPS agreement that Fiji, as a WTO member, is obliged to comply with. From a development perspective however, concern would be raised if Fiji was forced to sign TRIPS-plus provisions in future trade agreements that gave additional rights to patent holders, most of whom are foreign. For example, in 2005 Thailand estimated the effects of a five and ten year extended market exclusivity on the cost of 60 core drugs being proposed in a Thai-US FTA which added \$66 million USD for one additional year of extension to $\$ 5$ billion USD for 10 years of extension ${ }^{53}$, contributing to the rejection of these provisions.

As discussed under Section 3.3.2, under pressure from the EU to sign a regional Pacific EPA, in early December 2007, Fiji and PNG splintered off from the other 12 PICs to sign individual agreements, potentially leaving TRIPS to be negotiated during 2008. A comprehensive

\footnotetext{
${ }_{53}^{52}$ March 2008 exchange rate of \$1FJD $=0.67$ USD

${ }^{53}$ In, Personal notes on the Thai National Human Rights Commission seminar on the Human Rights implications of the Thai-US FTA, Bangkok 18 - 19 Jan, 2007, supplied by interview participant, on file with the researcher
} 
analysis of the implications this will have on the local economy and the Pacific region as a whole is beyond the scope of this thesis. Earlier EU draft agreements were expected to include TRIPS-plus provisions which were opposed by the international development community. Even though only two countries signed an agreement, it may still trigger PACER negotiations and require all PICs that are party to PACER to offer the same conditions to New Zealand and Australia.

\subsubsection{Is trade and access to medicines on, or off, the agenda?}

Research objective two is "to assess whether trade related impacts on access to medicines is on the agenda in the public or civil society sector in Fiji and, if not, to determine why, and what, factors would trigger this".

Under this objective I broadly contrasted the awareness level of trade and access to medicines amongst PICs with other developing countries, such as Indonesia. I then searched for evidence of how this awareness had registered, both at a formal level, for example in meeting agendas and policy documents, and informally, such as discussions with interview participants and articles by academic commentators. Reasons for my findings are then discussed.

In the Pacific region as a whole the profile of trade and access to medicines is generally low compared with some other developing countries and the emphasis appears to be on putting in place internal factors, such as financial and structural limitations, to improve affordability and availability of medicines. Furthermore, awareness appeared to be very low in some key regional stakeholder organisations identified under objective three.

This is in contrast to some Asian countries where external trade factors pose major obstacles to access to medicines and awareness levels are much higher. This is brought about by a combination of factors, such as a high HIV/AIDS levels, their economic development being such that they no longer qualify for as much aid to access essential drugs, large population size, and trade provisions that enables stronger IP enforcement. Such factors make the market more lucrative for pharmaceutical companies to file and enforce pharmaceutical patents 
At the regional level in the Pacific, access to medicines did not appear to have been explicitly or consistently raised on the agendas or in the policy documents of the key regional stakeholders. These regional stakeholders include the PIFS, health-related UN agencies (including WHO), SPC, regional NGOs and associations. For example, an opportunity had been missed to include access to medicines in regional strategies developed for HIV/AIDS and non communicable diseases when they were first drafted ${ }^{54}$. These strategies are signed off by the Forum Leaders and developed into national policy documents for individual PICs to implement. In addition, there did not appear to be any academic commentators on this subject at the University of the South Pacific where development issues are usually given a high profile.

In contrast, awareness levels were slightly higher at an informal level in the Pacific, but this was inconsistent and only amongst some organisations, for example, senior employees at Fiji Pharmaceutical Services, the Government's medicines procurement agency. It is conceivable that other Ministry of Health officials are aware of trade and access to medicines, but the Ministry was not included in participant interviews owing to unavailability for interviews. I was advised, for example, that trade and access to medicines is not included in the Ministry of Health strategic plan or on the 2007 agenda of meetings the Ministry has initiated with the Ministry of Foreign Affairs and External Trade.

In Section 4.3.3, I used the metaphor of a 'generics bubble' to describe how Fiji's existing public medicines procurement scheme, which is similar in many ways to other PICs, appears to condition national and regional stakeholders to focus on internal determinants of access to medicines rather than keeping external trade determinants under closer surveillance.

The relatively low rate of HIV/AIDS in Fiji and the Pacific is another reason for the finding that trade and access to medicines has a comparatively low profile. Whereas the HIV/AIDS pandemic has galvanised the access to medicines debate in other developing countries, such as South Africa, despite the pandemic levels reported in PNG, this debate has not been sparked in

\footnotetext{
${ }^{54}$ Comments made by field research interview participants
} 
the Pacific region. Of significance here is that the region is entirely dependent on aid for all HIV/AIDS treatment, provided by organisations such as UNAIDS and the Global Fund. Amongst other factors, such as denial that the disease exists, the foreign aid spent on HIV/AIDS relieves local governments from this financial burden. Easing the burden can inadvertently lead to these constraints not being translated into national trade and health policy or an awareness of the need to protect access to medicines in future international trade negotiations.

The linkages between dependence on aid assistance for health and awareness of how trade provisions can impede access to medicines is relevant to all PICs because they all receive foreign assistance, to varying levels, for treating communicable diseases such as HIV/AIDS, malaria and tuberculosis, and for pandemics preparedness such as SARS.

A different set of factors, that are unique to non communicable diseases, appears to be acting on the profile of access to medicines in this sector. Although non communicable diseases now account for $70-75 \%$ of all deaths in the Pacific region, they are generally treated with preventative, rather than curative, care. Preventative care promotes changes in lifestyle rather than daily drug treatment. A combination of these two regimes is extensively used in Western countries where governments can afford to pay for higher priced patented drugs or have these subsidised by private health insurance schemes. This is not an option in most developing countries because they are unaffordable. This difference in affordability and in medical philosophy means that expensive medicines associated with chronic diseases such as hypertension, cancer, diabetes and renal failure, are not part of the existing public healthcare system in the Pacific region. In contrast, the profile of trade and access to medicines has been elevated in other more economically advanced developing countries, such as Thailand, because these governments have begun to provide more comprehensive public healthcare services.

Other factors contribute to the low profile of trade and access to medicines amongst stakeholders that mainly work with non communicable diseases. These include: less visible physical signs of disease compared with HIV/AIDS; smaller and more fragmented lobby 
groups compared with HIV/AIDS that are sometimes misinformed about the mechanisms they should use to advocate for changes in health and medicines policy; difficultly measuring the social and economic impacts of chronic diseases compared with communicable diseases, and the separation within the Ministry of Health of curative and preventative treatment, leading to conflicts for resources and potential policy gaps (where there should be overlap).

The existence of a comparatively low western, or 'anti-western', health culture also plays a role here.

A significant number of Pacific people express a preference for using traditional herbal medicines only and use western drugs as a last resort. This difference may be contributing to the finding under objective five, that generally CSOs, and even some government officials, appear to place less emphasis on protecting access to medicines than on, say, civil rights for health. Here, it is important that 'outside', western development professionals do not assume that a western health philosophy is implicit in the region. The extent to which this factor is contributing to the finding of a low profile of trade and access to medicines would warrant further research as it could be a major factor that might otherwise be overlooked if research into trade and access to medicines were to focus exclusively on the trade sector.

This low acceptance of 'western health culture' is further compounded by the finding in objective three that most NGO's, working within limited resources, feel hesitant to move into trade and IPR advocacy because of its complexity. This has consequences for how well organised community groups are to lobby for protection of access to medicines. In turn, low constituent awareness places less pressure on the MOH and MFAT to have it included on their agendas or to push for greater trade and policy coherence. However, there were early signs of some of these factors changing. For example, the next phase of the non communicable diseases testing programme at the community level, organised by the WHO, could lead to a demand for public access to new technology, patented drugs after people receive their results.

Affordability and availability issues are also likely to raise constituent awareness in the future. Although not directly related to trade factors, the government's capacity to ensure affordable, 
available drugs is compounded by internal limitations that are reported to result in drug 'stockouts' in public hospitals and medical centres where these drugs are normally free to the public. People are then expected to pay full price for drugs at private pharmacies. Price is a significant barrier to access for poor people. Affordability also becomes a barrier to medication compliance which can prolong recovery periods, contribute to drug resistance and impact on economic growth through the loss of livelihoods. Although Fijian citizens are probably better off than other PICs for the range of free drugs they have access to, there was early evidence of individuals and CSOs starting to question the efficacy and availability of some medicines, including access to newer, more expensive ones for treating chronic diseases.

In summary, trade and access to medicines has a relatively low and inconsistent profile amongst national and regional stakeholders. A substantial resource exists in the knowledge and work of the Chief Pharmacist, and senior staff of Fiji Pharmaceutical Services. This resource is providing a point of reference for other PICs when they request assistance to understand the trade issues relating to medicines in their own countries. In the near future, it is conceivable that any one of the potential triggers identified by interview participants in Section 4.3.3 may puncture the 'generics bubble' that Fiji currently operates within, either as an internal push for greater access to medicines from CSOs and UN agencies, or as external factors play out, such as a pandemic.

\subsubsection{Which stakeholders should take responsibility for mainstreaming health into trade?}

Research objective three is "to elaborate which stakeholders have a role in putting a public health perspective into trade and intellectual property rights law and whether the impact of trade obligations on access to medicines is factored into trade negotiations".

The PIFS, SPC, several health-related UN agencies, particularly WHO, UNAIDS and UNDP, and regional NGOs and associations, for example, clinicians and pharmacists, were identified as the key regional stakeholders for taking responsibility for mainstreaming health into trade policy by interview participants and the literature review. The two most critical Pacific 
regional agencies to take the lead were identified as PIFS and SPC; with the UN agency WHO as a third critical stakeholder. At a national level the Ministry of Health and Fiji Pharmaceutical Services, the Ministry of Foreign Affairs and External Trade, Ministry of Justice, NGOs and national associations were identified as the main stakeholders.

The research findings suggest that these stakeholders could be doing more collectively to proactively raise the profile of trade and access to medicines; a finding that is reinforced in objective two.

The absence of a multi-sector approach between trade policy and health, policy misalignment between stakeholders, limited resources and capacity constraints, an exclusive technical focus rather than incorporating a strategic policy role, the division between curative and preventative services in the public health system, and the prioritisation of specialist resources to develop a traditional knowledge framework rather than intellectual property rights, appear to be factors contributing to this finding at both the national and regional level.

Public health perspectives are not commonly taken into account in trade policymaking in most countries. However it is something that is recognized as essential to protecting health development space in trade liberalization, with many developed countries aspiring to better link the two sectors. The finding that a multi-sector approach between trade policy and health is lacking is therefore not unexpected. For example, historically, health ministries have generally been marginalized in two ways: first excluded from foreign policy, and, secondly, disconnected from other policy areas within national policymaking. Ensuring that ministries of health take a leadership role on trade and health policy therefore requires a reversal of longheld practices (WHO, 2007d).

Mainstreaming health into trade policymaking, and in associated governance structures, has many benefits. Firstly, rather than centralised policymaking, the responsibility will be shared across multiple agencies. Secondly, it reduces the potential for trade policymakers and negotiators from signing up to greater obligations in future trade rounds than they are required to under the WTO TRIPS Agreement. This is particularly relevant in the Pacific region where 
there is a relatively high turnover of senior trade staff, and therefore lost knowledge, and of foreign consultants providing trade and IPR policy advice who potentially promote a neoliberal mindset (Slatter, 2006).

This sector-by-sector approach is exemplified at a regional level where technical assistance is provided to Forum Leaders on economic, trade and IPR issues by the PIFS under a separate agenda to health. The PIFS have a specific mandate under the Pacific Plan, to evaluate scales of economy relating to health which they mandate to the Secretariat for the Pacific (SPC) whose role is to provide technical assistance on social and cultural issues. SPC's public health programmes appear to focus on surveillance and managing internal limitations rather than incorporating linkages with trade. As a result, there appears to be a gap between the policy agendas of the PIFS and SPC where the linkages between health (access to medicines) and trade could be better managed.

A good example, however, of PIFS responding proactively to the impact of TRIPS-plus on medicines took place in early 2007 when the PIFS took the initiative to have the proposed draft EU EPA for the Pacific region analysed by the Geneva group associated with Dr Carlos Correa, the IP specialist who suggested Fiji's current IPR law is modified. They then circulated this (negative) critique to Forum Leaders to make their own assessment.

SPC is the other major regional organisation which could take a lead role in trade and access to medicines advocacy. The absence of a strategic policy role for SPC, rather than an exclusive focus on technical assistance, which is what they were originally established to deliver, is a further limiting factor that was raised by some interview participants. This is apparent from literature reviews, including a formal review in 2006 that referred to, amongst other things, health economics and trade policy needing 'better reinforcement' in SPC's programmes. Furthermore, SPC's current focus does not appear to include the impact of external trade on the public heath programmes they oversee. Providing a strategic policy role is also vital to other significant health-related stakeholders, including the WHO, which only has observer status at PIFS meetings and relies on SPC, who is an advisor, to raise strategic issues with the PIFS. 
The UN is a third group of agencies that could be taking a lead role in trade and access to medicines advocacy. Findings were that, whereas some UN agencies such as UNDP, UNAIDS and $\mathrm{WHO}$, are proactively involved in trade and access to medicines initiatives in some overseas countries, for example, Thailand, it does not appear to be on their agenda in Fiji or the PICs. Furthermore, WHO WPRO seek advice on trade issues from the trade and health regional advisor based in Manila which may mean that strategic opportunities to advocate for protecting access to medicines at a local level have been overlooked. For example, the Non Communicable Diseases Regional Framework has a section on trade and legislation in regard to physical activity, nutrition, alcohol and tobacco but not on access to medicines. This is a regional document that is translated into a national document which Cabinet endorses. It is multidisciplinary, in that it is so not just housed within Ministry of Health, and is in the process of being signed off by all PICs with implementation assisted by WHO and SPC.

At a national level, interview participants acknowledged that the Ministry of Health have started to collaborate more frequently with the Fijian MFAT on trade and health issues. Instead the agenda is based on Ministry of Health's current strategic plan, which doesn't include trade, TRIPS and access to medicines. Stakeholders are also limited by their capacity constraints, particularly at the civil society level. Here, national and regional NGOs are hesitant to move into trade and IPR advocacy, not only because of resource constraints, but because of its perceived complexity.

Whereas several NGOs are involved in health advocacy, relatively few are involved in trade, or intellectual property rights advocacy. Consequently there is very limited capacity for any trade and access to medicines advocacy amongst regional NGOs even if the issue was raised by their constituents. In contrast, the most effective access to medicines campaigns in other developing countries have often been mobilized by partnerships formed between grass roots NGOs and their international NGO counterparts in the north. This finding also relates to research objective five, which finds limited capacity amongst NGOs for human rights advocacy, as well as for trade and IPR. 


\subsubsection{Is trade and access to medicines considered in regional initiatives?}

Research objective four is "to place findings from the secondary objective within the broader context of the 'regional integration process' led by the Pacific Islands Forum Secretariat (PIFS) to evaluate whether the impact of trade-related factors on access to medicines is considered in the review of collective medicines procurement, medicines regulation, and regional integration of intellectual property rights."

Key findings for this objective are consistent with several of the findings discussed under objectives one, two and three. In particular, the finding that a sector-by-sector approach to decision making in the trade and health sector appears to affect whether trade and access to medicines, which ideally requires a multi sector approach, is taken into consideration under regional integration initiatives. The adverse effect on the profile of trade and access to medicines that arises from an apparent prioritisation of resources to further develop a traditional knowledge framework compared with IPR is a new finding under this objective.

This sector-by-sector approach is illustrated in the health sector where various regional initiatives are being led by the WHO and SPC and in the trade sector, where regional IPR initiatives are led by PIFS with assistance from WIPO, IP Australia and other international development agencies such as the Asia Development Bank.

Several initiatives led by WHO and SPC to review collective medicines procurement are progressing at a halting pace and do not appear to explicitly include the impact of IPR on access to medicines. Furthermore, medicines regulation (testing for quality), is not yet part of these regional reviews. However, it is worth noting that if out sourcing of medicines regulation, for example to the Australian Therapeutic Goods Authority, was ever considered in the future this could provide an alternative mechanism to international trade agreements (the conventional instrument for introducing TRIPS-plus provisions into national and regional IPR law), to introduce pharmaceutical patent law that is TRIPS-plus to the region. These TRIPSplus provisions were recently introduced to Australia in the free trade agreement with the United States. 
In the trade sector a contract to continue the review of regional integration of IPR has not been renewed by the PIFS. In 2004, the PIFS, WIPO and IP Australia finished implementing a three year Regionally Focused Action Plan (PIFS/WIPO/IP Aust, 2001)which included investigations into the integration of IP administration under a regional office. National sovereignty issues are a key factor for consideration in these reviews as currently the content and form of national IPR law varies widely in the region and is independently managed by each PIC. The two foreign agencies continue to work bilaterally with different countries such as PNG, which is the most technically advanced IP office.

Two observations are worth noting here. Firstly, the assistance PICs receive for IPR capacity building, for example from WIPO, is not from independent sources. This situation may introduce a neoliberal bias that is misaligned with development-friendly policy that is more appropriate for the Pacific region.

Secondly, research findings under objective one suggest that the terms of reference for a much referenced report prepared for the PIFS, titled 'A regional IPR Office for the South Pacific: cost benefit analysis' (Farquhar, 2005), were perhaps not broad enough from a development perspective. This report was an output from the Asia Development Bank technical assistance program to strengthen regional cooperation and integration in the South Pacific, funded by the Commonwealth Secretariat. Here, the terms of reference of this report could have been broadened to include the indirect economic impacts of streamlining patent registration.

The configuration of any proposed regional IP models will have a significant implication on national and regional development policy because it has the potential to accelerate patent registrations without commensurate economic benefit for PICs, who are not net IP generators. Three external environmental factors are of particular significance here. The trilateral patent office harmonisation underway between the EU, US and Japan, the Chapter three harmonisation of world wide PCT offices, described by Drahos as a 'patent pipeline' (Drahos, 2007), and increasing homogeneity of patent examination criterion. This global harmonisation is designed to make patent registration more seamless between countries and regional trading 
blocs. In theory this will increase economic growth and technology transfer. However, these gains are unlikely to be captured by developing countries, such as the PICs, as the majority of patents being filed are by foreigners.

This finding suggests that further investigation of alternative regional IPR initiatives, from a development-friendly perspective in particular, is timely. As noted, earlier negotiations with the EU EPA suggested the PICs could have to consider integrating IPR at a regional level and to join PCT as a regional bloc. Under pressure to meet negotiating deadlines, it is conceivable these concessions could be made by trade negotiators without adequate economic and social impact analysis being undertaken.

A prioritisation of limited resources within the PIFS to focus on further developing a regional traditional knowledge framework, in preference to IPR programmes, is a further significant finding. PICs continue to face unauthorized use of their traditional knowledge which, in the main, conventional IP law fails to protect. A draft model law on 'Traditional Biological Knowledge, Innovation and Practices' was developed for the Pacific region in 2000 by the Secretariat of the South Pacific Environmental Programme (SPREP). At the request of Forum Leaders, traditional knowledge will be further developed by the Forum Secretariat in 2008/2009. Resource constraints are likely to mean that traditional knowledge will be prioritised over further research into an appropriate regional or national IPR framework, development of an IPR policy framework for the CROPS, and assistance to individual PICs to ensure WTO safeguards are incorporated into national IPR law.

There is an understandable preference for traditional knowledge amongst Pacific people because of a perception it may capture greater economic benefits for the region compared with IPR and because the ownership rights shared by a group under traditional knowledge are more culturally relevant and highly important to them than IPR, where rights are owned by individuals. However, evidence from the literature reviews suggest that taking this approach may mean the region risks being forced to adopt an IPR model that is not development friendly. Findings from objective one suggest a shift in thinking would be advantageous so IPR is not viewed by Pacific people from a purely economic perspective. Instead, discussions 
about IPR might be better 'reframed' as an essential instrument of development policy that can be applied to protect Pacific islanders' rights to public goods, to reinforce national sovereignty, and to achieve social, cultural and health development goals. In a worst case scenario the public commons the PICs and Fiji already have access to, may be eroded away through international trade agreements, such as EU EPA and WTO accession packages, while the PIFS work programmes remain focused on developing the traditional knowledge model.

\subsubsection{What is the scope for using human rights?}

Research objective five is "to assess the general scope for using human rights instruments to protect access to medicines in Fiji." The findings from this objective are best discussed in the context of credibility issues raised following on from the recent political instability, capacity limitations, and human rights challenges and opportunities.

In the first instance, findings suggest that any philosophical or political application of human rights instruments by the Fijian government (taking the moral high ground) to analyse the impact of trade agreements on health could lack credibility in the international arena because of the treatment of civilians by the military regime in the 2006 coup. Political credibility could be compromised further by the temporary suspension of the Fijian Human Rights Commission from the United Nations. Lack of ratification of the ICESCR, the main international convention used to challenge international trade agreements on the right to health, is a further limitation.

In general terms, findings are that the capacity for human rights advocacy amongst the PIFS, CROPS, national governments, and NGOs appears to be limited while the greatest capacity exists within some UN agencies, for example UNDP and their special human rights programme, RRRT. The primary focus of human rights mechanisms is generally on civil and political rights, with few organisations promoting the right to health, and none promoting the right to access to medicines. For example, the UNDP have linked human rights into HIV/AIDS policy and the regional strategy. However, here the emphasis appears to be on civil rights, such as non discrimination, rather than the right to access to medicines. 
Human rights mechanisms face unique challenges in the Pacific where people are generally suspicious of human rights and raise concerns relating to the conflict with customary rights, limitations on resources, and onerous international treaty body reporting obligations as limitations to its implementation. The Pacific region has the lowest ratification rates worldwide of the core international treaties. It has been acknowledged that a human rights blend with customary rights needs to be developed involving Pacific islanders. Despite these challenges there is a broad infrastructure for its promotion.

Interviewees expressed a wide range of views, from supporting the concept of applying human rights to protect access to medicines, to rejecting the concept. This response is likely to reflect the underlying suspicion of human rights by Pacific people as well as the political nature of advocating for health rights in the wider global trading system. However, the 'right to health' was considered easier to promote, than say civil rights, because it is less likely to offend power bases associated with traditional forms of decision making in the Pacific.

In the short term, these challenges suggest the human rights approach to health may be better fostered through UN agencies and NGOs. This view was endorsed by several interviewees from NGOs and RRRT, who commented the potential exists to develop access to medicines as a right if the need was demonstrated by the people they represent. The absence of demandside factors, identified under objective two, that could galvanise UN and NGO constituents to raise the profile of trade and access to medicines might limit this from happening in the medium term

The literature research and interviews highlighted several areas where human rights could most practically be introduced to mitigate trade obstacles to access to medicines in Fiji and at a regional level. These, along with other suggested responses, are listed in Appendix 5.

\subsection{The significance of this research for human rights theory}

As discussed in Section 1.5, rather than applying human rights theory as a research lens, this 
thesis uses human rights as one system, in a multi-system approach. The findings that are significant for human rights theory therefore reflect this approach by either describing the interface of human rights with these other systems, for example human rights and new regionalism, or they are specific to human rights, for example, putting the principle of indivisibility into practice.

In this research, human rights appeared to have the least significant influence on shaping how Fijian and Pacific people view trade and access to medicines compared with other national and regional factors relating to trade, health and local culture. Of significance, from a human rights perspective, these other factors also appear to be shaping how Pacific people view human rights instruments rather than the other way around. From a human rights theory perspective it would be interesting to observe how, and at what point this dynamic could shift so that human rights, or a human rights blend with local custom, became a key driver to stimulate access to medicines advocacy either at government or civil society level.

All of the complex challenges facing the international human rights framework, discussed in Chapter 2, appear to be reinforced at both the regional and national level in the Pacific. The most significant of these is cultural relativism; the perceived conflict between the hegemonic human rights model with values and customs in the Pacific.

Difficulty experienced with implementing the principle of indivisibility of human rights was also reinforced because often 'development' involves making trade offs between conflicting interests. The significance here for human rights theorists was that the UNDP special human rights programme, RRRT, found this principle relatively easy to implement. The interview participant mentioned this was helped by the organisation being modeled on a rights based approach. This observation might suggest the principle of indivisibility is more easily put into practice by organisations that focus exclusively on human rights compared with other 'variant' organisations that apply human rights in conjunction with other multidisciplinary tools, for example ECREA. If this is so it would be important to acknowledge these differences and to encourage information exchange between these diverse organisations to help develop the new tools and mechanisms needed to assist with this. 
Some of the research findings suggest that a unique set of factors associated with small island developing states having limited resources, together with the pressures of regionalism may be creating a context that is uniquely shaping the views of Pacific islanders on trade and access to medicines. This raises the question for human rights theorists, while acknowledging there are human rights issues that are unique to small island developing states (for example, rising sea levels as a result of climate change) is there a unique set of human rights mechanisms, challenges and responses that are specific to small island developing states undergoing regionalism and how might these be supported.

The research identified the emergence of two new challenges for human rights theory. First, the concept of collective rights of individual countries in the 'new regionalism' envisaged by the EU, particularly for regions comprised of small island developing states, such as the Pacific region, and second, the relationship of human rights at the interface with traditional knowledge. This would warrant further research, particularly as human rights mechanisms currently function at the state level, whereas the proposed EU EPA envisaged dealing with institutions and aid distribution through new regional architecture versus individual states. An example of this could be the justification on human rights grounds for collective compulsory licensing to achieve regional health development goals, as opposed to compulsory licenses being raised by individual states.

The interest in developing traditional knowledge model law amongst developing countries, including the PICs, provides a new opportunity to scope out the relationship of human rights at its interface. I would expect this to be more compatible and synergistic than the relationship with IPR, because of the focus on socioeconomic and cultural development and collective distribution of the commercial benefits.

In the global context, this research reinforces the significance for human rights theory to provide an alternative perspective to the dominant, global trading system and to counter the expansion of intellectual property rights, which is the main legal instrument that restricts access to public goods for developing countries, in particular access to essential medicines. 
Finally, findings that refute aspects of human rights theory were less clear. However, the human rights theory was a useful framework for this thesis because it offered insights into how socioeconomic and cultural rights are traded off civil and political rights in the neoliberal order, which is particularly relevant in the Pacific region where trade liberalisation is dominating the economic agenda.

\subsection{Conclusion}

"The world we have made, as a result of the level of thinking we have done thus far, creates problems we cannot solve at the same level of thinking at which we created them".

Albert Einstein

The extent to which trade restricts access to medicines and has adverse effects on health and economic development in Fiji and the Pacific region may depend critically on how Pacific Island Countries cope with the forces of regionalism and the realities of joining the global trading system, where there are pressures to make concessions in areas such as TRIPS. Yet, the level of awareness of these potential trade restrictions generally appear to be low and inconsistent amongst most of the key health and trade stakeholders at the national and regional level. A central question being asked in this research is what underlying factors shape how Pacific islanders view trade and access to medicines, notably in the area of trade, health, local culture, and human rights, and what are the regional and national responses to mitigate potential trade impediments.

By combining a public health lens with a multi-system review of population health trends, intellectual property rights law, trade policymaking, and human rights, this research has elaborated findings that are usually less evident because they are conventionally researched and managed in isolation, on a sector-by-sector basis. The findings suggest human rights are less significant, while the challenges associated with small island developing states, together with local cultural preferences and the pressures of regionalism have a more direct influence. The combined effect of these factors may be creating a unique context that is leading the 
Pacific region not to deal with these issues as well as some other developing countries might.

In a worst case scenario, TRIPS flexibilities may be signed away by trade negotiators, unaware of the indirect costs to the health sector, and subsequently to economic development through sickness and loss of livelihoods. Once integrated into national legislation, these obligations might sit, like a 'trojan horse', until they are triggered at a later stage and cost the government more with no commensurate economic benefits.

Improvements to current, declining population health trends in the Pacific region are crucial to the region being able to sustain any future benefits from economic development, especially if the PICs have had to absorb significant adjustment costs and suffer the loss of national sovereignty under the pressures of trade liberalisation and regionalism.

By not acting now to declare public good priorities in the Pacific region, opportunities are already being lost to limit potential trade restrictions on access to medicines which could have an irreversible, adverse effect on health and economic development in the region in the future. National and regional stakeholders in trade policy and health should therefore start to acknowledge trade and access to medicines in their agendas, and begin to systematically implement a broad range of multidisciplinary responses to mitigate these, some of which are suggested in this research paper. 


\section{References}

Abbott, F.M. (2005). Managing the hydra: The herculean task of ensuring access to essential medicines. In, Maskus, K.E. and Reichman, J. H (eds). International Public Goods and Transfer of Technology under a Globalised Intellectual Property Regime. Cambridge University Press, Cambridge. pp 393 - 425

ADB (Asia Development Bank) (2006). Pilot strengthening of civil society participation in development in the Pacific. Technical Assistance Report, Asian Development Bank, Manila. Available at http://www.adb.org/documents/TARS/PAC last accessed 4/11/07

Bailey, M. (2004). Affordability of medicines in Fiji. Association of Professional Pharmacy, Fiji School of Medicine, Suva. Available at http://www.haiweb.org/medicineprices/surveys/20409FJ/survey report.pdf, last accessed $15 / 1 / 08$

Balasubramaniam, K. (2002). Access to medicines: Patents, prices and public policy consumer perspectives in global intellectual property rights. In Drahos, P. and Mayne, R.(eds), Global Intellectual Property Rights: Knowledge, Access and Development, Palgrave Macmillan, London. pp. 90 - 107

Bilaterals website on trade negotiation processes available at www.bilaterals.org. last accessed $10 / 2 / 08$

Brockington, D. and Sullivan, S. (2003). Qualitative research. In, Scheyvens, R. and Storey, D. (eds). Development Fieldwork: A Practical Guide. Sage Publications, London. pp. 57 - 74

Chand, S and Bowna, C. (2007). Size matters: the impact of aid on institutions. Working Paper Series prepared at the National Centre for Development Studies, Australia National University. Available at http://ssrn.com/abstract/1007639, last accessed 15/2/08

Chang, H-J. (2005). Kicking away the ladder: good policies and good institutions in historical perspective. In, Gallagher, K (ed). Putting Development First: The Importance of Policy Space in the WTO and International Financial Institutions, Zed Books, New York. pp.102 125 ,

CIEL (Centre for International Environmental Law) (2007). The European approach to intellectual property in European partnership agreements with the African, Caribbean and Pacific Group of countries, Discussion Paper, April 2007. Available at www.ciel.int, last accessed 3/1/08

Correa, C. (2003). Report review of intellectual property legislation in Fiji in relation to antiretroviral therapy. Prepared for Fijian Government, Suva, Dec. 2003, on file with the researcher 
Correa, C. (2007). Guidelines for the examination of pharmaceutical patents: Developing a public health perspective. Available at www.iprsonlie.org, last accessed 12/12/07 Working Paper organised by WHO/ICTSD/UNCTAD

Correa, C. and others (2007). EU in danger of breaking its promise to the poor. Letter published 24 May, 2007, The Financial Times Limited, United States of America. Available at www.bilaterals.org/article.php3?id_article $=8635$, last accessed 15/12/07

Crocombe, R.(2005). International context and lessons from other regions: A perspective. Prepared for the Pacific Island Forum Secretariat. Available at www.pacificplan.org/tiki_download_file.php last accessed on 20/11/07

Cullet, P. (2005). Patents and medicines: the relationship between TRIPS and the human right to health. In, Gruskin, S., Grodin, M.A., Annas, G.J, Marks, S.P.,(eds), Perspectives on Health and Human Rights, Routledge, New York. pp.179 - 202.

Danzon, D.M. and Towse, A. (2005). Theory and implementation of differential pricing for pharmaceuticals. In, Maskus, K.E. and Reichman, J. H (eds). International Public Goods and Transfer of Technology under a Globalised Intellectual Property Regime. Cambridge University Press, Cambridge pp. 425 - 456

Deere, C. (2007). Disparities seen in developing countries' TRIPS implementation. Presentation to South Centre working group on TRIPS implementation by the Director of the Global Trade Governance Project at the University of Oxford, posted on http://www.ipwatch.org/weblog/index.php? $\mathrm{p}=865$ accessed on 11/12/07

Drahos, P. (2001). Intellectual property and human rights. Journal of World Intellectual Property (4) pp.791-808

Drahos, P.and Mayne, R.(eds) (2002). Global Intellectual Property Rights: Knowledge, Access and Development. Palgrave Macmillan, London and New York

Drahos, P. (2005). An alternative framework for the global regulation of intellectual property rights. Working Paper: October 2005, Centre for Governance of Knowledge and Development, Australian National University, Canberra. Available at http://cgkd.anu.edu.au/menus/workingpapers.php last accessed 20/11/07

Drahos, P. (2007). Trust me: Patent offices in developing countries. Centre for Governance of Knowledge and Development, Australian National University, Canberra. Available at www.cgkd.anu.edu.au last accessed 30/1/08

Evans, T. (2004). The human rights of health. In, Poku, N. and Whiteside, A.(eds). Global Health and Governance: HIV/AIDS 7 (25). Palgrave Macmillan, London. Available at www.hmb.utorotho.ca/HMB303H/weekly_supp/week_03/Evans_Right_to_Health.pdf , last accessed 6/11/07 
Ey, F. (2005). Institutional framework and procedures regulating access to pharmaceutical products to address public health problems: Pacific regional case study. Prepared for the Commonwealth Secretariat, Samoa, Dec 2005 on file with the researcher

Fairbairn-Dunlop, P. (2002). Civil society participation in the Pacific. In Time to Talk. Program 10 Opinion, ABC Radio Australia. Available at http://www.abc.net.au, last accessed 11/12/07.

Farmer, P. and Gastineau, N. (2005). Rethinking health and human rights: Time for a paradigm shift. In Gruskin, S., Grodin, M.A., Annas, G.J, Marks, S.P.,(eds). Perspectives on Health and Human Rights. Routledge, New York. pp. 73-94

Farquhar, S.(2005). A regional international property rights office for the South Pacific: Costbenefit analysis. Working Paper 3 (16) Pacific Studies Series: Toward a New Pacific Regionalism. An ADB-Commonwealth Secretariat joint report to the PIFS. Available at www.pacificplan.org last accessed 3/2/08

Francois-Xavier Bagnoud Center website http://www.hsph.harvard.edu/fxbcenter/international_hhr.htm contains links to documents, organisations and other references on health and human rights, including http://www.glphr.org/resources/appendix, last accessed 1/2/08

Gruskin, S., Grodin, M.A., Annas, G.J and Marks, S.P.,(eds), (2005). Perspectives on Health and Human Rights. Routledge, New York

Hau'ofa, E. (1998). The Ocean in Us. In, The Contemporary Pacific, Vol 10 (2) 1998. University of Hawaii Press, Hawaii. pp. 391 - 410

Hestermeyer, H. (2007). Human Rights and the WTO: The Case of Patents and Access to Medicines. Oxford University Press, Oxford

Hoen, E.(2005). TRIPS, pharmaceutical patents and access to essential medicines: A long way from Seattle to Doha. In, Gruskin, S., Grodin, M.A., Annas, G.J, Marks, S.P.,(eds). Perspectives on Health and Human Rights, Routledge, New York. pp. 203 - 222

Hughes, H. (2003). Aid has failed the Pacific. In, Issues Analysis (33) 7, May 2003. Prepared at the Centre for Independent Studies, Australia. Available at http://www.cis.org.au/issuesanalysis/ia33/ia33.htm, last accessed 15/2/08

Hunt, P. (2005). The right to health: an interview with Professor Paul Hunt. Essex Human Rights Review (2) 1, pp.57 -61. Available at http://projects.essex.ac.uk/EHRR/archive/pdf/File4-Hunt.pdf, last accessed 24/11/07

Johnston, R. J., Gregory, D., Pratt, G. and Watts, M. (eds) (2000). The Dictionary of Human Geography $\left(4^{\text {th }}\right.$ ed). Blackwell Publishers, Oxford 
Kitchin, R. and Tate, N. (2000). Conducting Research in Human Geography: Theory, Methodology and Practice. Prentice Hall, Harlow

Kelsey, J. (2004). A people's guide to PACER: The implications for the Pacific islands of the Pacific Agreement on Closer Economic Relations. Commissioned by the Pacific Network on Globalisation (PANG), Suva

Kelsey, J. (2005). A people's guide to the Pacific's economic partnership agreement. Commissioned by the World Council of Churches Office in the Pacific, Suva

Kelsey, J. (2006). Going nowhere in a hurry? The Pacific's EPA negotiations with the European Union. In, Victoria University of Wellington Law Review, Vol 38 (1), 2007. pp. 81104

Lofgren, H. (2007). The global biopharma industry and the rise of Indian drug multinationals: implications for Australian generics policy. In, Australia and New Zealand Health Policy 2007. 4 (10). Available at http://www.anzhealthpolicy.com/content/4/1/10 last accessed 16/1/08

Love, J. (2007) Prizes, not patents: James Love explains the idea. Available at http://www.pharmalot.com/2007/10/jamie-love-interview/ published on 31 October 2007, accessed 31/10/07

Marks, S. P. (ed) (2004) Health and Human Rights: Basic Introductory Documents. FrancoisXavier Bagnoud Centre for Health and Human Rights, Harvard School of Public Health, Harvard University Press, Massachusetts

Marmot, M and Wilkinson, R.G. (1999). Social Determinants of Health. Oxford University Press, Oxford

Maskus, K.E. and Reichman, J.H (eds) (2005). International Public Goods and Transfer of Technology under a Globalised Intellectual Property Regime. Cambridge University Press, Cambridge

Mayne, R. (2002). The global campaign on patents and access to medicines: an Oxfam perspective. In, Drahos, P. and Mayne, R. (eds). Global Intellectual Property Rights: Knowledge, Access and Development, Palgrave MacMillan, London, pp. 244 - 258

Mead. A, and Ratuva, S. (eds), (2007). Pacific Genes and Life Patents; Pacific Indigenous Experiences and Analysis of the Commodification and Ownership of Life, United Nations Institute of Advanced Studies. Available at www.earthcall.org last accessed 21/12/07

Mould. R, (2004). Expensive new drugs - do we really need them?, In, Australian Prescriber 27 (6), December 2004. Available at www.australianprescriber.com last accessed 2/11/07 
Murray, W.E. and Overton, J. (2003) Designing development research. In, Schevyens, R. and Storey, D. (eds). Development Fieldwork: A Practical Guide. Sage Publications, London. pp. $17-36$

Narsey, W. (2006). PICTA, PACER, and EPAs: Weaknesses in current trade policies and alternaticve integration options. Pacific Futures, Pandanus Books, Canberra.pp. 72 - 90

New Zealand Law Commission. (2006). Converging Currents: Custom and Human Rights in the Pacific. Study Paper 17. Available at www.lawcom.govt.nz, last accessed 12/12/07

NZ MFAT (New Zealand Ministry of Foreign Affairs and Trade) (2003). New Zealand Handbook on International Human Rights. Printlink, Wellington

NZ MFAT (New Zealand Ministry of Foreign Affairs and Trade) (2006). Republic of the Fiji Islands country paper, March 2006. Available at the official website http://www.mfat.govt.nz/foreign last accessed 5/11/07

Ostry, (2002). The trade policymaking process level one of the two level game: Country studies in the western hemisphere, INTAL-ITD-STA, Occasional Paper 13, Buenos Aires. Available at http://thedialogue.org/publications , last accessed 26/12/07

Oxfam Australia and Oxfam NZ (2006). Bridging the gap between State and Society: New directions for the Solomon Islands (26). Available at www.oxfam.nz, last accessed 12/10/07

Oxfam New Zealand (2007) website, www.oxfam.org.nz last accessed 4/1/08. A description of the EU EPA trade negotiations with the PICs and other updates

Oxfam International, (2005). Make extortion history: The case for development-friendly WTO accession for the world's poorest countries, Briefing Paper 79, Oxfam International, London. Available at www.oxfam.org, last accessed 23/1/08)

Oxfam International (2006a). Public health at risk; a US free trade agreement could threaten access to medicines in Thailand. Briefing Paper 86. Oxfam International, London. Available at www.oxfam.org.uk last accessed 11/2/08

Oxfam International, (2006b). Unequal partners: How the EU-ACP economic partnership agreements (EPAs) could harm the development prospects of many of the world's poorest countries, Oxfam Briefing Note, Sept 2006, Oxfam International, London

Oxfam International, (2006c). Workshop for civil society on EU-ACP trade negotiation facilitated by Oxfam New Zealand, Press Release, 16 June 2006. Available at www.oxfam.org.nz, last accessed 11/11/07 
Oxfam International (2007a). Investing for life: meeting poor people's needs for access to medicines through responsible business practices. Briefing Paper 109, Oxfam International, London. Available at http://www.oxfam.org/en/policy/briefingpapers/bp109_investing_for_life_0711 last accessed $28 / 11 / 07$

Oxfam International, (2007b). Signing away the future: How trade and investment agreements between rich and poor countries undermine development. Briefing Paper 101, Oxfam International, London. Available at www.oxfam.org.uk last accessed 14/1/08

Pacific Islands Legal Information Institute website www.paclii.org, last accessed 12/1/08

PIFS/WIPO/IP Aust (Pacific Islands Forum Secretariat/World Intellectual Property Organisation/IP Australia) (2001). Regionally focused action plan for intellectual property development. Suva. Available at www.pifnet.ib.wipo.net/library/regionally_focussed_Action_Plan.doc, last accessed 20/11/07

PIFS. (Pacific Islands Forum Secretariat) (2005). Pacific Plan. Available at www.pacificplan.org last accessed 5/12/07

PIFS/NZHRC (Pacific Island Forum Secretariat and NZ Human Rights Commission) (2006). National Human Rights Institutions: Pathways for Pacific States. Pacific Human Rights Issues Series 1. Copies available from NZ Human Rights Commission, Wellington

Robertson, R.(2006). Fiji futuring: Connectivity and development. In, Pacific Economic Bulletin 21 (2), Asia Pacific Press. Based at Australia National University, Canberra. pp.22 35

Robinson, M. (2004). Neglected diseases and neglected communities: a human rights perspective. Available at http://www.realizingrights.org/?option=content\&task+views\&id=61, last accessed 7/11/07

Rodrik, D. (2001). The global governance of trade: as if development really mattered. Harvard University, John F. Kennedy School of Government, Massachusets. Available at www.policyinnovaitons.org/ideas/policy_library/data/01253, last accessed 12/12/07

Rothman, J. and Rothman, S. (2006). Trust is Not Enough: Bringing Human Rights to Medicine. New York Review of Books, New York

RRRT (Regional Rights Resource Team) website available at http://www.rrrt.org last accessed $5 / 12 / 07$

RRRT/UNDP (Pacific Regional Rights Resource Team/United Nations Development Programme) (2005). The Big Seven: Human Rights Conventions \& Judicial Declarations. Published by UNDP, Suva 
Santoro, M. A. and Gorrie, T. M., (eds), (2005). Ethics and the Pharmaceutical Industry. Cambridge University Press, Cambridge

Scheyvens, R. and Storey, D. (2003). Ethical issues. In, Schevyens, R. and Storey, D. (eds). Development Fieldwork: A Practical Guide. Sage Publications, London. pp. 139 -166

Shaffer, G. (2005). Recognising public goods in WTO dispute settlement: Who participates? Who decides? The case of TRIPS and pharmaceutical patents protections. In, Maskus, K.E. and Reichman, J.H (eds). International Public Goods and Transfer of Technology under a Globalised Intellectual Property Regime. Cambridge University Press, Cambridge. pp. 884 908

Slatter, C. (2006). Neo-liberalism and the disciplining of pacific island states - the dual challenges of a global economic creed and a changed geopolitical order. In, Powles, M (ed). Pacific Futures, Pandanus Books, Canberra. pp 91-110

South Pacific Civil Society Library, available at http://www.vanuatu.usp.ac.fj, last accessed 5/11/07. Contains useful documents on civil society in the Pacific

Stairs, D. (2000). Foreign policy consultations in a globalising world: The case of Canada, the WTO, and the shenanigans in Seattle. In, Institute of Research in Public Policy, Vol 1 (8), Dec 2000 , pp. 8 - 39. Available at http://www.centreforforeignpolicystudies.dal.ca , last accessed $5 / 1 / 08)$

Stiglitz, J. (2005). Development policies in a world of globalisation. In, Gallagher, K (ed). Putting Development First: The Importance of Policy Space in the WTO and International Financial Institutions, Zed Books, New York. pp. 15 - 32.

Tansey, G. (2005). Comment: Whose rules, whose needs? Balancing public and private interests. In, Maskus, K.E. and Reichman, J.H (eds) (2005). International Public Goods and Transfer of Technology under a Globalised Intellectual Property Regime. Cambridge University Press, Cambridge. pp. 662 - 668

The Republic of the Fiji Islands Ministry of Foreign Affairs and External Trade (2006) website available at www.foreignaffairs.gov.fj, last accessed 21/1/08 for information on bilateral and other trade agreements

Third World Network website http://www.twnside.org.sg/heal.htm last accessed 3/3/08

Thomas, S. (2004). EUphoria in the Pacific? Regional economic partnership agreements implications for the Pacific. Paper presented at the New Zealand Asia Pacific European Studies Association Conference, "Outside Looking In", National Centre for Research on Europe, University of Canterbury, New Zealand, 9-11 September, 2004. Available at http://www.eusanz.org/pdf/conf04/thomas.pdf, last accessed 14/2/08 
Tukuitonga, C. (2006). Background paper: population health and health care in the Pacific region - a situation analysis. Prepared for WHO/SPC Meeting of Pacific Health Ministers, 24 February 2007. Available at www.spc.org last accessed 5/11/07

UNCHR (United Nations Commission on Human Rights) website www.uncchr.ch, last accessed 12/2/08

UNCHR PRC (United Nations Commission on Human Rights Pacific Regional Centre), Suva. Available at http://www.regionalcentrepacific.undp.org.fj, last accessed 7/11/07

UNCTAD (United Nations Conference on Trade and Development) website http://www.unctadxl.org/templates/DocSearch779.aspx , last accessed 3/2/08

UNDP (United Nations Development Programme) (2005). Human Development Report 2005: Fiji. Available at http://www.hdr.undp.org/statistics, last accessed 16/12/07

UNDP (United Nations Development Programme) (2006). Thailand national technical consultation on, free trade agreements and intellectual property rights: Implications for access to medicines. 8 - 9 Dec. 2005. Bangkok, Thailand. Available at www.undp.org.th/pulbicaitons/documents/UNDPTRIPS, last accessed 20/2/08

UNDP (United Nations Development Programme) (2007). White Paper outlines joint UN approach for 2008-2012. Available at http://www.undp.org.fj last accessed 7/11/07,

UNESCAP (United Nations Economic and Social Commission for Asia and the Pacific) (2007). Development of health systems in the context of enhancing economic growth towards achieving the millennium development goals in Asia and the Pacific. Available at http://www.unescap.org/publications/detail.asp?id=1221, last accessed 23/10/07

UK DFID (United Kingdom Department for International Development) (2004). Non-state justice and security systems. Available at http://www.gsdrc.org last accessed 9/11/07. This briefing paper considers strategies for engagement with non-state justice systems (including customary systems)

University of Minnesota Human Rights Collection http://www1.umn.edu/humanrts/links/bioethics.html, last accessed 1/2/08, provides a valuable list of documents on human rights and bioethics

Ulrich, H. (2005). Expansionist intellectual property protection and reductionist competition rules: A TRIPS perspective. In, Maskus, K.E. and Reichman, J.H (eds) (2005). International Public Goods and Transfer of Technology under a Globalised Intellectual Property Regime. Cambridge University Press, Cambridge. pp 726 - 757

Uvin, P. (2004). Human Rights and Development, Kumarian Press Inc, Bloomfield

Wade, R. (2005). What strategies are viable for developing countries today?: the WTO and the 
shrinking of policy space. In, Gallagher, K (ed). Putting Development First: The Importance of Policy Space in the WTO and International Financial Institutions, Zed Books, New York. pp. $94-102$

Werhane, P.H. and Gorman, M.E., (2005). Intellectual property rights, access to lifeenhancing drugs, and corporate moral responsibilities. In, Santoro, M. and Gorrie, T.M., (eds), Ethics and the Pharmaceutical Industry. Cambridge University Press, Cambridge. pp. 261-281

WHO (World Health Organisation) website www.WHO.int, last accessed 3/3/08

WHO (World Health Organisation) (2002). 25 questions and answers on health and human rights. World Health Organisation, Geneva. Available at www.WHO.int, last accessed $15 / 11 / 07$

WHO (World Health Organisation) (2004). World medicines situation. World Health Organisation, Geneva, pp.72. Available at www.essentialdrugs.org/edrug/archive/200410/msg00016.php, last accessed 17/1/08

WHO (World Health Organisation) (2005). Regional strategy for improving access to medicines in the western pacific region 2005-2010. Manila. Available at www.wpro.who.int/rcm/en/archives/rc55/rc_resolutions/wpr_rc55_r04.htm, last accessed $14 / 1 / 08$

WHO (World Health Organisation) (2006a). Patent and access to medicines - an introduction to key issues, prepared by Milani. B and Oh. C. Available at http://www.who.int/medicines/en/, last accessed 15/12/07

WHO (World Health Organisation) (2006b). The World Health Report 2006: Working Together for Health. World Health Organisation, Geneva. Available at http://www.who.int/whr/2006/en/, last accessed 7/11/07

WHO (World Health Organisation) (2007a). Public Health, Innovation and Intellectual Property Rights. Report of the Commission on Intellectual Property Rights, Innovation and Public Health (CIPIH). Available at http://www.who.int/intellectualproperty/en/, last accessed $27 / 10 / 07$

WHO (World Health Organisation) (2007b). Global health diplomacy: training across disciplines. In, Bulletin of the World Health Organisation, December 2007, 85 (12). Available at http://www.who.int/bulletin/volumes/85/12/07-045856.pdf , last accessed 10/11/07

WHO (World Health Organisation) (2007c). Obesity ranking. Available at www.WHO.org, last accessed 3/12/07 
WHO (World Health Organisation) (2007d). Trade policy and health: from conflicting interests to policy coherence. In, Bulletin of the World Health Organisation, March 2007, 85 (3). pp.169-173. Available at http://www.who.int/bulletin/volumes/.pdf , last accessed $10 / 11 / 07$

WHO/HPR/HEP/95.1 at www.who.int, last accessed 12/11/07, for a description of the Ottawa Charter

Winters, A. (2005). Small economies in a globalizing world: the policy challenges ahead. In, Pacific Economic Bulletin 20 (3) pp. 94 - 102. Asia Pacific Press, based at Australia National University, Canberra. Available at http://www.peb.anu.edu.au, last accessed 8/1/08

Winters, A. (2003). Trade policy as development policy: Building on fifty years' experience. In, Toyes, J.F.J., (ed) Trade and Development: Directions for the $21^{\text {st }}$ Century. Published in association with the United Nations Conference on Trade and Development (UNCTAD). Edwards Elgar Publishing, New York. pp. 62-82

Youth Research (1997). Naked wire and naked truths: a study of reproductive health risks faced by teenage girls in Honiara, Solomon Islands. In, Pacific Aids Alert Bulletin, Hawaii (16) pp.11-12 


\section{Recommended websites}

Several recommended websites (in no particular order) providing information about the relationships between economic globalisation, international trade agreements, TRIPS and economic policy, and public health.

www.cpath.org - Center for Policy Analysis on Trade and Health

www.cptech.org - Consumer Project on Technology

www.keionline.org - Knowledge Ecology International

$\underline{\text { www.IP-health }}$ - Intellectual property relating to health watch

$\underline{\text { www.IP-watch }}$ - Intellectual property watch

http://www.ciel.org/ - Centre for International Environmental Law

http://www.twnside.org.sg/heal.htm - Third World Network

http://www.msf.org/ - Médecins Sans Frontières

www.ictsd.org - International Centre for Trade and Sustainable Development

http://www.3dthree.org/en/ - trade, human rights, equitable economy

http://www.southcentre.org/ an intergovernmental organisation of developing countries

http://www.oxfam.org/en/ - Oxfam International

http://cgkd.anu.edu.au/ - Centre for Governance of Knowledge and Development, Aust

National University, publishers such as Peter Drahos.

http://www.vanuatu.usp.ac.fj, - useful documents on civil society in the Pacific are available in the South Pacific Civil Society Library 


\section{Appendices}

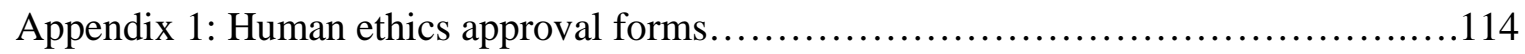

Appendix 2: Question/themes covered in interviews................................119

Appendix 3: Description of key trade agreements................................ 120

Appendix 4: Overview of intellectual property rights in the Pacific.................... 126

Appendix 5: Protecting access to medicines: suggested regional and national responses in the Pacific.............................................. 134 


\section{Appendix 1: Human Ethics Approval Forms}

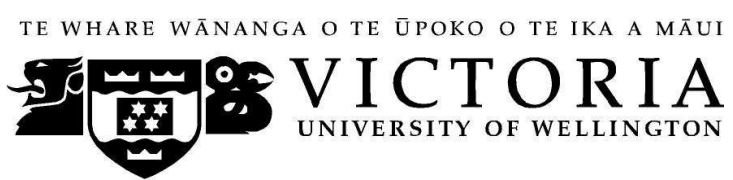

MEMORANDUM
Phone 0-4-463 5676

Fax $\quad 0-4-4635209$

Email_Allison.kirkman@vuw.ac.nz

\begin{tabular}{l|l}
\hline TO & Sarah Meads \\
\hline COPY TO & Professor John Overton, Supervisor \\
\hline FROM & Dr Allison Kirkman, Convener, Human Ethics Committee \\
\hline
\end{tabular}

\begin{tabular}{l|l}
\hline DATE & 1 October 2007 \\
\hline PAGES & 1 \\
\hline
\end{tabular}

SUBJECT Ethics Approval: No 129/2007, The impact of international trade agreements on access to essential medicines in Fiji: national and regional responses.

Thank you for your application for ethical approval, which has now been considered by the Standing Committee of the Human Ethics Committee.

Your application has been approved and this approval continues until 31 January 2008. If your data collection is not completed by this date you should apply to the Human Ethics Committee for an extension to this approval.

Best wishes with the research.

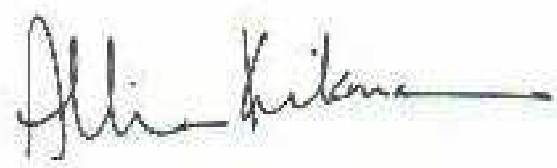

Allison Kirkman

Convener 


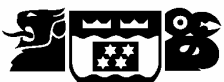 \\ INFORMATION SHEET}

\section{Putting a Public Health Perspective into International Trade Negotiations and Trade Related Intellectual Property Rights in Developing Countries: A human rights-based approach to accessing essential medicines - Fiji as a case study}

Dear Project Participant,

My name is Sarah Meads and I am a Masters student in Development Studies at Victoria University of Wellington. As part of this degree I am undertaking a thesis research project. The project will investigate the extent to which trade obligations, such as Trade Related Intellectual Property Standards (TRIPS), restrict access to essential, affordable medicines in Fiji. My intention is to identify responses Fiji may use, either at a national or regional level, to mitigate any adverse restrictions, particularly during trade negotiations. I have obtained ethics approval from the University before involving human participants.

I am inviting over 20 participants from several different government and non government organisations associated with health development and medicines procurement in particular, to participate in this study over a three week period. Participants will be interviewed on an individual basis. They will be asked a series of semi-structured questions prompted by a check list that I have prepared in advance. Questions will not be of a personal nature and you have the right to refuse to answer any question at anytime. The interview is expected to take one hour. I will record the interview either on an audiotape recorder, or by taking notes, and type up the main points as a draft transcript after the interviews are complete. You will be given an opportunity to modify the draft transcript of your interview before it is finalised for use in my thesis.

Information from the interview will form the basis of my research project. It will not be possible for you to be personally identified, or for your organisation to be named, unless you 
are comfortable with this and have signed an 'Informed Consent Form' to that effect. All material collected will be kept confidential. No other person besides myself and my Supervisor, Professor John Overton, will see the transcripts or hear any audiotape recordings of the interview.

The thesis will be submitted for marking to the School of Geography, Environment and Earth Sciences and a copy kept in the University Library. It is possible that one or more articles will be submitted for publication in scholarly journals. Transcripts of the interview will be destroyed and any audiotape recordings will be electronically wiped two years after the end of the project unless you indicate that you would like them returned to you.

Should you feel the need to withdraw from the project, you may do so without question at any time before the information is analysed.

If you have any questions about this project or would like to receive further information, please feel free to ask me now, or to contact me later on ++ 64-4-934-0081 or smeads@paradise.net.nz or my supervisors, Professor John Overton, at the School of Geography, Environment and Earth Sciences at Victoria University of Wellington, P O Box 600, Wellington, phone ++64-4- 472-1000 and/or Dr Peggy Fairbairn-Dunlop, Associate Professor Va'aomanu Pasifika, at the School of Humanities and Social Sciences, Victoria University of Wellington, phone ++64-4-463-6867.

I wish to thank you most sincerely for participating.

Yours sincerely

Sarah Meads

(Student enrolled in Master of Development Studies, Victoria University of Wellington) 
VICTORIA UNIVERSITY OF WELLINGTON

Te Whare Wananga o te Upoko o te Ika a Maui

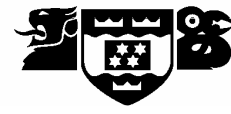

\section{CONSENT TO PARTICIPATION IN RESEARCH}

\section{Putting a Public Health Perspective into International Trade Negotiations and Trade Related Intellectual Property Rights in Developing Countries: A human rights-based approach to accessing essential medicines - Fiji as a case study}

I have been given, and have understood, an explanation of this research project. I have had an opportunity to ask questions and have them answered to my satisfaction. I understand that I may withdraw myself (or any information I have provided) from this project (before information collection and analysis is complete) without having to give reasons or without penalty of any sort.

I understand that any information I provide will be kept confidential to the researcher, the supervisor. The transcript of the interview will be destroyed and audiotape recordings will be electronically wiped two years after the end of the project unless I indicate that I would like them returned to me.

\section{Please cross-out which is not appropriate:}

I agree to take part in this research

I consent to information or opinions which I have given being attributed to me in this research thesis and in any articles or reports related to this research

I wish to remain anonymous so that information or opinions which I have given and that are being used in this research thesis and in any articles or reports related to this research does not identify me. 
I understand that I will have an opportunity to check and to modify the draft transcript of my interview before publication.

I understand that the information I provide will not be used for any other purpose or released to others without this written consent.

I would like to receive a copy of the summary of this research thesis when it is completed.

I would like the audio tape recordings, if that was the method used to record my interview, to be sent to me at the conclusion of the project.

Participant:

Name:

Signature:

Date:

Researcher:

I certify that this form and its attached "Information Sheet" cover letter provide a complete and accurate description of the aims and processes of this research project.

Name: $\underline{\text { Sarah Meads }}$

Signature:

Date: 


\section{Appendix 2: Themes covered in field research interviews}

1. Elaboration of the process of medicines selection and procurement by the Fijian government and private sector and of how global procurement schemes, eg.Global Fund, function in Fiji.

2. The extent to which these are influenced by regional integration, in particular, the review of collective medicines procurement, the review of regional intellectual property rights and the process of conducting regional trade negotiations, eg. EU EPA.

3. Identification of any reported restrictions of trade-related factors on access to essential medicines in Fiji.

4. Evaluation of any desirable essential medicines, or medicine groups, not currently procured because trade-related factors restrict their access.

5. Elaboration of the mechanisms used to assess the potential impact of regional trade agreements on access to medicines in Fiji and how this is factored into the national and regional trade negotiations process.

6. Identification of strategic and policy responses Fiji may use, either at a national or regional level, to mitigate adverse restrictions, particularly during trade negotiations and the process of regional integration. 


\section{Appendix 3: Description of the key international trade agreements}

\subsection{Bilateral Trade Agreements}

Fiji is partied to non-reciprocal bilateral trade agreements (BTAs) with small island states of the Forum such as Tonga, Tuvalu and the Cook Islands, and reciprocal agreements with larger trading partners that have the capacity to trade with Fiji on an equal footing, for example, Papua New Guinea, Vanuatu, Australia and China. Negotiations for BTAs are continuing with New Zealand, Solomon Islands, Kiribati, Nauru, Samoa and New Caledonia (The Republic of the Fiji Islands Ministry of Foreign Affairs and External Trade, 2006).

\subsection{Regional Trade Agreements}

Fiji's regional trade agreements (RTAs) include the Melanesian Spearheads Group (MSG), which Fiji joined in 1998 with the founding participants: PNG, Vanuata and Solomon Islands; the South Pacific Regional Economic Cooperation Partnership (SPARTECA); the Pacific Island Countries Trade Agreement (PICTA), and the Pacific Closer Economic Relations (PACER). Fiji is also a member of the African, Caribbean and Pacific (ACP) group engaged in negotiations for an Economic Partnership Agreement (EPA) with the EU. The major regional trade agreements are described below.

\subsection{SPARTECA}

In 1981 Australia and New Zealand guaranteed 13 Pacific Island Countries (PICs) nonreciprocal preferential access for a long list of exports under the SPARTECA. This was critical to the establishment of the textile and garment industry in Fiji, reinforced by the Free Economic Zones established under the first Rabuka Government. By 1999 Australia was taking 70\% of Fiji's total textile exports (Kelsey, 2004) accounting for 26\% (1997) of Fiji's total domestic exports. The Australian government introduced a self fulfilling Import Credit Scheme (ICS) which ran foul of WTO Rules of Origin and was replaced in 2001 by the SPARTECA Textiles, Clothing and Footwear (TCF provisions). The benefits have since 
reduced in the face of NZ and Australia lowering tariffs to imports from China and Asia and cheaper competition forcing down garment worker wages to below the poverty line. In August 2004, Australia announced it would be extended for seven years with a review after three years, however the benefits for renewal of SPARTEC-TCF are diminishing as a result of these trends.

\section{$2.2 \quad$ PICTA}

In 1999 Pacific Island Forum Leaders endorsed, in principle, a free trade area among Forum Members. In 2001, 9 PICs ${ }^{55}$ signed the Pacific Island Countries Trade Agreement (PICTA) which is now in place and, together with Australia and New Zealand signed the Pacific Agreement on Closer Economic Relations (PACER), seen as an umbrella agreement for PICTA.

Fundamentally, PICTA is supposed to lead to a free trade area amongst ratifying PICs. Tariff and non-tariff barriers to PICTA trade are to be gradually removed over the next ten years for products which have at least $50 \%$ of PIC value added. If all the parties ratified it is expected to create a consumer base of over 7 million. Theoretically the concept is seen as a 'training ground' for lifting competitiveness and an economic 'stepping stone' to the eventual integration with multinational trading system.

However, many international studies have concluded that developing countries, especially small island developing states, will not do as well setting up free trade areas amongst themselves (see for example Narsey, 2006) compared with a developed country. This is due to the tendency in small markets for monopoly domination, lack of scales of economy, resistance to trade and likelihood of loss of jobs. Theoretically, if PICTA succeeds in the medium term, and PACER also comes into effect, then investors are likely to invest in areas they know will have a fast turnaround of their capital before their industries eventually collapse under competition with Australia and New Zealand.

\footnotetext{
${ }^{55}$ Fiji, PNG, Solomon Islands, Tonga, Samoa, Cook Islands, Niue, Nauru and Kiribati have ratified. Vanuatu and Tuvalu have not yet signed, while the three Compact countries have been given a grace period
} 
Furthermore, there has been external pressure from the EU for PICs to form a regional trading bloc arguing that the post-Cotonou EPAs will be facilitated if the PICs are bound by an FTA, which then would facilitate the WTO compatibility of the EPAs.

The Pacific Plan, signed off in 2004 by Pacific Forum Leaders is a framework for coordinating dialogue and research on regionalism and the economic and social gains this may bring for Pacific Island people.

\subsection{PACER}

PACER is the agreement signed and ratified by all PICs and Australia and New Zealand. Negotiations are scheduled to begin eight years after the PICTA came into force (in 2013) unless they are triggered earlier by PICs granting significant tariff reductions to other developed countries, for example, the EU through the EPAs. It has been described by Kelsey as a 'reactive' agreement, protecting the trading interests of Australia and New Zealand (Kelsey, 2004). However, access to labour markets in Australia and New Zealand under the PACER agreement would represent a significant advantage to PICs.

\section{$2.4 \quad$ EPA}

Fiji is signatory to the Lome Convention under which the European Union (EU) grants nonreciprocal trade preferences to countries in Africa, the Caribbean and the Pacific (ACP States). The EU ACP trade negotiations is a legacy of the British Empire and the incorporation of preferential trading arrangements in Lome Conventions since 1975 with their ex-colonies. As is the present case in Fiji, the 'rent-seeking' governments and elites were in many cases the beneficiaries rather than the poor and proved an obstacle to industrial productivity (Robertson, 2006).

The economic, political and aid dimensions of the Lome Conventions reflected Europe's development ideology. By the time of Lome IV in the 90's, aid funding through the European 
Development Fund was used to complement the World Bank structural adjustment agenda, requiring ACPs to pursue neoliberal policies in the name of development (Kelsey, 2005).

In 2000 a new partnership, the Cotonou Agreement, was announced requiring ACP countries to implement reforms and replace trade preferences with reciprocal rights for European goods to have access to their markets. Aid was bound to trade, making it conditional for ACPs to display 'good governance' before being rewarded with aid.

The EU ACP Partnership Agreement is the most important foreign policy instrument of the EU . This is because the majority of the WTO membership involved with the EU regard the Agreement as an essential element in an overall strategy for the evolution of global trading arrangements.

Economic and trade conditions under Cotonou are required to produce 'WTO compatible' outcomes, bringing non WTO members within the ACP under its rules. Moreover the EU Commission secured 'WTO-Plus' negotiations, including the issues of competition policy and investment that ACP States have steadfastly resisted in the WTO. Negotiations on services are designed to advance the current WTO negotiations on GATS. For two Pacific Islands these requests include reducing foreign ownership restrictions on land (Kelsey, 2005).

The alternatives available to ACPs that decide not to participate, the 'Everything But Arms' option for LDCs and the 'Generalised System of Preferences' for developing countries, carry fewer risks, but leave those countries at the whim of the EU, which can alter, or eliminate, those arrangements at will.

As part of the new convention between ACP countries and the EU, there is a move towards Regional Economic Partnership Agreements (REPAs) whose objectives are the progressive removal of barriers to trade between the parties in accordance with WTO negotiations.

Very little of the PICs duty revenues will be directly at risk because of reduction of duties on imports from the EU. Thus while the EPAs will not pose any great danger to Pacific ACP 
fiscal stability, their triggering of PACER will have drastic consequences, because they would have to offer the same concessions to New Zealand and Australia, reducing their revenue from import duty. Percentages of total import duty lost if duty on $90 \%$ of imports from Australia and New Zealand were reduced would mean none lose $38 \%$ of revenue (Narsey, 2006). The EU however, is not expected to make any concessions as they could set a precedent for other larger ACP states or developing countries.

In early December 2007, under trade negotiation deadlines set by the EU, rather than a regional agreement being signed between the EU and the 14 PICs, both Fiji and PNG signed individual trade agreements. The implications of these agreements for the countries and the region as a whole are still being analysed.

\subsection{Sugar Protocol Agreement}

The Lome and Cotonou supply agreements with the EU underlay Fiji's export-led growth through sugar in the mid to late twentieth century. Fiji, along with sugar producers from the ACP group has depended on an annual export quota to the EU, at prices aligned with the price of sugar within the EU itself.

At the WTO, the EU recently lost a case mounted by Australia, Brazil and Thailand against its subsidised sugar exports, and also lost its subsequent appeal against the decision. The EU therefore announced the regime would be overhauled.

The EU has proposed price cuts, due to begin 2005, but extended to 2006. Negotiations are ongoing, however, in 2006 these cuts were predicted to result in a 23\% fall in the price of sugar to Fiji (Narsey, 2006).

The Fijian Cabinet approved in principle a reform plan for the sugar industry, which was prepared by Indian Experts, and commenced negotiating with the EU for aid to overhaul the industry. These negotiations were stalled after the 2006 coup, when aid was withheld until certain conditions were met by the military, for example a date set for a democratic election. 


\subsection{Multilateral Trade Agreements}

Fiji acceded to the GATT in 1993, becoming a member of the WTO in 1996. It accords at least Most Favoured Nation (MFN) tariff status to all its trading partners. As part of its undertakings in the Uruguay Round, Fiji bound all its agricultural tariffs and some 43 per cent of its industrial lines. Under the General Agreement on Trade in Services (GATS), Fiji has scheduled commitments to grant foreign suppliers the rights to establish a commercial presence and to invest in two sectors, hotels and restaurants.

Fiji is working towards WTO TRIPS compliance. 


\section{Appendix 4: Overview of intellectual property rights in the Pacific region}

\subsection{WIPO intellectual property treaties}

The Paris Convention, administered by WIPO, is the key Treaty dealing with substantive patent law. Many of its provisions are incorporated by reference into the WTO TRIPS Agreement. Through this web of obligations under the WIPO and WTO frameworks, PNG, Tonga, Fiji and Solomon Islands have international obligations regarding substantive patent law. WIPO has been active in the region providing technical assistance for countries to join and implement the various treaties that it administers. The status of PICs under the various Treaties is summarised in Table 3 below.

The Patent Cooperation Treaty (PCT) is a registration treaty and simplifies the process of applying for patent protection in member countries. A single PCT 'international' application can be used to apply simultaneously for patent protection in all PCT member countries. This is in contrast to the national registration system under Treaties such as the Paris Convention which requires individual applications to be filed in each country where patent protection is sought. At present only PNG is a member of PCT. If other PICs join the Treaty, the currently low rate of patent registration in the region could escalate dramatically. This may raise a barrier to some generic drugs being imported and increase the price of patented drugs for the PICs. 
Table 3: Summary of Country Development Status, WTO Membership, and IP Treaty

\section{Membership}

\begin{tabular}{|c|c|c|c|c|}
\hline $\begin{array}{l}\text { Country } \\
\text { DC/LDC }\end{array}$ & $\begin{array}{l}\text { WTO Membership Status } \\
\text { And TRIPS Agreement } \\
\text { (Tot. members 149) }\end{array}$ & $\begin{array}{l}\text { Paris } \\
\text { Convention } \\
\text { Treaty } \\
\text { (Tot. mbers } \\
\text { 169) }\end{array}$ & $\begin{array}{l}\text { PCT Treaty } \\
\text { (Tot. } \\
\text { members } \\
\text { 128) }\end{array}$ & $\begin{array}{l}\text { WIPO } \\
\text { Convention } \\
\text { Membership } \\
\text { (Tot. mbers } \\
\text { 183) }\end{array}$ \\
\hline $\begin{array}{l}\text { Fiji } \\
\text { DC }\end{array}$ & $\begin{array}{l}\text { Member } 1996 \\
\text { (former GATT member) }\end{array}$ & & & Member1972 \\
\hline $\begin{array}{l}\text { PNG } \\
\text { DC }\end{array}$ & $\begin{array}{l}\text { Member } 1996 \\
\text { (former GATT member) }\end{array}$ & $\begin{array}{l}\text { Member } \\
1999\end{array}$ & $\begin{array}{l}\text { Member } \\
2003\end{array}$ & Member 1997 \\
\hline $\begin{array}{l}\text { Solomon } \\
\text { Islands } \\
\text { LDC }\end{array}$ & $\begin{array}{l}\text { Member } 1996 \\
\text { (former GATT member) }\end{array}$ & & & \\
\hline $\begin{array}{l}\text { Tonga } \\
\text { DC }\end{array}$ & $\begin{array}{l}\text { Working Party on accession established } 15 \\
\text { Nov } 1995 \text {, WTO members approved } \\
\text { Tonga's terms of accession at the } \\
\text { Ministerial Meeting, Dec } 2005 \text {. Ratified by } \\
\text { Govt of Tonga in July } 2007 \text {, becoming } 150^{\text {th }} \\
\text { member }\end{array}$ & $\begin{array}{l}\text { Member } \\
2001\end{array}$ & & Member 2001 \\
\hline $\begin{array}{l}\text { Samoa } \\
\text { LDC }\end{array}$ & $\begin{array}{l}\text { Working party on accession established July } \\
\text { 1998. Samoa submitted initial offers in } \\
\text { goods and services and informal } \\
\text { consultations held 2003. Still working } \\
\text { through the process of accession in } 2007 \text {, } \\
\text { however the Working Party terms appear to } \\
\text { include harsh provisions }\end{array}$ & & & Member 1997 \\
\hline $\begin{array}{l}\text { Vanuatu } \\
\text { LDC }\end{array}$ & $\begin{array}{l}\text { Final meeting of the Working Party held on } \\
\text { Oct } 2001 . \text { Vanuatu postponed forwarding to } \\
\text { WTO General Council after realizing giving } \\
\text { away too much in accession package. Still } \\
\text { under review }\end{array}$ & & & \\
\hline
\end{tabular}

Source: Ey, F. (2005). pp. 14 and 15

Key: 'DC' - Developing Country; 'LDC' - Least Developed Country (as per UN classification). All the countries in the PICs are also classified by the UN as Small Island Developing States (SIDS) 


\subsection{WTO membership}

WTO membership and accession, are key drivers for patent law reform in the Pacific, as they are in many other regions. The current status of WTO membership is summarised in Table 3.

Fiji and PNG have to provide patent protection for pharmaceutical products from 1 January 2005, however, because it is an LDC, the Solomon Islands does not have to comply until 2016. The Solomon Islands also has until 2013 to implement other elements of TRIPS Agreement. Under its WTO accession package, Tonga has until 1 June 2008 to implement TRIPS obligations.

For countries seeking to accede to the WTO, these timeframes are determined by the terms of their accession. Samoa and Vanuatu, both LDCs, should seek to have these extended timeframes included in their WTO accession packages. However, in June 2007, the proposed accession package for Samoa contained tough obligations which attempt to 'bring forward' TRIPS implementation and to include TRIPS-plus provisions such as data exclusivity ${ }^{56}$.

\subsection{Main features of national patent laws and patent activity}

Patent laws in the Pacific vary widely across the region. They are influenced by factors such as WTO membership activity, donor assistance and colonial-era regimes, summarised in Table 4 below. These differences are broadly classified under three categories:

(i) Registration countries: only re-register United Kingdom (or other overseas) patents and do not have the capacity to examine and register in their own country eg. Kiribati, Nauru, Solomon Islands, Tuvalu and Vanuatu;

(ii) WTO-based reform countries: these states have joined WTO, or are in the process of doing so, and have revised their patent laws to be TRIPS-consistent eg. PNG, Tonga and Vanuatu (although Vanuata's legislation has not yet commenced operation as law). In some cases the legislation is 'TRIPS-plus' going beyond the minimum standard

56 Personal correspondence with Oxfam New Zealand re.evaluation of Samoa's WTO accession package, July 2007 
required by the WTO TRIPS Agreement. WIPO has been active in providing technical assistance to these countries, including drafting and providing model laws. As a consequence, there are many similarities in the legislation in these countries;

(iii) Transitional countries: in the process of reviewing and amending their patent regimes, either to update colonial era or early post-colonial laws to ensure TRIPS compliance. These reviews are undertaken in the context of either the country being a WTO member (as for Fiji) or seeking to accede to the WTO (as for Samoa). This is particularly the case for compulsory licencing where some countries do not take full advantage of the TRIPS flexibilities. For example, Fiji has been redrafting national patent law to remove some of the 'inflexibilities' with support from external experts such as Dr Carlos Correa, a prominent IPR expert advocating for developing countries.

\section{Table 4: Patent laws in the Pacific Island Countries}

\begin{tabular}{|c|c|c|}
\hline Category & Country & Patent Law \\
\hline Re-registration & $\begin{array}{l}\text { Kiribati } \\
\text { Nauru } \\
\text { Solomon Islands } \\
\text { Tuvalu } \\
\text { Vanuatu }\end{array}$ & $\begin{array}{l}\text { Re-registration of United Kingdom Patents Ordinance (Cap 87) } \\
\text { Patents Registration Act } 1973 \\
\text { Registration of United Kingdom Patents Act } \\
\text { Re-registration of United Kingdom Patents Ordinance (Cap 61) } \\
\text { Registration of United Kingdom Patents Act (Cap 80) }\end{array}$ \\
\hline $\begin{array}{l}\text { WTO-based } \\
\text { reform }\end{array}$ & $\begin{array}{l}\text { Papua New Guinea } \\
\text { Tonga } \\
\text { Vanuatu }\end{array}$ & $\begin{array}{l}\text { Patents and Industrial Designs Act } 2000 \\
\text { Industrial Property Act } 1994 \\
\text { Patents Act } 2003 \text { (not yet in force) }\end{array}$ \\
\hline Transitional & $\begin{array}{l}\text { Fiji } \\
\text { Samoa }\end{array}$ & $\begin{array}{l}\text { Patents Act (Cap 239) Patent Bill under consideration - based } \\
\text { on UK and Singapore patent legislation } \\
\text { Patents Act } 1972\end{array}$ \\
\hline
\end{tabular}

Source: Ey, F.(2005) pp. 19

Patent offices in each country are usually a small office that deals with all IP rights and in many countries it is combined with the company's registry. PNG has a patent office with the greatest capacity.

Generally the Patent Office is responsible for three functions: (i) searching (ii) examination and the granting of patent applications, and (iii) administration of a register of patents that 
have been granted, working within the context of the national patent laws. In some countries, their function is limited to re-registration of patents already granted in another nominated country., for example the United Kingdom, while in others, all patents are registered without scrutiny and their validity is tested in court if they are appealed.

Search and examination capacity is limited and IP Australia has an arrangement to provide patent searches and examination for the IP offices of Tonga, Fiji and PNG (Farquhar, 2005).

Patent activity is very low in the Pacific. The vast majority of applications are made by foreign applicants and many are in the pharmaceutical categories. This can be expected to increase rapidly, as experienced by other developing countries, if TRIPS obligations or PCT was introduced to more countries in the region. This could happen as a result of three independent mechanisms: (i) trade agreements such as EU EPA or PACER, (ii) collective medicines procurement which triggers a review (and harmonisation) of IPR amongst the countries that take part, or (iii) a review of collective medicines regulation which results in joining the proposed joint Aust/NZ TGA that already incorporates TRIPS-plus patent obligations Australia inherited under the Australia/US free trade agreement.

\subsection{Doha declaration and 'paragraph 6 decision' application in the Pacific}

There are two factors that currently limit the application of the "Paragraph 6 Decision" in the Pacific region: (i) it only applies to PICs that are WTO members (PNG, Fiji, Solomon Islands, Tonga) that are bound by the WTO TRIPS Agreement (ii) the low patent activity in the region means that it is less likely a compulsory licence needs to be issued to overcome a patent.

The Decision could be of significance to the WTO members given that their health priorities include combating rising levels of HIV/AIDS and many of the new and second generation drugs are on patent. However, there is again an issue about whether there are patents in force for relevant medicines that require a compulsory licence mechanism.

The "Paragraph 6 Decision" incorporates a regional mechanism for pharmaceutical 
procurement and production. This is based on establishing a regional exporting hub in which a country either manufactures and exports to other countries under a regional trade arrangement or imports pharmaceuticals under a compulsory licence and re-exports.

The regional mechanism has a number of strict parameters however which limits its application in the Pacific. Firstly it requires a pre-existing regional trade agreement rather than a political or economic grouping of states. Secondly, at least half of the current membership must be LDCs (PICTA currently has nine member countries of which three are LDCs). At the sub-regional level, Vanuatu and Solomon Islands are LDCs in the Melanesian Spearhead Group Trade Agreement with Fiji and PNG, however, it is far from a comprehensive regional mechanism. Thirdly, both the manufacturing country and the receiving country must share the disease in question.

Lastly, this model was conceived using regional arrangements based in Africa. These make assumptions about the existence of regional patents and health, political and economic parameters that do not apply in the Pacific. For example, in Africa the regional models have their roots in regional patent laws that facilitate the re-export of pharmaceuticals whereas, in the Pacific there is no regional system, patent laws vary, and there is resistance to forfeit sovereign patent systems for a regional system.

A more effective means of harnessing the benefits of a regional approach in the Pacific would be through a pooled procurement mechanism outside of the WTO framework. Such a regional mechanism is under review by WHO, PIFS and SPC.

\subsection{Intellectual property rights: regional initiatives}

The PIFS have been facilitating IP initiatives in the region since 2000 in cooperation with agencies such as WIPO and IP Australia (PIFS/WIPO/IP Aust, 2001). WIPO has been active in the Pacific providing technical assistance for countries to join and implement the various treaties that it administers. IP Australia is the Australian government agency that administers patents, trade marks and designs in Australia. The Australian government is positioning IP 
Australia to provide services to the greater Pacific region, including some services to New Zealand.

In 2004, PIFS, WIPO and IP Australia finished implementing a three year 'Regionally Focused Action Plan' (RFAP) in the Pacific which included work on regional IP administration (PIFS/WIPO/IP Aust, 2001). Two models under review include:

(i) stand-alone: a stand-alone regional patent administration ie. PICs undertake their own searching and examination using shared resources based in a joint regional office;

(ii) outsourced: a regional patent administration located in a central office in the PICs, however, substantive searching and examination outsourced, for example to IP Australia.

The PIFS did not renew the IPR contract with WIPO and IP Aust. Both organisations continue to work with PICs bilaterally. If further research into a regional facility is progressed, there will be a number of issues to be resolved, including the relationship between the regional facility and national offices and laws, the level of fees to be charged and possible loss of skills and expertise in national IP offices. The costs and benefits of a regional IP office have also been considered as part of the Pacific Plan (Farquhar, 2005) and are earmarked for further analysis.

\subsection{IPR, traditional knowledge and medicines}

Traditional knowledge (TK) and medicines are used locally, often in preference to, or to complement, conventional medicines. The principle of integrating traditional knowledge (TK) and medicines into the public health system is promoted by the WHO on cultural and cost effectiveness grounds. The key to more effective integration lies in the standardisation of medicines dispensed under these systems, the training of providers and the issuance of guidelines on their use. As in most other countries however, the two systems generally remain philosophically and scientifically separate. 
Traditional medicines systems could also serve as a base for bio-prospecting, for example, an official traditional medicines research centre is operating in Kiribati and Samoa. However, currently there is no international IPR Treaty for TK which leaves the PICs, and other developing countries, unprotected against 'biopiracy' (the act of foreign firms commercialising plant and animal extracts and genetic material that have traditionally been used or owned by indigenous groups without authorisation and for commercial gain).

WIPO, WHO and WTO acknowledge that eventually an international Traditional Intellectual Property System (TIPS) will need to be developed. This would govern bioprospector's use of TK and ensure indigenous people's authorise its use and share in any commercial benefits. In its absence TK law is being developed ad hoc at a country level or between regional trading blocs. For example, in New Zealand the Ministry of Economic Development has recently engaged with the New Zealand public and private sector on developing TK law as currently there are no recognised guidelines on bioprospectors' use of TK in New Zealand. In contrast, a form of TK patent law has existed in Peru and China for several years.

PICs continue to face unauthorised use of their TK, innovations and practices (Mead and Ratuva, 2007). While conventional IP laws exist in all PICs, to protect certain forms of IP, in the main they fail to protect TK from exploitation. The model law on 'Traditional Biological Knowledge, Innovation and Practices' developed for the Pacific region both complements conventional IP laws and overrides them.

Drafted in 2000 by the Secretariat of the South Pacific Environmental Programme (SPREP), the framework provides PIC officials with a starting point for dialogue at regional meetings. The model law requires further development which is proposed to be led by the PIFS in $2008 / 2009$. 


\section{Appendix 5: $\quad$ Protecting access to medicines: suggested regional and national responses in the Pacific}

The research findings, together with suggestions made by interview participants and personal observations, were used to compile a range of multidisciplinary responses to help mitigate trade restrictions on access to medicines at the national and regional level. The responses are designed to assist with the mainstreaming of public health development into trade policymaking. This will enable any adverse effects on the health sector to be considered during trade negotiations and the design of regional institutions. The responses are categorised into four main areas (advice given to trade negotiators, drafting IPR law and regional IPR initiatives, monitoring pharmaceutical patents and, integrating health into trade policymaking) and presented as summarised bullet points (in no particular order) under each of the key health stakeholders.

\subsection{Technical advice given to national and regional trade negotiators}

\section{Pacific Islands Forum Secretariat (PIFS):}

- Establish formal mechanisms to scrutinise international trade agreements from a public health perspective ( For example, previously PIFS arranged for the draft EU EPA agreement to be critiqued by a group of pro-poor development IPR and health experts associated with Dr Carlos Correa. Their response was then circulated to Forum Leaders and trade negotiators).

- Build policy and programme coherence with SPC in the trade and health sector

- Advocate for WTO TRIPS safeguards and exemptions in national and regional IPR law and in trade agreements

- In conjunction with health stakeholders, provide capacity building relating to knowledge of IPR laws, implementation of WTO flexibilities and exemptions, and impact analysis of trade agreements on health

\section{Secretariat for the Pacific Community (SPC):}

- Incorporate health economics and trade into current policy and programmes

- Shift focus from technical assistance to include strategic, policy advice on health, including 
the impact of trade on access to medicines

- Take the lead on trade and access to medicines in joint WHO/SPC initiatives and as an advisor to PIFS

\section{UN agencies:}

- Exchange knowledge and expertise on access to medicines from other regions in the South where a high profile already exists

- $\mathrm{WHO}$ - undertake empirical studies of affordability and efficacy of government procured drugs and population health trends to build evidence based research for monitoring pharmaceutical patents and mitigating trade impediments to access to medicines in the future

\section{National Governments:}

- Clearly identify public (health)goods priorities that are non negotiable in trade negotiations

- Do the minimum in terms of commitment to international IPR standards

- Provide capacity building relating to knowledge of IPR laws and implementation of the WTO flexibilities and exemptions

- Formalise regular meetings with MFAT, MOH, FPS and other stakeholders on access to medicines

\subsection{Drafting intellectual property law and regional IPR initiatives}

\section{Pacific Islands Forum Secretariat (PIFS):}

- Promote a paradigm shift amongst Forum Leaders of IPR as an instrument of development policy that may protect national sovereignty, reinforce existing rights to public goods, and help to achieve social, cultural and health development goals. In contrast, IPR currently appears to be viewed primarily from an economic perspective as an instrument for the PICs to gain commercial advantage. However, as 'net users' of IPR, rather than 'net generators', the PICs appear to be investing limited resources in the development of traditional knowledge on the basis that this may generate financial returns in the future. This mindset may inadvertently limit IPR development in the short term and lead to existing rights to access public goods being traded away

- Allocate resources to develop IPR strategy guidelines as requested by the CROPS 
- Re-commence IPR national and regional design initiatives using (independent) international experts and a multi-sector approach to review alternative IPR models. The review should take into account key drivers influencing the global IPR agenda and its implications for the Pacific region, the potential indirect costs this could generate for public goods, such as health, as well as considering an existing ADB report on the cost/ benefit analysis of regional IPR mechanisms (Farquhar, 2005) which appears to have a narrower Terms of Reference

\section{UN agencies:}

- Provide technical assistance on the use of competition law and other national exemption mechanisms to mitigate trade impediments to access to medicines

\section{National Government:}

- Evaluate national IPR law to ensure minimum WTO TRIPS safeguards are incorporated (see below), delay for as long as possible joining PCT

- Do the minimum in terms of commitment to international IPR standards, including:

$>$ supporting parallel importation,

$>$ Compulsory License is subject to conditions under TRIPS Article 31 only,

$>$ limit the scope and duration of data exclusivity under TRIPS Article 39.3,

$>$ grant patents only for truly new and inventive products/processes TRIPS Art. 27.1,

$>$ no linkage between patents and drugs registration,

$>$ create national exemption mechanisms, for example, competition law

- Develop a simple and easy to use compulsory licence system at national and regional level

- Fijian Ministry of Justice - speed up progress of national draft IPR Bill to ensure TRIPSplus provisions are removed (Correa, 2003)

\subsection{Monitoring pharmaceutical patents}

\section{Pacific Islands Forum Secretariat (PIFS):}

- Promote the monitoring of pharmaceutical patents and assist with capacity building for this

\section{UN agencies:}

- Share knowledge amongst the PICs relating to monitoring of pharmaceutical patents

- Establish a 'hotline' to help countries ascertain pharmaceutical patent status 
- Assist to negotiate with pharmaceutical companies not to insist on pharmaceutical patent protection

\section{National Government:}

- Establish a formal preventative mechanism where Patent Office notifies MOH of every pharmaceutical patent registered

- Establish an Expert Group to monitor pharmaceutical patent examinations, for example, the Brazilian Model, against appropriate criterion and to oppose if necessary, during pre-grant phase

- Train professionals in the field of interpreting pharmaceutical patents, including lawyers, pharmacists, economist, chemists, medical doctors

- Implement methods for delaying registration, such as increased filing fees and bureaucratic delays, to deter patent holders from automatically filing in several countries

\subsection{Integrating health into trade and property rights}

\section{Pacific Islands Forum Secretariat (PIFS):}

- Establish a formal working group on IPR, trade and health which includes ALL trade and health-related stakeholders

- Ensure seamless policy and programmes with SPC on trade implications on health development

- Include trade and access to medicines in existing and any future regional health development strategies signed off by the Forum Leaders, for example Regional HIV/AIDS Strategy

- If a human rights desk is established in the future, include rights to access to medicines

\section{Secretariat for the Pacific Community (SPC):}

- Build a strategic policy role, rather than a purely technical assistance role, to fill a 'gap' between health and trade that appears to exist between SPC, and PIFS as the two major health stakeholders identified in this research, and with WHO, the major UN agency stakeholder

\section{CROPS:}

- Include trade, IPR and health on the agenda of the inaugural CROPS Working Group 
attended by the Executive Directors of the various CROPS

- Include trade, IPR and health development in University of the South Pacific academic research and development agenda

\section{UN agencies role:}

- UNAIDS - include a broader group of stakeholders in the inaugural meeting of the Pacific AIDS Commission attended by Commission Experts to enhance knowledge exchange. Example of stakeholders include: PIFS, SPC, MFAT, Ministry of Justice, MOH, Fiji Pharmaceutical Services and health-related regional associations

- Assist with sharing of drug price information amongst PICs

- Share learning from South experiences, for example, Thailand, including knowledge exchange through workshops

- Promote the concept of using human rights instruments to protect the right to access to medicines

- $\mathrm{WHO}$ - build stronger trade and health advocacy

- Include trade and access to medicines in existing, and in any future, regional health strategies, for example, WHO Regional NCD strategy, Regional HIV/AIDS strategy

\section{National Government:}

- Create a mechanism for monitoring the impact of new trade agreements on healthcare

- Promote strong institutional linkages between MOH and MFAT, and include trade, IPR and health development on the agenda and establish an informal working group working on IP and health from a national perspective that interfaces with trade policymaking at the regional level

- Include access to medicines in the MOH Strategic Plan

- Increase capacity within $\mathrm{MOH}$ to trigger the implementation of safeguards under the Patents Act

- Formalise holding two yearly workshops with all stakeholders, organised and funded by the WHO

- For PICs signed up to International Human Rights Conventions whose progress is monitored by a Human Rights Committee, reinforce and expand the agenda of the Committee, for example, CEDAW to uphold women's' and children's' rights, to include protecting the right to access to medicines 


\section{Non Government Organisations:}

- Expand awareness of trade and access to medicines by including on the agenda of regional and national workshops for associations eg. Nurses, Pharmacists, Clinicians, Economists

- Identify appropriate lobbying mechanisms for trade and access to medicines advocacy

- RRRT broaden current human rights policy and training to include access to medicines. For example, expand talks to graduating lawyers on human rights case law to include talks to graduating health care workers, including medical students, on access to medicines and human rights advocacy

- ECREA, build advocacy for access to essential medicines with community groups (including the use of human rights instruments alongside other multidisciplinary tools to do this). Build information relating to affordability and efficacy of drugs provided free by the public health system and of desirable patented medicines, for example for treating chronic non communicable diseases, in the future

- Explore the role of advocating for improving the interface between different sectors and structures to improve multi-sector collaboration on trade and health issues

- NGOs that are accredited to attend Working Groups with the PIFS, for example, PCRC, use the 'new observer' status to introduce trade and health issues to the level of the Forum Secretariat 